\title{
Radiological Safety Analysis Computer (RSAC) Program Version 7.0 Users' Manual
}

\author{
Bradley J. Schrader
}

March 2009

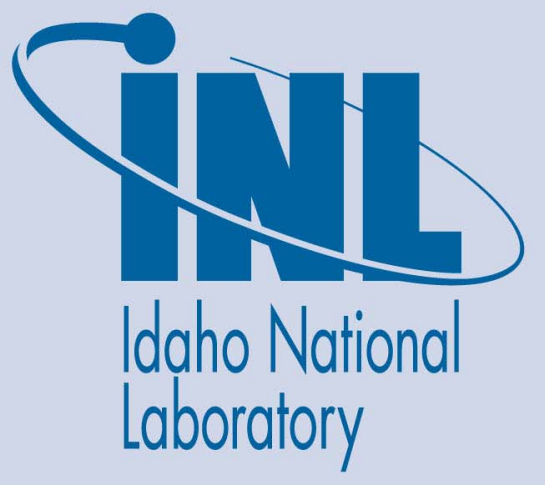

The INL is a U.S. Department of Energy National Laboratory operated by Battelle Energy Alliance 
INL/EXT-09-15275

\title{
Radiological Safety Analysis Computer (RSAC) Program \\ Version 7.0 Users' Manual
}

\author{
Bradley J. Schrader
}

March 2009

\begin{abstract}
Idaho National Laboratory
Idaho Falls, Idaho 83415
\end{abstract}

http://www.inl.gov

Prepared for the

U.S. Department of Energy

Office of National Nuclear Security Administration

Under DOE Idaho Operations Office

Contract DE-AC07-05ID14517 


\section{DISCLAIMER}

NOTICE: This computer software was prepared by Battelle Energy Alliance, LLC under Contract No. DE-AC07-05ID14517 with the U. S. Department of Energy. The United States Government is granted for itself and others acting on its behalf a non-exclusive, paid-up, irrevocable worldwide license in this software to reproduce, prepare derivative works, and perform publicly and display publicly, by or on behalf of the Government. NEITHER THE UNITED STATES NOR THE UNITED STATES DEPARTMENT OF ENERGY, NOR ANY OF THEIR EMPLOYEES, MAKES ANY WARRANTY, EXPRESS OR IMPLIED, OR ASSUMES ANY LEGAL LIABILITY OR RESPONSIBILITY FOR THE ACCURACY, COMPLETENESS, OR USEFULNESS OR ANY INFORMATION, APPARATUS, PRODUCT, OR PROCESS DISCLOSED, OR REPRESENTS THAT ITS USE WOULD NOT INFRINGE PRIVATELY OWNED RIGHTS. 


\begin{abstract}
The Radiological Safety Analysis Computer (RSAC) Program Version 7.0 (RSAC-7) is the newest version of the RSAC legacy code. RSAC-7 calculates the consequences of a release of radionuclides to the atmosphere. A user can generate a fission product inventory from either reactor operating history or a nuclear criticality event. RSAC-7 models the effects of high-efficiency particulate air filters or other cleanup systems and calculates the decay and ingrowth during transport through processes, facilities, and the environment. Doses are calculated for inhalation, air immersion, ground surface, ingestion, and cloud gamma pathways. RSAC-7 can be used as a tool to evaluate accident conditions in emergency response scenarios, radiological sabotage events and to evaluate safety basis accident consequences.

This users' manual contains the mathematical models and operating instructions for RSAC-7. Instructions, screens, and examples are provided to guide the user through the functions provided by RSAC-7. This program was designed for users who are familiar with radiological dose assessment methods.
\end{abstract}




\section{CONTENTS}

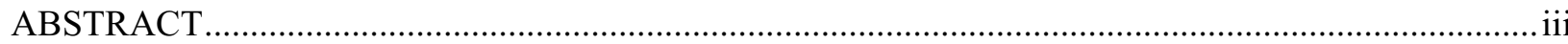

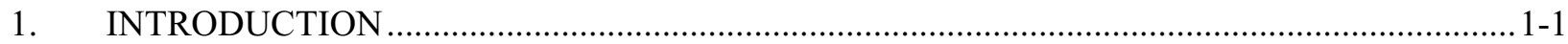

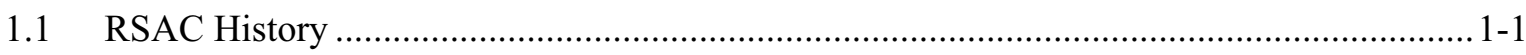

1.2 Summary of RSAC-7 Capabilities ............................................................................. 1-4

1.2.1 1000 Series - Fission Product Calculation and Inventory Decay ............................ 1-4

1.2.2 2000 Series - Direct Radionuclide Input ............................................................. 1-4

1.2.3 3000 Series - Dose Summary Option ................................................................ 1-5

1.2.4 5000 Series - Meteorological Data Input........................................................... 1-5

1.2.5 6000 Series - Radionuclide Inventory Decay for Printout ................................... 1-5

1.2.6 7000 Series - Internal/External Dose Calculations.............................................. 1-6

1.2.7 9000 Series - Cloud Gamma Dose Calculation.................................................... 1-6

2. RSAC-7 Software Management ............................................................................................ 2-1

2.1 Hardware and Software Requirements....................................................................... $2-1$

2.2 Loading Instructions and Validation of Installation.....................................................2-2

2.3 Point-of-Contact and Issues Reporting .................................................................... 2-4

2.4 Software Management and Quality Assurance .................................................................2-4

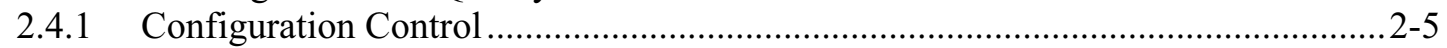

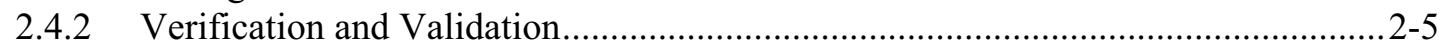

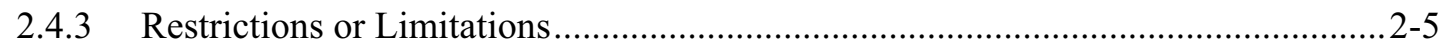

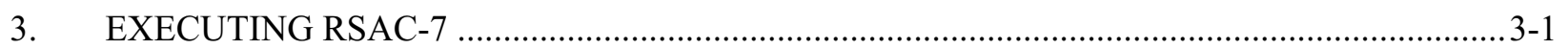

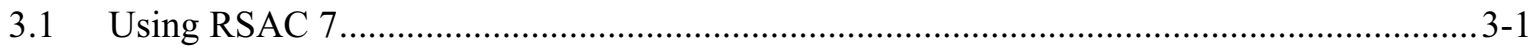

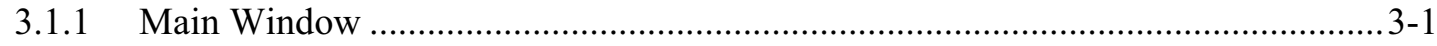

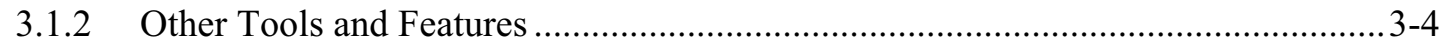

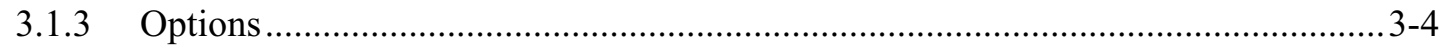

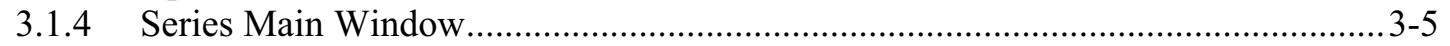

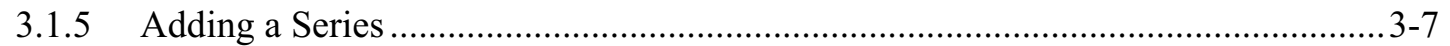

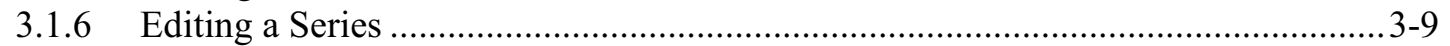

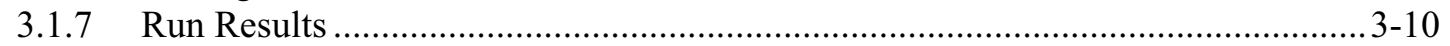

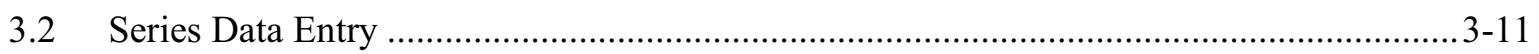

3.2.1 1000 Series - Fission Product Inventory Calculation ....................................... 3-11

3.2.2 2000 Series - Direct Radionuclide Input …......................................................

3.2.3 3000 Series - Dose Summary Option ……....................................................... 3-23

3.2.4 5000 Series - Dispersion Control Input ............................................................ 3-25

3.2.5 6000 Series - Radionuclide Inventory Decay and Printout …...............................3-35

3.2.6 7000 Series - Internal/External Dose Calculation ........................................... 3-43

3.2.7 9000 Series - Cloud Gamma Dose Calculation .............................................. 3-61

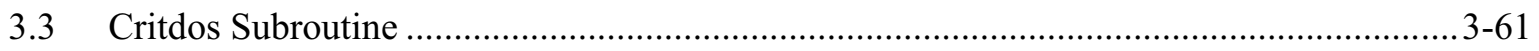

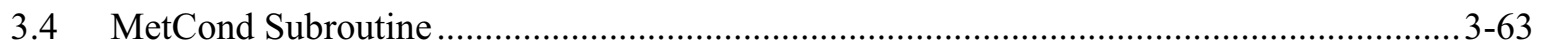

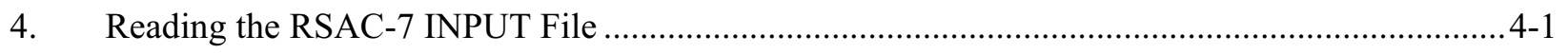

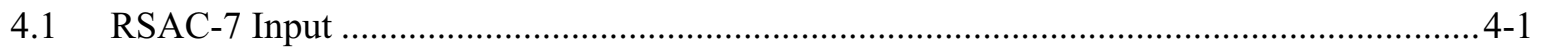

4.2 Calculation Title Line .............................................................................................. 4-2

4.2.1 1000 Series - Fission Product Inventory Calculation and Inventory Decay ............. 4-3 


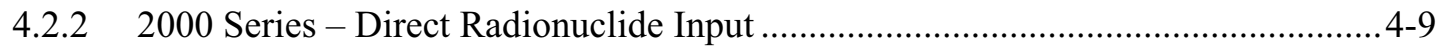

4.2.3 3000 Series - Dose Summary Option ................................................................. 4-11

4.2.4 5000 Series - Dispersion Control Input .......................................................... 4 -13

4.2.5 6000 Series - Radionuclide Inventory Decay for Printout ................................... 4-21

4.2.6 7000 Series - Internal/External Dose Calculation .............................................. 4-25

4.2.7 9000 Series - Cloud Gamma Dose Calculation ..................................................... 4-1

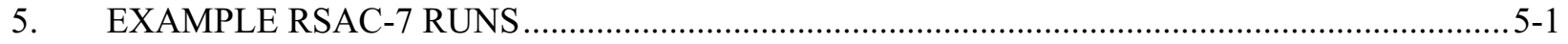

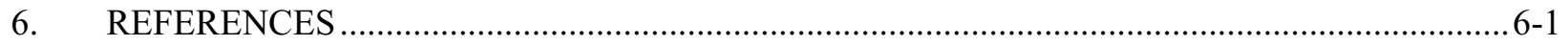

\section{FIGURES}

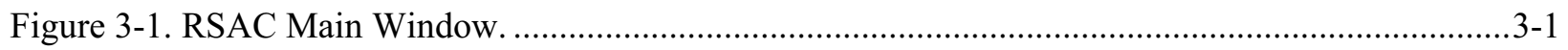

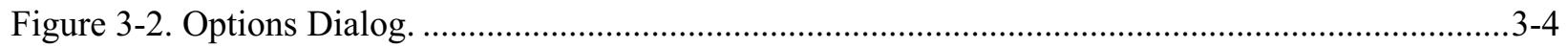

Figure 3-3. Series Main Window...........................................................................................

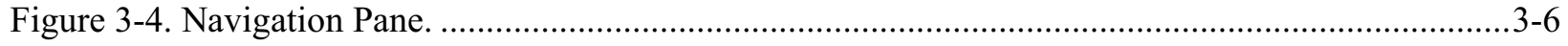

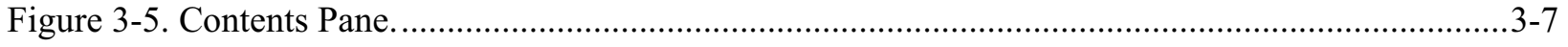

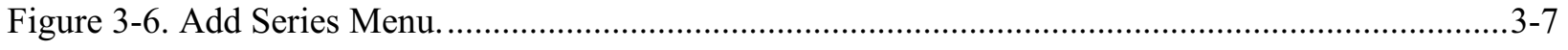

Figure 3-7. Series Main Window with Title Input.........................................................................

Figure 3-8. Series Main Window in Edit Mode ................................................................................. 3-9

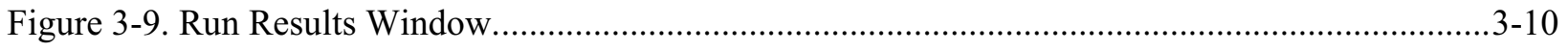

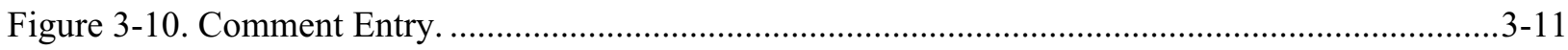

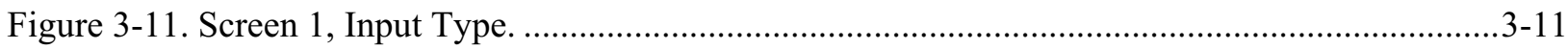

Figure 3-12. Screen 2A (Optional), Inventory Decay..................................................................

Figure 3-13. Input Completion Notification. ................................................................................ $3-13$

Figure 3-14. Screen 2B (Optional), Reactor Operation. .................................................................. 3-13

Figure 3-15. Screen 3A, Release During Reactor Operation............................................................ 3-14

Figure 3-16. Screen 4A, Release During Fission Product. ................................................................ $3-15$

Figure 3-17. Screen 2C (Optional), Fractionate Inventory. …......................................................... 3-15

Figure 3-18. Screen 3B (Optional), Fractionation by Group. …........................................................ $3-16$

Figure 3-19. Screen 3C (Optional), Fractionation by a Constant. ...........................................................16

Figure 3-20. Screen 3D (Optional), Fractionation by Element.............................................................. 17

Figure 3-21. Screen 4B, Element Fractionation Specification............................................................. $3-18$

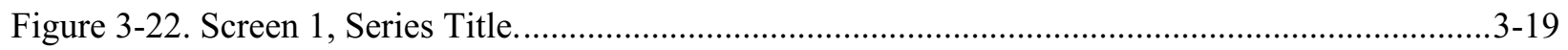

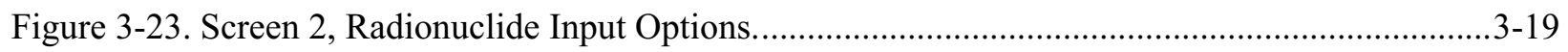

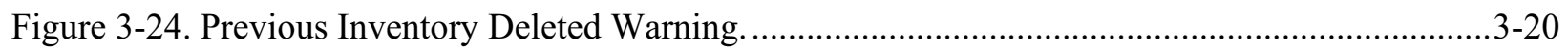

Figure 3-25. Screen 3, Direct Radionuclide Input. ...................................................................... 3-20

Figure 3-26. Screen 4A (Optional) Radionuclide Curie Input............................................................. 3-21 
Figure 3-27. Screen 4B (Optional), External File for Radionuclide Entry......................................... 3-22

Figure 3-28. Screen 5, Series Complete Notification. ....................................................................... $3-22$

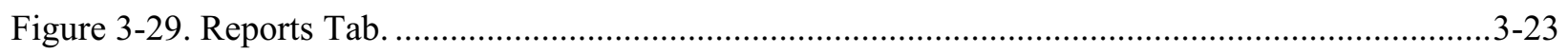

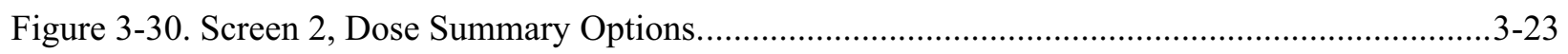

Figure 3-31. Screen 3 (Optional), Organ Selection....................................................................... $3-24$

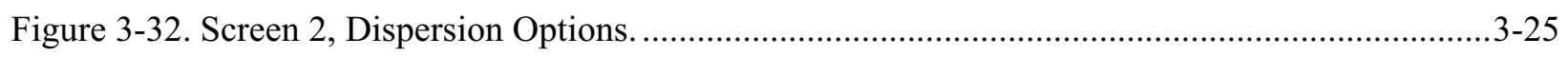

Figure 3-33. Screen 3 (Optional), General Meteorological Information. ............................................3-26

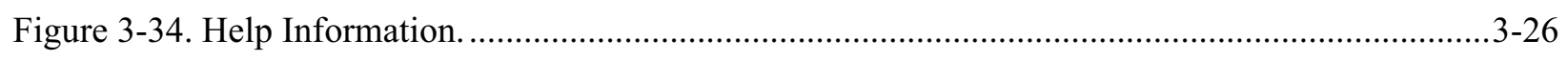

Figure 3-35. Screen 4 (Optional), Dry Deposition Variables. ............................................................ 3-27

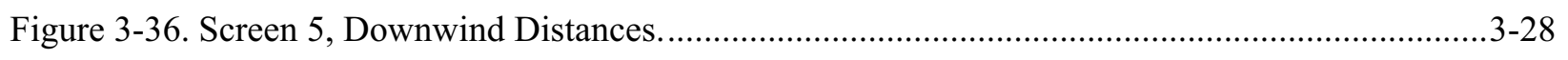

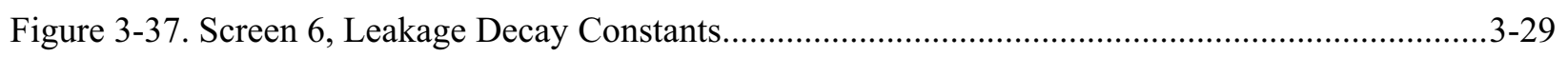

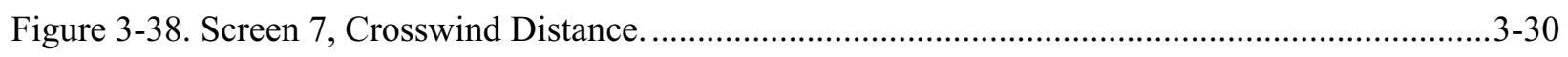

Figure 3-39. Screen 8, Diffusion Coefficient Control.....................................................................3-31

Figure 3-40. Screen 10A (Optional), Coefficient of Standard Deviation. ............................................3-32

Figure 3-41. Screen 10B (Optional), Plume Standard Deviation Control. .............................................3-33

Figure 3-42. Screen 10C (Optional), Direct Chi/Q Input......................................................................3-34

Figure 3-43. Screen 11A (Optional), Jet Plume Rise Parameters....................................................... 3-34

Figure 3-44. Screen 11B (Optional), Buoyant Plume Rise Parameters. .................................................3-35

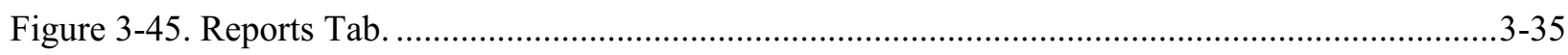

Figure 3-46. Screen 2, Radionuclide Decay Control. .......................................................................3-36

Figure 3-47. Screen 3 (Optional), Exponential Leakage Decay. .........................................................3-37

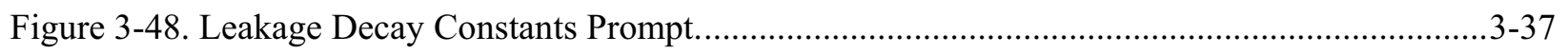

Figure 3-49. Screen 4 (Optional), Leakage Decay Constants..............................................................3-38

Figure 3-50. Screen 5 (Optional), Radionuclide Selection. ...............................................................3-39

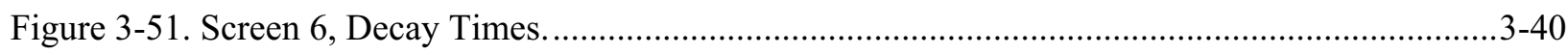

Figure 3-52. Screen 7 (Optional), Summation Control........................................................................ $3-41$

Figure 3-53. Screen 8 (Optional), Element Summation.......................................................................... $3-42$

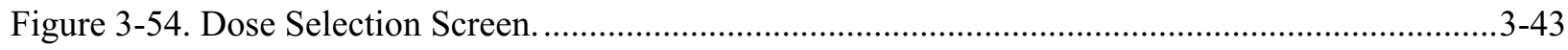

Figure 3-55. Screen 2, Dose Control Calculation. ............................................................................. 3-44

Figure 3-56. Screen 3A (Optional), Inhalation Dose Control................................................................. 3-45

Figure 3-57. Screen 4A (Optional), Inhalation Parameters Dose Calculation..........................................3-46

Figure 3-58. Screen 5A (Optional), Clearance Class Entry................................................................... 3-47

Figure 3-59. Screen 6 (Optional), Resuspension of Activity....................................................................

Figure 3-60. Screen 3B (Optional) - Ingestion Dose Parameters......................................................... 3-51

Figure 3-61. Screen 4B (Optional), Ingestion Dose Control. ............................................................... $3-52$ 
Figure 3-62. Screen 5B (Optional), Usage Constants Tab................................................................

Figure 3-63. Screen 5B (Optional), Retention Constants Tab........................................................... 3-54

Figure 3-64. Screen 5B (Optional), Field Factors Tab...................................................................... $3-55$

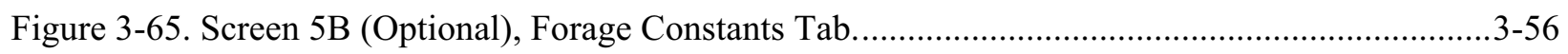

Figure 3-66. Screen 5B (Optional), Acute Modifiers. ...................................................................... $3-57$

Figure 3-67. Screen 3C (Optional), Ground Surface Dose Parameters. ................................................3-58

Figure 3-68. Screen 3D (Optional), Air Immersion Dose Parameters....................................................3-58

Figure 3-69. Screen (Optional), Internal/External Organ Selection......................................................3-59

Figure 3-70. Screen (Optional), Element Selection. ........................................................................ 3-60

Figure 3-71. Screen 2, Cloud Gamma Dose Control. ....................................................................... 3-61

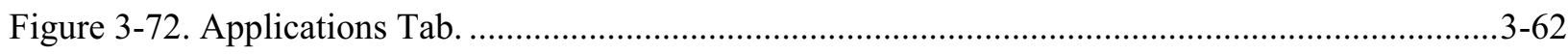

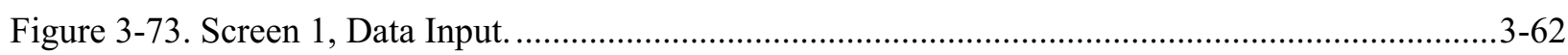

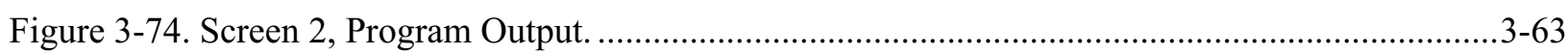




\section{INTRODUCTION}

Radioactive releases from nuclear facilities may contribute to radiation exposure through a number of pathways: external exposures by direct radiation from plumes or deposited radionuclides; internal exposures from inhalation or ingestion of radioactive material. The Radiological Safety Analysis Computer (RSAC) Program Version 7.0 (RSAC-7) calculates the consequences of a release of radionuclides to the atmosphere. Using a personal computer, a user can generate a fission product inventory; calculate inventory decay and ingrowth; the inventory during transport through processes, facilities, and the environment; model the downwind dispersion of the activity; and calculate doses to downwind individuals.

A fission product inventory can be calculated from reactor operating history and can be used to simulate a nuclear criticality accident. Radionuclide inventories can also be directly input into RSAC-7 if desired. Source term modeling allows for complete progeny ingrowth and decay during all accident phases. RSAC-7 release scenario modeling allows fractionation of the inventory by chemical group or element. RSAC-7 also models the effects of high-efficiency particulate air (HEPA) filters or other cleanup systems. RSAC-7's meteorological capabilities include Gaussian plume diffusion for PasquillGifford, Hilsmeier-Gifford, and Markee models. RSAC-7 possesses the unique ability to model Class F fumigation conditions. Optionally, users can supply plume standard deviations $(\sigma s)$ or atmospheric diffusion $(\chi / \mathrm{Qs})$ to the code as input data. RSAC-7 also includes corrections for deposition (wet and dry) plume rise (jet and buoyant), resuspension, and release in a room and building wake. Doses are calculated through inhalation, immersion, ground surface, and ingestion pathways, and cloud gamma dose from semi-infinite plume model and finite plume model.

RSAC 7 calculates internal dose using the dose conversion factors and methodology from both ICRP 26/30 and ICRP 60/68/72. In addition to the calculation of lifetime dose, RSAC 7 calculates the acute 24 hour dose from radiological sabotage events.

RSAC 7 is an excellent tool to evaluate accident conditions in emergency response scenarios and to evaluate of safety basis accident conditions.

\subsection{RSAC History}

RSAC was originally developed and written in assembly language (MAP) for the IBM 7044/44 in 1966 by R. L. Coates and N. R. Horton for support of the Advanced Test Reactor dose consequence calculations. In 1968, a FORTRAN version of the program was prepared by L. C. Richardson. Since 1968 , RSAC has undergone substantial revision.

In 1973, RSAC-2 was issued by D. R. Wenzel (Wenzel 1973) to:

- $\quad$ add input and output options

- change the inhalation dose calculations (lung and gastro-intestinal tract)

- change the numerical integration methods for cloud gamma dose calculations

- change the gamma-ray buildup factor model

- revise radionuclide yields and half-lives in the standard library

- refine output format for ease of reading

- reduce computer memory requirements. 
In 1982, RSAC-3 was issued (Wenzel 1982) to:

- $\quad$ add a fifty-mile population dose calculation

- use the U.S. Nuclear Regulatory Commission (NRC) Regulatory Guide 1.109 for ingestion dose calculations

- use the International Commission for Radiological Protection (ICRP) Lung Dynamics Model for inhalation dose calculations

- $\quad$ use the Dolphin and Eve Gastro-intestinal Tract Model

- improve error detection.

After undergoing an extensive verification and validation, RSAC-4 (Wenzel 1990) was enhanced and issued in 1990 to:

- $\quad$ convert the program to FORTRAN 77

- execute RSAC-4 on a personal computer

- use internal dose conversion factors from DOE/EH-0071 and external dose-rate conversion factors from DOE/EH-0070

- add dose summary tables

- add an ingestion dose model for an acute release

- increase the number of organs in the dose calculations

- include water immersion dose calculations

- program calculated plume rise for either jet or buoyant plume

- revise fission yields and half-lives

- add radionuclides to the standard library

- update the photon data library

- enhance error diagnostics

- include verification and validation necessary to meet the additional requirements for software imposed by ASME-NQA-1, "Quality Assurance Program Requirements for Nuclear Facilities."

In 1994, RSAC-5 (Wenzel 1994) was issued to:

- add an option to calculate cloud-gamma doses expressed in external dose equivalent

- add a variable particle size option for inhalation dose calculations

- resolve the over depletion for ground level releases during stable meteorology that was observed in earlier versions of RSAC

- add a reflective meteorological model to better model diffusion below the mixing depth

- include additional radionuclides to more accurately model the U-235 fission chain

- add a dose summing option

- incorporate a simplified notation for radionuclide identification

- include a capability to read radionuclide inventories from external files 
- correct errors observed in earlier versions of RSAC for the finite-plume model integration for cloudgamma dose calculations and large plumes

- add meteorological diffusion using Pasquill-Gifford parameters

- include an option to simulate the release of fission products from an operating reactor

- update forage and vegetation yields

- include an option to read ingestion transfer parameters from an external file

- refine the model for ingestion dose calculations from an acute release.

After major modifications, RSAC-6 was released in 2001 to:

- add radionuclides to the program library

- use internal dose conversion factors from Federal Guidance Report (FGR)-11 and external dose-rate conversion factors from FGR-12

- calculate doses at distances of less than 100 meters

- correct minor errors identified in the program

- printout radionuclides in a logical order

- add default lung clearance classes to provide the maximum dose based on each element

- allow entry of radionuclide input in either upper or lower case characters

- eliminate a discontinuity in the leakage function

- add an option to allow the user to enter a respirable fraction for inhalation dose calculations

- add an option to allow the user to enter an occupancy factor for ground surface dose calculations

- incorporate editorial changes in program output

- enhance the method to estimate the building wake effect

- evaluate the instantaneous release to a room

- evaluate the resuspension of particulate activity

- enhance the method for evaluation of dry deposition

- $\quad$ perform calculation of an effective $\sigma_{\mathrm{y}}$ and $\sigma_{\mathrm{z}}$ when $\chi / \mathrm{Q}$ is directly input.

RSAC-7 is the latest version of RSAC. This revision of RSAC included the following additions

- $\quad$ add internal dose conversion factors from ICRP 68 and 72

- add acute dose conversion factors for a 24 hour exposure from a sabotage event.

- Correct minor errors in the printing and display features

- Add the capability to perform joint frequency meteorological conditions to calculate both $50 \%$ and 95\% metrological conditions for input into RSAC.

- Establish an internal validation process to assure proper verification of installation parameters.

- Establish 20 new examples for execution of the enhanced capabilities of RSAC-7

- Input units of Curies, grams and Becquerel are available in the direct input model. 


\subsection{Summary of RSAC-7 Capabilities}

RSAC-7 consists of nine subroutines. Each subroutine performs a type of calculation and operates together with or independently of the others, depending on the analysis being performed. Historically these subroutines have been referred to as series. For consistency with earlier versions this nomenclature has been retained. Both the series number and the subroutine function are indentified. These series are identified by input series lines of multiples of 1000. A summary of each of the program series follows.

\subsubsection{Series - Fission Product Calculation and Inventory Decay}

RSAC-7 allows the user to establish an inventory of fission products (and subsequent decay products) by simulating the operation of a thermal reactor. The user can simulate steady-state, transient, or cyclic reactor operation. A refueling option is also available. After establishing the reactor operating history, the user can then specify the fractional release of the radionuclide inventory by individual element, by groups of elements (solids, halogens, noble gases, cesium, or ruthenium), or by a single release fraction for the entire inventory.

RSAC-7 calculates inventories for fission products only. The nuclear data library contains selected activation products, actinides, and the daughters of actinides in addition to the fission products.

Inventories for activation products and actinides are not calculated by RSAC-7; however, they can be added to the inventory by using the radionuclide direct input section of the program. Subsequent sections of the program calculate the radioactive decay and doses from these additional radionuclides.

The model used by RSAC-7 to calculate fission product inventories is simple compared to the model used in the ORIGEN2 program (Croff 1980, RSICC 1991). RSAC-7 is simple to run and requires less computer time than ORIGEN2. In general, the RSAC-7 model calculates fission product inventories well. However, it does not calculate inventories for activation products or actinides. While the RSAC-7 model corrects for depletions of fission products by neutron activation, it does not calculate all of the subsequent radionuclides that are produced by the neutron activation of fission products. When irradiation times are long, the burnup is relatively high, or the enrichment of the fuel is low, inventories of radionuclides produced primarily by the activation of fission products (Cs-134, Pm-147, Sm-151, Eu-154 and Eu-155) can differ from ORIGEN2-calculated inventories by more than $20 \%$. When doses from these radionuclides are significant compared to the other fission products, users should use a more sophisticated computer program such as ORIGEN2 and import the final inventory using the 2000 Series direct radionuclide input option. RSAC-7 can then be used to calculate inventory decay and simulate additional reactor operation or fuel handling accidents such as a criticality.

The 1000 Series of RSAC-7 can be reentered as many times as desired to modify the radionuclide inventory. One of the options in this series is to fractionate the radionuclide inventory and to simulate removal of activity by cleanup systems such as HEPA filters. The inventory can be fractionated for a chemical group, element, or the entire inventory.

\subsubsection{Series - Direct Radionuclide Input}

This series allows users to input a radionuclide inventory from an external file or to directly input the amounts of radionuclides to be used in subsequent calculations. The direct radionuclide input option should be used to add activation products and other radionuclides not generated by the 1000 series source term generation function. 


\subsubsection{Series - Dose Summary Option}

This series allows doses from different exposure pathways and multiple RSAC-7 calculations within the same input run to be summarized, added, and reported in summary tables. This option has strict operating guidelines [see Section 4.1, Dose Summary Option Control Line (3000)].

\subsubsection{Series - Meteorological Data Input}

This series allows the user to specify meteorological conditions at the time of release and to calculate diffusion, dispersion, and depletion factors.

This input series of RSAC-7 must normally be entered before any dose calculations are requested. After establishing basic meteorological parameters (such as stack height, wind velocity, and mixing layer depth), the user specifies points of interest for dose calculations at downwind and/or crosswind positions.

RSAC-7 models the release of radioactivity from containment structures using exponential functions. Instantaneous and continuous releases are modeled using a single exponential function. Complex release scenarios can be modeled using a series of up to 10 exponential functions. These functions calculate the radionuclide inventory decay while it is held up by the containment structure before it is released.

Atmospheric diffusion parameters can be input directly by the user or calculated by RSAC-7. RSAC-7 calculates plume standard deviations ( $\sigma s)$ developed for three different conditions. HilsmeierGifford $\sigma \mathrm{s}$ (Clawson et al. 1989) were developed for desert terrains and releases from a few to 15 minutes. Markee os (Clawson et al. 1989) were also developed for a desert terrain; however, they were developed for releases from 15 to 60 minutes in duration. Pasquill-Gifford $\sigma \mathrm{s}$ are presented in the NRC Regulatory Guide 1.145 (NRC 1982) and by Slade (1968) from the Prairie Grass experiments for effluent releases with durations of 10 to 60 minutes.

Other meteorological options available in RSAC-7 are corrections for plume rise using models by Briggs (1969), building wake corrections (Ramsdell, 1997), and plume depletion using modeling of Markee (1967) and Chamberlain (1953).

\subsubsection{Series - Radionuclide Inventory Decay for Printout}

This series allows the user to calculate the radioactive decay of the entire radionuclide inventory or of selected radionuclides for printout. Decay of the radionuclide inventory for subsequent dose calculations is not done in this series, but in the 1000 Series. If downwind distances have been previously specified in the meteorological section of the program (5000 Series), decay times are calculated for each downwind position. Alternately, the user can directly specify decay times in this series. Radionuclide inventory printout options are then available. Inventories for activation products and actinides are printed only when 2000 Series input has been used to enter these radionuclides. 


\subsubsection{Series - Internal/External Dose Calculations}

This series allows the user to perform a variety of dose calculations. The radionuclide source term for these calculations is the radionuclide inventory created and operated on in the 1000 and 2000 Series. An internal dose can be calculated for up to 23 organs in addition to the committed effective dose equivalent (CEDE) for the inhalation or ingestion pathways. Internal doses are calculated using dose conversion factors from Federal Guidance Report No. 11(Eckerman 1988). Ingestion doses from a chronic release are calculated using models described in Regulatory Guide 1.109 (NRC 1977a). Because of the lack of a consensus model, equations for calculating ingestion doses from an acute release have been developed specifically for RSAC-7. Standard ingestion constants are provided in the program; however, the user can alter any of the constants. External dose can also be calculated for up to 23 organs in addition to the external effective dose equivalent (EDE) for the ground surface and for air immersion pathways. The air immersion model should be used with caution to ensure that the plume has diffused to the ground level and that the plume size is large compared to the mean free path of the gamma rays. Otherwise, using the air immersion model can result in significant error in the dose calculation. External doses are calculated using dose-rate conversion factors from Federal Guidance Report No. 12 (Eckerman 1993). External exposure from a release to a room and internal exposure from resuspension are also available.

\subsubsection{Series - Cloud Gamma Dose Calculation}

RSAC-7 calculates cloud gamma doses (in addition to the air immersion model provided in the 7000 Series input) using either a finite plume model or a semi-infinite cloud gamma model. The finite plume model is accurate for any plume size, location, or release point. However, compared to the air immersion or semi-infinite models, it requires longer computer time to perform calculations. When the plume has diffused to ground level and is large compared to the mean free path of the gamma rays, both the semiinfinite and the air immersion models give accurate results. However, as noted in the 7000 Series discussion in this section, significant errors can result when the proper conditions for these simplified models do not exist. Whenever in doubt, the user should use the finite plume cloud gamma model. By comparing the results of the finite plume model with the semi-infinite plume model, users can establish when the simplified models can be used. 


\section{RSAC-7 Software Management}

This chapter provides the software management (SM) and software quality assurance (SQA) requirements of DOE O 414.1C, Quality Assurance, dated 6-17-05, for RSAC-7. This chapter supplements the quality assurance program (QAP) requirements of Title 10 Code of Federal Regulations (CFR) 830, Subpart A, Quality Assurance, for DOE nuclear facilities and activities. The SQA requirements for DOE, including the National Nuclear Security Administration (NNSA), and its contractors are necessary to implement effective quality assurance (QA) processes and achieve safe nuclear facility operations.

DOE promulgated the software requirements and this guidance to control or eliminate the hazards and associated vulnerability posed by security software. Software failures or unintended output can lead to unexpected program failures and undue risks to the DOE/NNSA mission, the environment, the public, and the workers. This standard includes software application practices covered by appropriate national and international consensus standards and various processes currently in use at DOE facilities. This guidance is considered to be of sufficient rigor and depth to ensure acceptable reliability of safety software at DOE/NNSA facilities.

This chapter should be used by organizations to help determine and support the steps necessary to address possible design or functional implementation deficiencies that might exist and to reduce operational hazards-related risks to an acceptable level. Attributes such as the facility life-cycle stage and the hazardous nature of each facility's operations should be considered when using this standard. Alternative methods to those described in this standard may be used provided they result in compliance with applicable requirements. Another objective of this guidance is to encourage robust software quality methods to enable the development of high quality applications. This section describes the installation procedures for loading RSAC-7 onto a personal computer. The minimum hardware and software requirements are listed.

The section also identifies the point-of-contact for questions about the program and a summary of quality assurance activities conducted to ensure the integrity of RSAC.

\subsection{Hardware and Software Requirements}

RSAC-7 runs on an personal computer or compatible computer running Windows XP or Vista. Although the code does run on earlier versions of Windows operating systems, it has not been validated on those earlier versions of Windows. The computational program is written in FORTRAN, and the user interface is written in VisualBasic for DOS. 


\subsection{Loading Instructions and Validation of Installation}

Place the RSAC-7 CD in the CD reader. Double click on "My Computer," Double click on the drive letter for your CD reader. Double click on "Setup" and answer the questions. You will be requested to have a key to install the software. There is a readme file included with the software that can assist with installation if necessary. Once the program has been installed and opened a screen will open that requires a response. That screen is shown below.

\section{Notice}

This computer software was prepared by Battelle Energy Alliance, LLC under Contract No. AC07-05ID14517 with the U. S. Department of Energy. For five years from March 2005, the Government is granted for itself and others acting on its behalf a nonexclusive, paidup, irrevocable worldwide license in this data to reproduce, prepare derivative works, and perform publicly and display publicly, by or on behalf of the Government. There is provision for the possible extension of the term of this license. Subsequent to that period or any extension granted, the Government is granted for itself and others acting on its behalf a nonexclusive, paid-up, irrevocable worldwide license in this data to reproduce, prepare derivative works, distribute copies to the public, perform publicly and display publicly, and to permit others to do so. The specific term of the license can be identified by inquiry made to Contractor or DOE. NEITHER THE UNITED STATES NOR THE UNITED STATES DEPARTMENT OF ENERGY, NOR ANY OF THEIR EMPLOYEES, MAKES ANY WARRANTY, EXPRESS OR IMPLIED, OR ASSUMES ANY LEGAL LIABILITY OR RESPONSIBILITY FOR THE ACCURACY, COMPLETENESS, OR USEFULNESS OR ANY INFORMATION, APPARATUS, PRODUCT, OR PROCESS DISCLOSED, OR REPRESENTS THAT ITS USE WOULD NOT INFRINGE PRIVATELY OWNED RIGHTS.

In order to continue with use of the software the terms of the license must be accepted each time the software is opened. The next step is to validate the installation. This is done by clicking on the RSAC QC selection under the help menu. Once the selection is made acceptance of the verification is required as shown below.

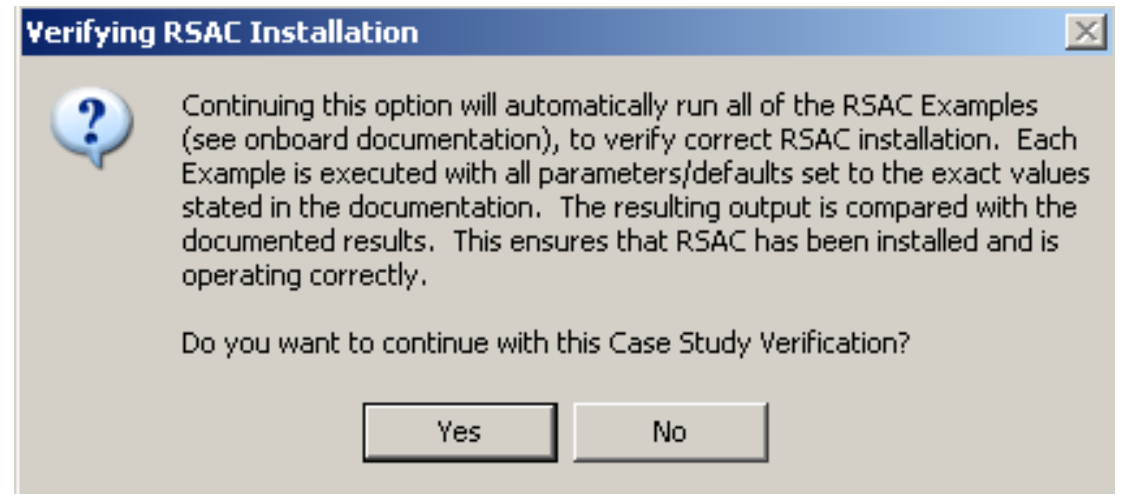


A selection of Yes will continue with the installation validation and a selection of No will abort and return you to the main screen. If Yes was selected as the option, all 20 examples are executed and compared against the verified and validated results. If the following screen is displayed the installation has been successfully verified. This QC check should be performed each time a change is made to the operating system. This assures that the change has not affected the RSAC execution capabilities.

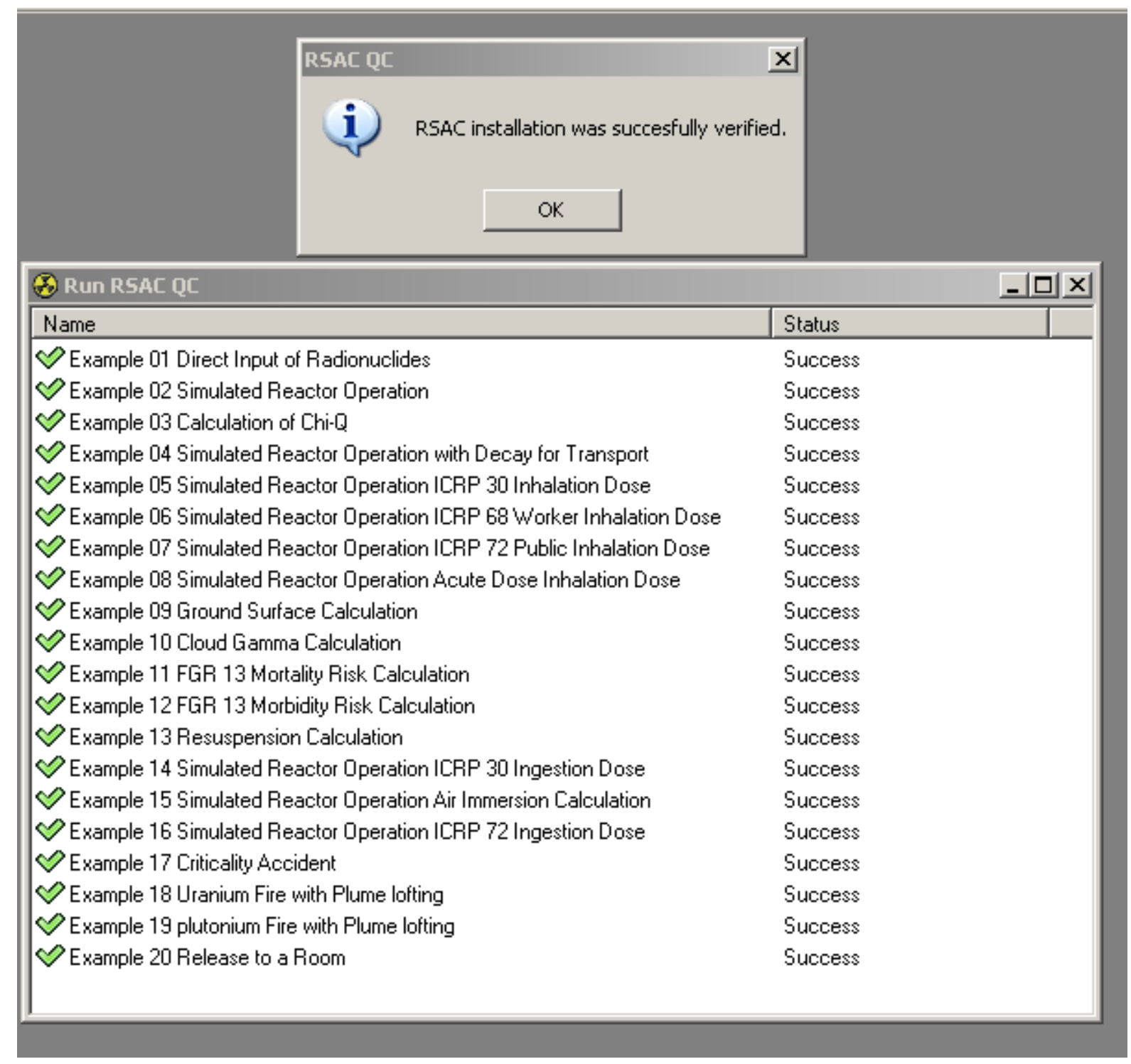

If the screen shown above does not display it will show an error and request that you no longer use the software and notify the RSAC program point of contact of the problem through the bug reporting system. 


\subsection{Point-of-Contact and Issues Reporting}

RSAC-7 has imbedded in the help menu a method to report bugs, provide suggestions and look for program updates. These options are available when the website is selected under the Help menu. This links you directly with the Idaho National Laboratory RSAC website. Located on the website are links to report bugs, provide suggestions, look up product information, obtain downloads for program updates and manuals.

Information on how to obtain a copy of RSAC-7 or to resolve problems encountered running RSAC-7 can also be directly obtained by contacting:

Dr. Bradley .J. Schrader P.E., CHP

Idaho National Laboratory

P.O. Box 1625

Idaho Falls, ID 83415-3214

(208) 526-0912

email: Bradley.Schrader@inl.gov

\subsection{Software Management and Quality Assurance}

The scope of the Department of Energy Quality Assurance (QA) Rule, 10 CFR 830 Subpart A, is stated as "This subpart establishes quality assurance requirements for contractors conducting activities, including providing items or services, that affect, or may affect, nuclear safety of DOE nuclear facilities." The scope of the QA Rule encompasses the contractor's conduct of activities as they relate to software (items or services). Therefore the RSAC software application for nuclear safety, safeguards and security, emergency preparedness are within its scope. DOE O 414.1C establishes the Software Quality Assurance (SQA) requirements to be implemented under the Rule for RSAC.

DOE O 414.1C requires that an appropriate level of quality infrastructure be established and a commitment made to maintain this infrastructure for the software. The RSAC SQA program establishes the appropriate software life-cycle practices, including design concepts, to ensure that software functions reliably and correctly performs the intended work specified for that software. The RSAC SQA program is fully documented and available for review from the software point of contact. The software management program has 10 software quality work activities that ensure that safety software performs its intended functions. The RSAC SQA plan documents the implementation strategies and appropriate standards for these ten activities.

1. Software project management and quality planning.

2. Software risk management.

3. Software configuration management (SCM).

4. Procurement and supplier management.

5. Software requirements identification and management.

6. Software design and implementation.

7. Software security.

8. Verification \& Validation.

9. Problem reporting and corrective action.

10. Training of personnel in the design, development, use, and evaluation of security software. 
RSAC nuclear safety software is controlled in a traceable, planned, and orderly manner. The software quality work activities defined in this section provide the basis for planning, implementing, maintaining, and operating safety software.

\subsubsection{Configuration Control}

Configuration control is maintained by issuing copies of RSAC-7 with a unique serial number. Only binary copies of RSAC-7 and its libraries are issued to users to prevent user changes to the program that would invalidate the extensive validation and verification.

\subsubsection{Verification and Validation}

RSAC-7 has been subjected to extensive independent verification and validation (V\&V) for use in performing safety-related dose calculations to support safety analysis reports and emergency response conditions (INEEL 2001). RSAC verification and validation files are contained in 7 volumes in excess of 10,000 pages. The files are maintained by the Idaho National Laboratory and are available for review. The INL maintains a Software Management Plan and a Software Quality Assurance Plan in accordance with DOE recommendations.

\subsubsection{Restrictions or Limitations}

The RSAC is based on the Gaussian model of dispersion. As such, RSAC is best suited for specific types of conditions. Conditions that should be considered before applying RSAC include:

- RSAC is best suited for "short" duration plumes, ranging from approximately several minutes to several days. It should be understood that plume meander has a significant effect on releases longer than an hour. Meteorological conditions change and will cause plume variations from that approximated using the Gaussian model.

- RSAC does not model dispersion close to the source (less than 100 meters from the source), especially where the influence of structures or other obstacles is still significant. Although the selection of distances inside of 100 meters can be performed, the results should be understood as only a conservative approximation. Dispersion influenced by several, collocated facilities, within several hundred meters of each other should be modeled with care. Similarly, RSAC should be applied with caution at distances greater than ten to fifteen miles, especially if meteorological conditions are likely to be different from those at the source of the release. Long-range projections of dose conditions are better calculated with mesoscale, regional models that are able to account for multiple weather observations. Nevertheless, some applications may require fifty-mile or greater radius analysis to meet requirements, e.g. Environmental Impact Statements (EISs) or Probabilistic Safety Assessments (PSAs).

- Gaussian models are inherently flat-earth models, and perform best over regions of transport where there is minimal variation in terrain. Because of this, there is inherent conservatism (and simplicity) if the environs have a significant nearby buildings, tall vegetation, or grade variations not taken into account in the dispersion parameterization.

- $\quad$ RSAC does not account for momentum-driven releases from detonation type events. 
- In plumes arising from fire-related source terms, the user should exercise caution with the models such as RSAC that use the Briggs algorithm. The Briggs approach for accounting for sensible energy in a plume is valid for "open-field" releases (not impacted by buildings and other obstacles), or if used in combination with building wake effects.

- Dose conversion factor applicability - The user should ensure that the dose conversion factors used in RSAC are applicable to the radionuclides in the source term and the physicochemical characteristics. For example, plutonium nitrates and oxides have different time scales for dosimetric effects in the body. Thus, the appropriate lung absorption type should be used in the dose conversion factor file used in the RSAC run. In all cases RSAC will default to the lung absorption type that results in the highest dose. 


\section{EXECUTING RSAC-7}

RSAC-7 can be executed directly using a user-supplied ASCII input file or the windows graphical user interface can be used to build input files. For those familiar with RSAC inputs and a DOS based environment the same input-output techniques used since RSAC-2 (1973) can be applied and is not discussed here. Further information on this command line process can be found in the user manuals of all earlier versions. However for a complete description of the command line inputs for RSAC-7 see chapter 4.

\subsection{Using RSAC 7}

As previously discussed in section 2.2, the software installation should be validated upon installation and when any changes are made to the computer/operating system that may affect the accurate execution of RSAC.

\subsubsection{Main Window}

The RSAC main window (Figure 3-1) provides access to all of the programs tools and features.

\begin{tabular}{|c|c|c|}
\hline 8 Rsac 7 - Inputfile1.rsac* & & $-|\square| x$ \\
\hline File Édit Run Examples Iools & Window $\underline{\text { Help }}$ & \\
\hline 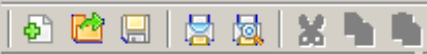 & 1. & \\
\hline Add a Series $\quad \boldsymbol{7} \mathbf{x}$ & InputFile1.rsac** & $-\triangleleft D x$ \\
\hline General Reports & Title: & \\
\hline Fission Product Inventoru Calculation & Double-clicks to spe & \\
\hline Direct Radionuclide Input & \begin{tabular}{|l|} 
Description: \\
Details:
\end{tabular} & \\
\hline Meteorological Data Input & & \\
\hline Internal/External Dose Calculation & & \\
\hline Cloud Gamma Dose Calculation & & \\
\hline Applications $\quad 7 \times$ & & \\
\hline$\Leftrightarrow$ Direct Radiation Criticality Dose & & \\
\hline$\Leftrightarrow \frac{\text { Joint Frequency Meteorological }}{\text { Conditions }}$ & & \\
\hline InputFile1 & & \\
\hline
\end{tabular}

Figure 3-1. RSAC Main Window. 
Some of the most commonly used components are:

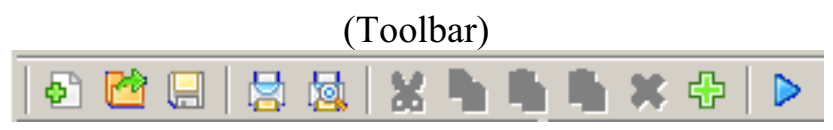

The toolbar provides shortcuts for:

- Opening files

- Printing

- Cut, Copy, Paste, Insert, and Delete series

- Run the currently open file with RSAC

(Add Menu)

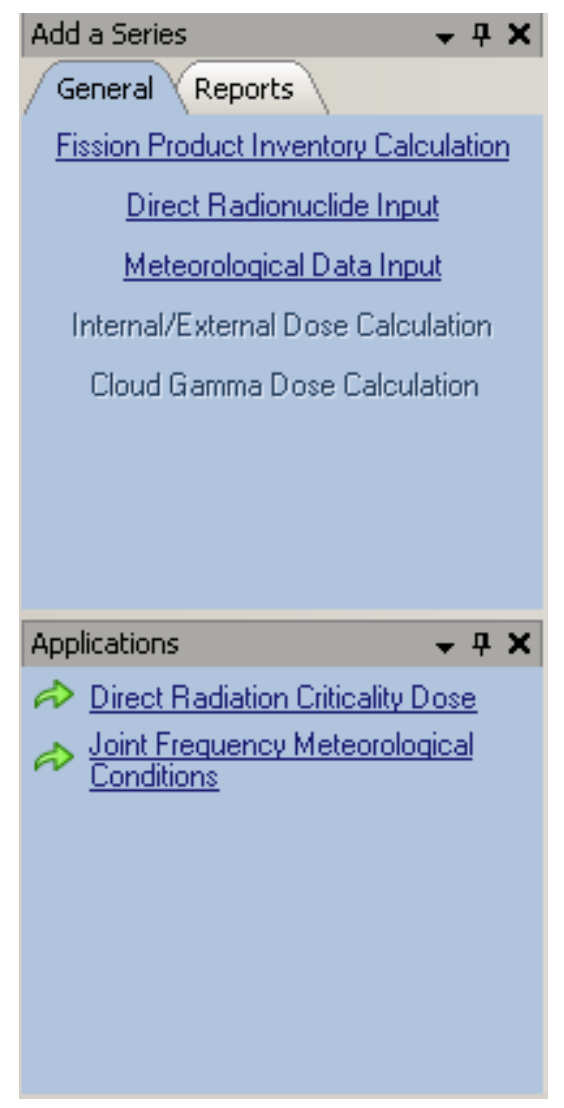

The Add Series menu allows selecting which series to add to the open file. It works similar to a tab control, just click on General to add a series or Reports to generate a report. Note that some series may be disabled until its prerequisites are met. 
(File Summary)

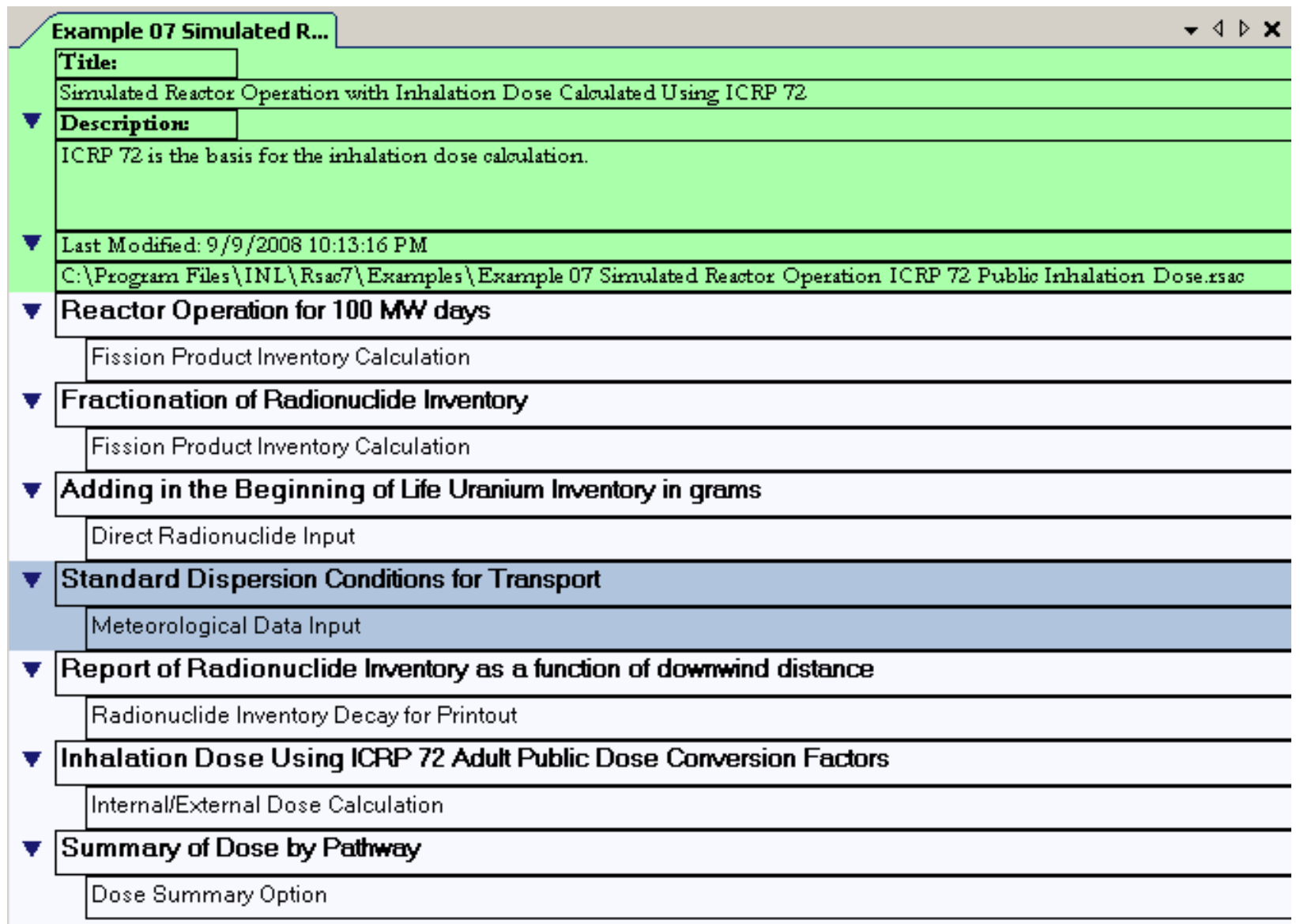

The file summary provides the following:

- Quick view of what series are in the file

- Selection of series to Cut, Copy, Paste, Insert, and Delete

- Double-click a series to open in edit mode

(File information)

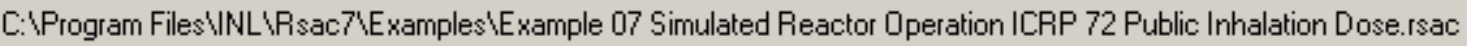

The file information at the bottom of the screen shows the full path of the currently open file and the date and time it was last modified. 


\subsubsection{Other Tools and Features}

Other tools and features that are accessible under the drop-down menu at the top of the window are:

- Create Text File - Creates a text file from the currently open file.

- $\quad$ Edit Text and ASCII Files - Opens the selected file in Notepad for editing.

- Browse File - Browse the currently open file in text format.

- Run Batch - Allows running a batch of mixed file types with RSAC.

- Run History - Views history database of all files run with RSAC.

- View Existing - Opens existing run output files for viewing.

- Options - Controls user settings for WinRp.

- Website - Opens the RSAC website in Internet Explorer.

RSAC Manual - Opens the RSAC pdf manual, Adobe Acrobat Reader is required.

\subsubsection{Options}

The options dialog (Figure 3-2) is where certain features of WinRp can be controlled. To open the options dialog click the Tools menu then Options.

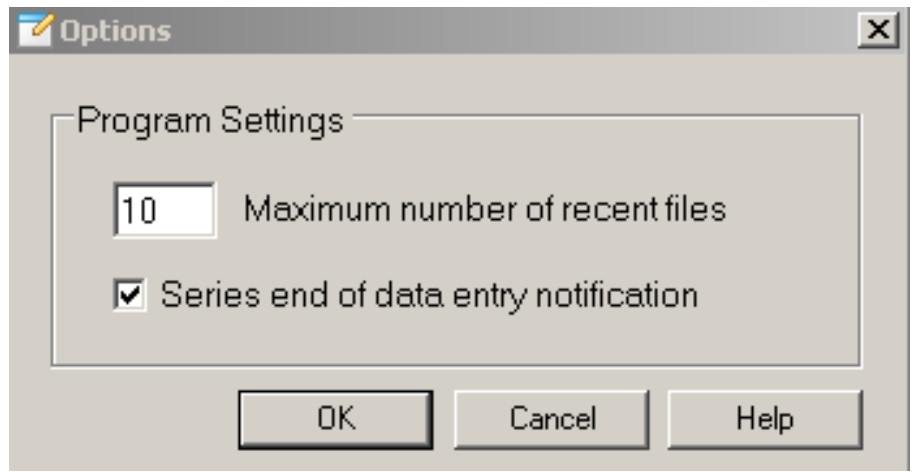

Figure 3-2. Options Dialog. 


\subsubsection{Series Main Window}

The series main window (Figure 3-3) provides a summary of all data that has been entered for the current series. Data can be reviewed then saved, edited, or discarded using the buttons on the lower right corner of the window.

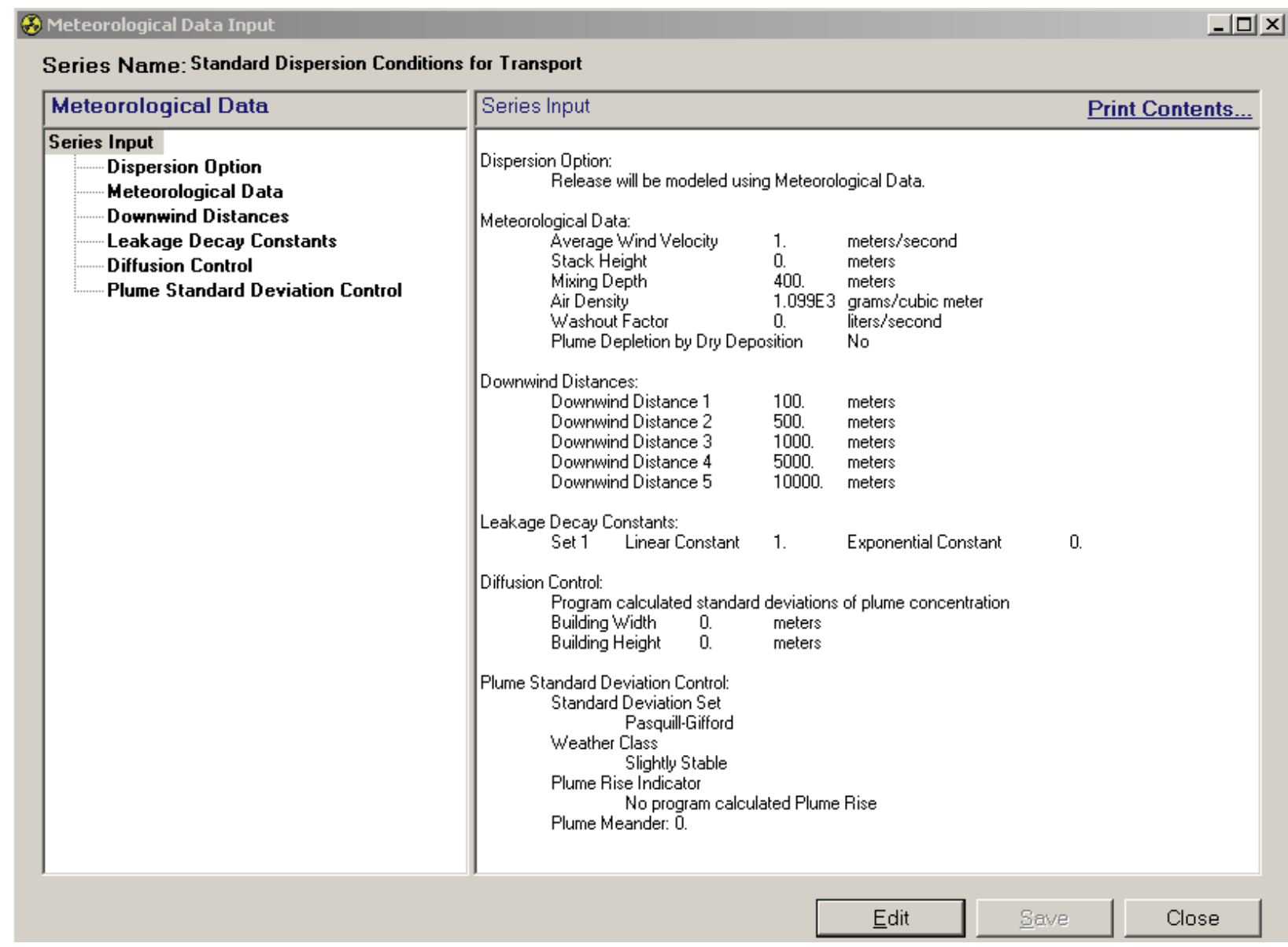

Figure 3-3. Series Main Window. 
The navigation pane (Figure 3-4) on the left side of the series main window, gives a brief outline of what data has been entered into the Series.

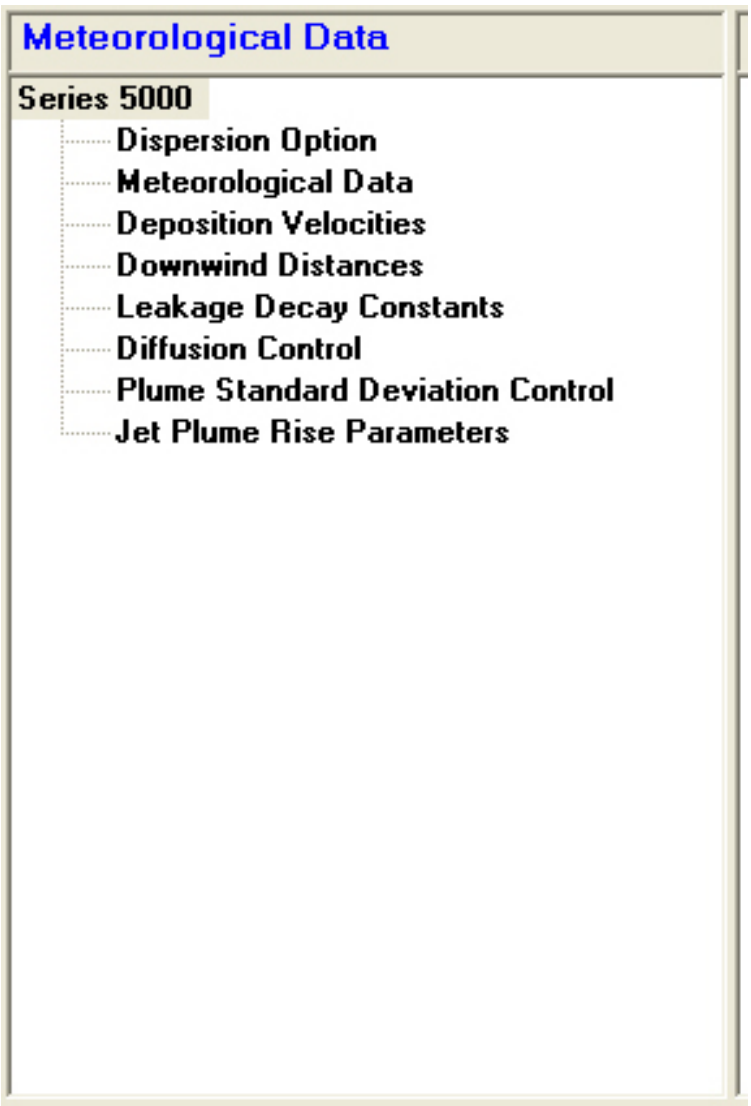

Figure 3-4. Navigation Pane. 
The contents pane (Figure 3-5) will display the data for the selected item in the navigation pane. Thus, when a sub item is selected in the navigation pane the corresponding data for that item is displayed in the contents pane. This provides quick access to the specific data that in question. Using the Print

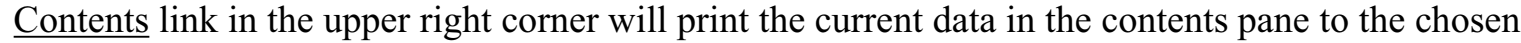
printer.

\begin{tabular}{|c|c|c|c|c|c|}
\hline \multicolumn{3}{|l|}{ Series 5000} & \multicolumn{3}{|c|}{ Print Contents... } \\
\hline \multicolumn{4}{|c|}{$\begin{array}{l}\text { Dispersion Option: } \\
\text { Release will be modeled using Meteorological Data. }\end{array}$} & & $\hat{\sim}$ \\
\hline $\begin{array}{l}\text { Meterological Data: } \\
\text { Average Wind Velo } \\
\text { Stack Height } \\
\text { Mixing Depth } \\
\text { Air Density } \\
\text { Washout Factor } \\
\text { Plume Depletion by }\end{array}$ & y Dry Dep & $\begin{array}{l}2 \\
76 \\
380 \\
1.099 \mathrm{E} 3 \\
0 \\
\text { sition }\end{array}$ & $\begin{array}{l}\text { meters/second } \\
\text { meters } \\
\text { meters } \\
\text { grams/cubic meter } \\
\text { liters/second } \\
\text { Yes }\end{array}$ & & \\
\hline $\begin{array}{c}\text { Deposition Velocities: } \\
\text { Solids } \\
\text { Halogens } \\
\text { Noble Gases } \\
\text { Cesium } \\
\text { Ruthenium }\end{array}$ & $\begin{array}{l}0.001 \\
0.01 \\
0 \\
0.001 \\
0.001\end{array}$ & $\begin{array}{l}\text { meters/se } \\
\text { meters/se } \\
\text { meters/se } \\
\text { meters/se } \\
\text { meters/se }\end{array}$ & $\begin{array}{l}\text { econd } \\
\text { econd } \\
\text { econd } \\
\text { econd } \\
\text { econd }\end{array}$ & & \\
\hline $\begin{array}{l}\text { Downwind Distances: } \\
\text { Downwind Distanc }\end{array}$ & & $3 . \mathrm{E} 3$ & meters & & \\
\hline $\begin{array}{l}\text { Leakage Decay Constants: } \\
\text { Set } 1 \text { Linear Co }\end{array}$ & onstant & 1 & Exponential Constant & 0 & \\
\hline $\begin{array}{l}\text { Diffusion Control: } \\
\text { Program calculated } \\
\text { Building Width } \\
\text { Building Height }\end{array}$ & $\begin{array}{l}\text { d standarc } \\
0 \\
0\end{array}$ & $\begin{array}{l}\text { deviations } \\
\text { meters } \\
\text { meters }\end{array}$ & of plume concentration & & \\
\hline
\end{tabular}

Figure 3-5. Contents Pane.

\subsubsection{Adding a Series}

To add or append a new series to the file use the Add Series Menu (Figure 3-6) on the main window and click the name of the desired series.

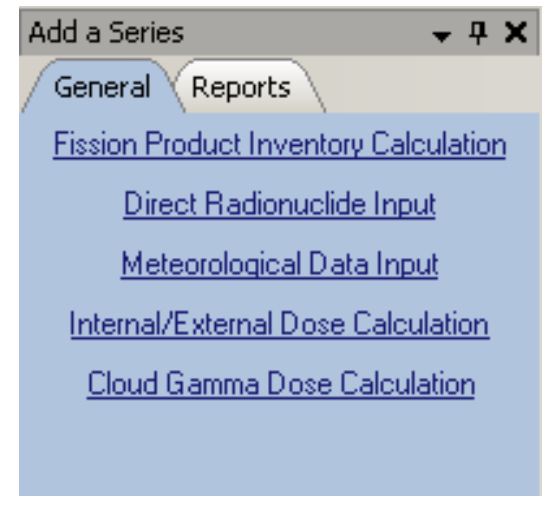

Figure 3-6. Add Series Menu. 
When the series name is clicked the main series window will appear with the series title window on top of it (Figure 3-7).

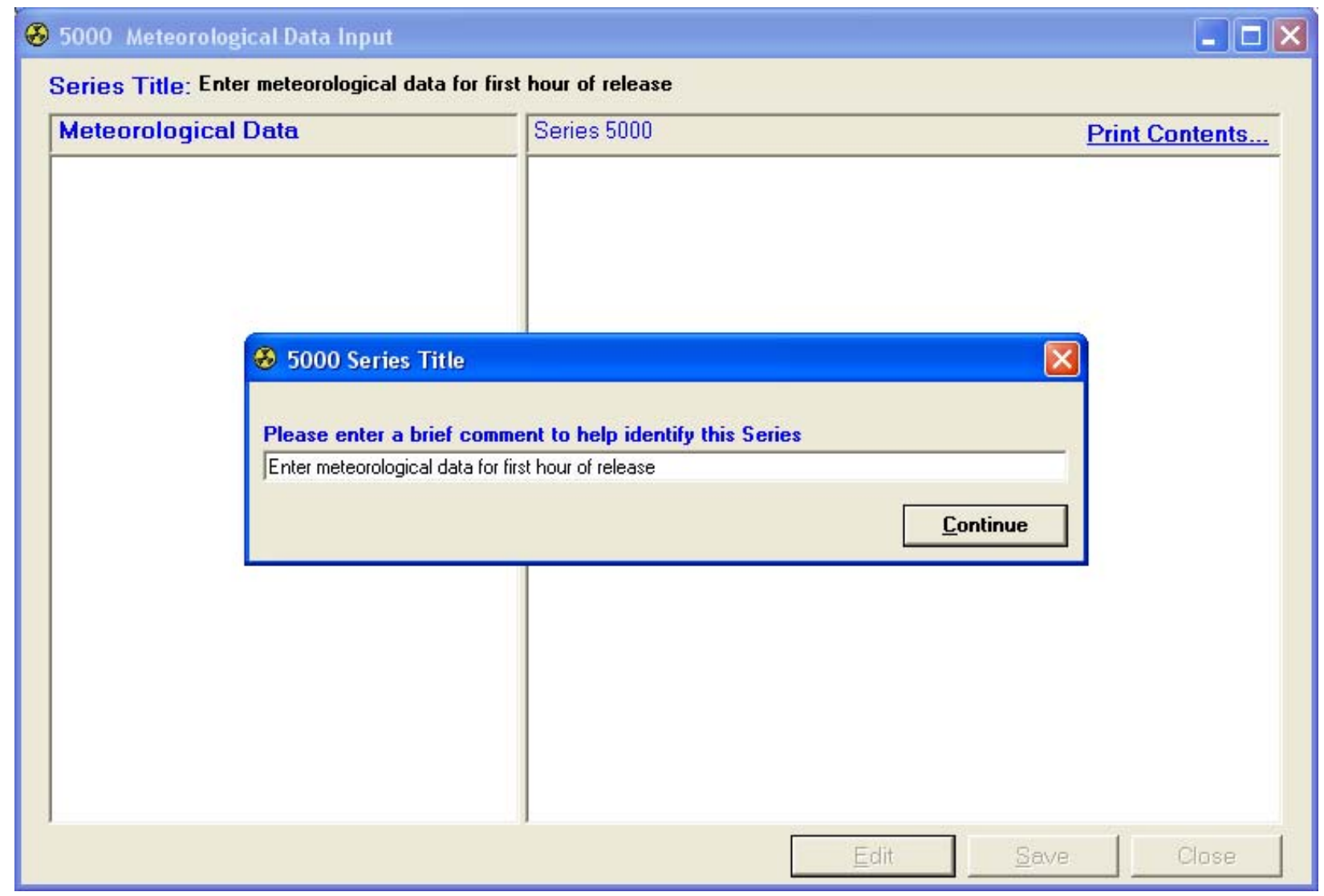

Figure 3-7. Series Main Window with Title Input.

The series title is used to identify the series in the file summary on the main window to make future editing sessions easier. Once the series title has been entered, the data entry screens will be shown in sequence to allow input of the data for that series. When all the data has been entered for that series, the series main window will be come active again allowing review of the data and the option to save or discard the data.

To cancel data entry for a series click the $\mathrm{X}$ in the upper right corner of the current data entry screen and click yes in response to the confirmation. The series main window will become active again allowing the click of the cancel button. 


\subsubsection{Editing a Series}

To edit a series in the open file, use the file summary on the main window and double-click the series to edit. The series main window will appear similar to Figure 3-8.

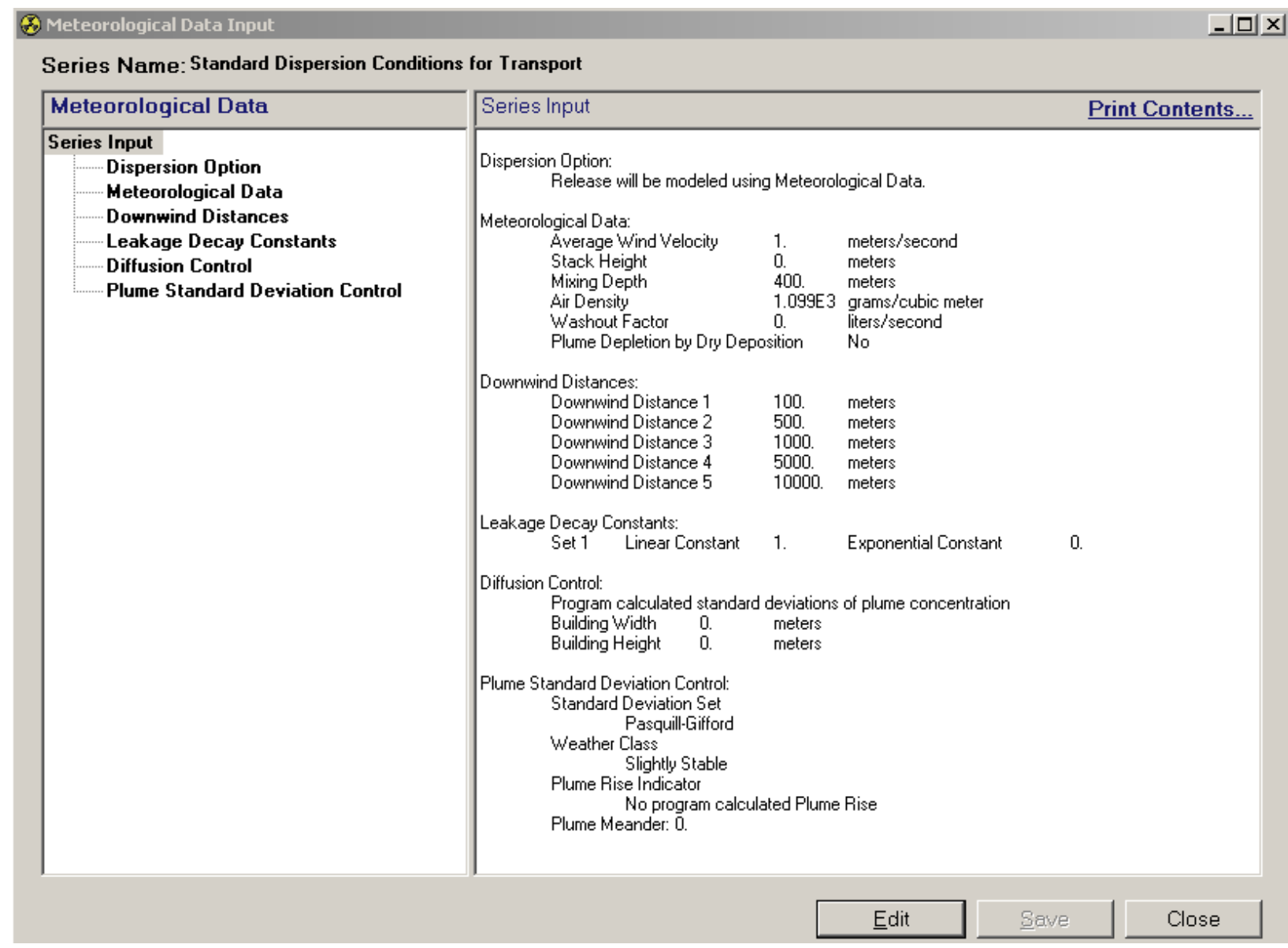

Figure 3-8. Series Main Window in Edit Mode.

The series main window shows the data that was entered in for the series. To edit the data, click the edit button and each data entry screen will be shown in sequence for editing. Once through the whole series the data can be reviewed and saved or discarded. If the data is discarded the original data will remain in the file.

To cancel the edit of a series click the $\mathrm{X}$ in the upper right corner of the current data entry screen and click yes in response to the confirmation. The original data will then be reloaded into the series main window. 


\subsubsection{Run Results}

The run results window (Figure 3-9) gives an explorer like view of the run output from RSAC allowing the user to explore the results of several files at a time.

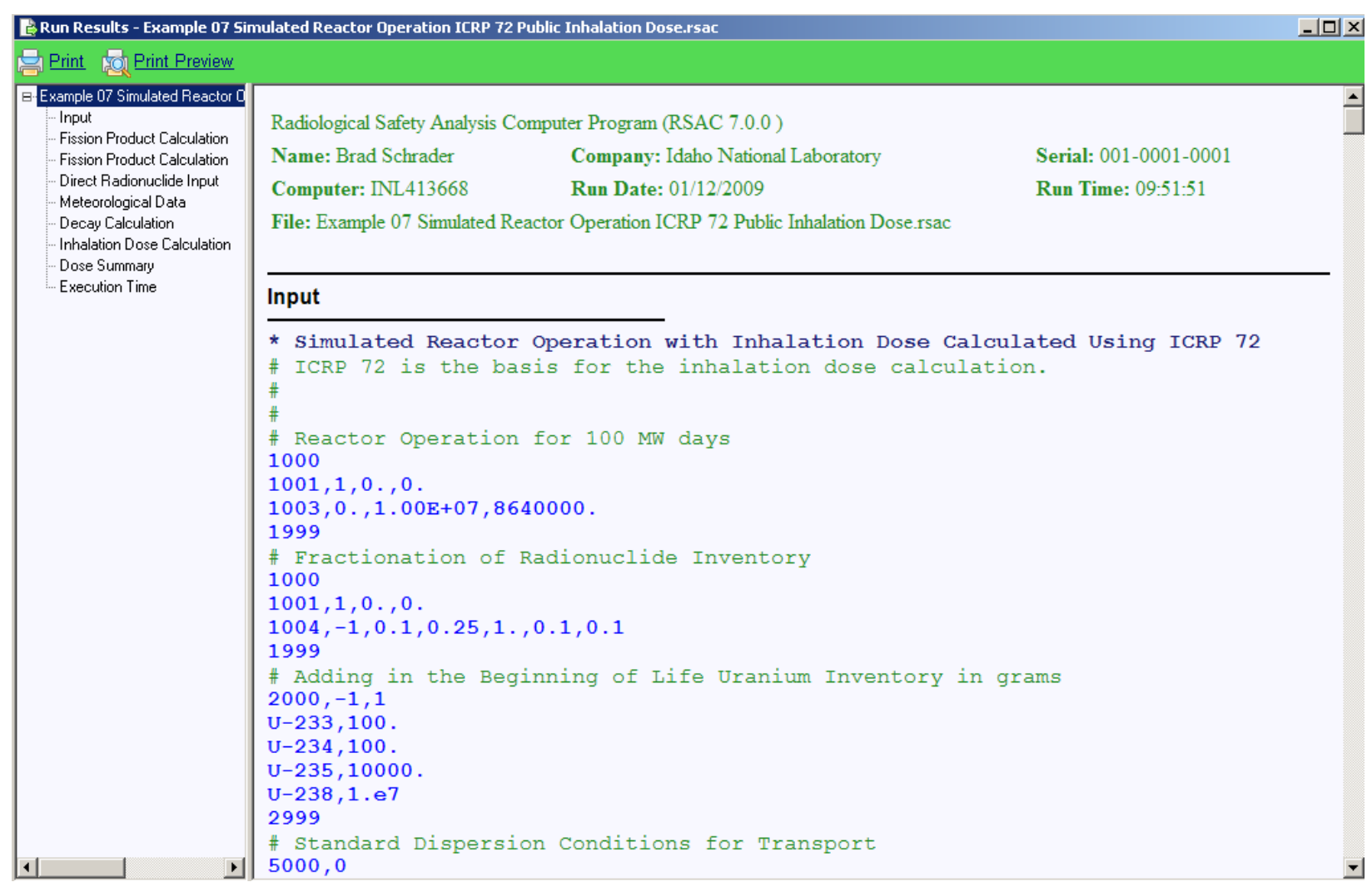

Figure 3-9. Run Results Window.

Each file that was run with RSAC will appear as the top level item in the left navigation pane. The file will be broken down into sections that are identified in the output, which will be the sub items under the file. The item that is currently selected in the navigation pane is displayed in the right pane.

- To view the contents of the whole file click the top level item which has the same name as the file.

The whole contents of the file will then be displayed in the right pane. To view just one section of the file click on the sections item in the navigation pane that is listed under the file. 


\subsection{Series Data Entry}

The following section steps through the data entry options available in each series to build an input file for RSAC. If at anytime a comment button is active during series input, a comment screen is available for use (Figure 3-10). Information can be cut and paste into the comment screen from any windows based program or it can be directly typed into the form.

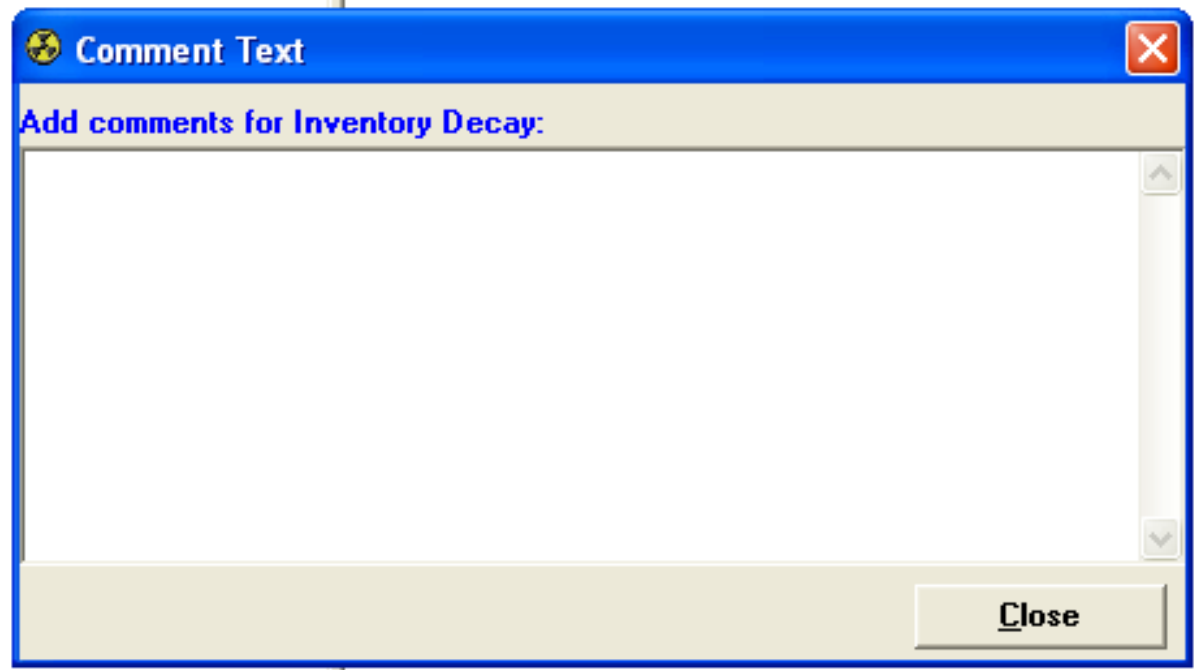

Figure 3-10. Comment Entry.

\subsubsection{Series - Fission Product Inventory Calculation}

Screen 1 - Input Type: The first data entry screen for the 1000 series is the Input Type

(Figure 3-11). Select the type of input to be generated. Only one type can be selected at a time. The option chosen determines the sequence of screens that follow screen 1.

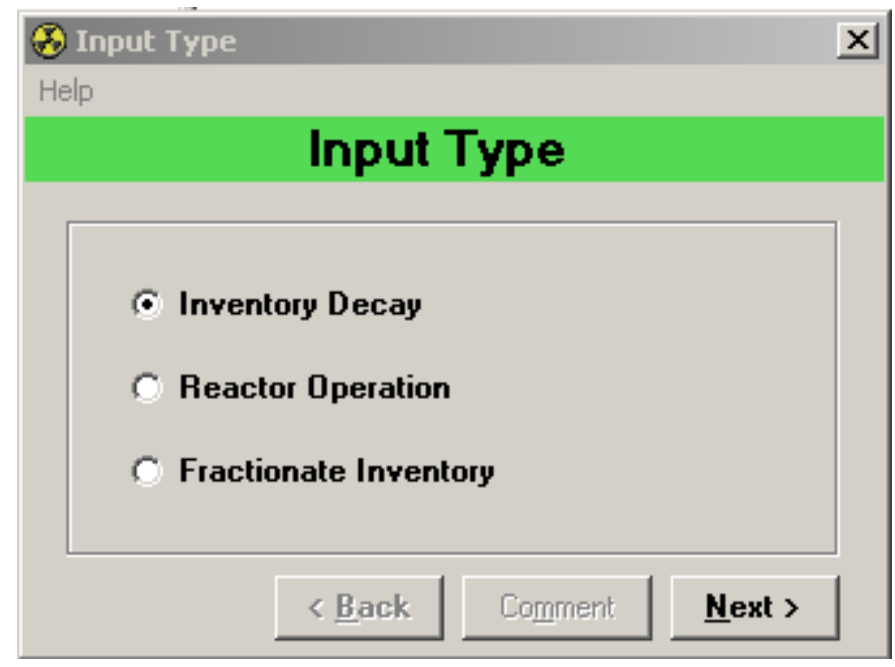

Figure 3-11. Screen 1, Input Type. 
Screen 2A (Optional) - Inventory Decay: Shown only if Inventory Decay is chosen on screen 1. Indicate the inventory decay time (Figure 3-12). You must have input an inventory previously for this to function properly. A pull down menu is available to allow for a variety of input options.

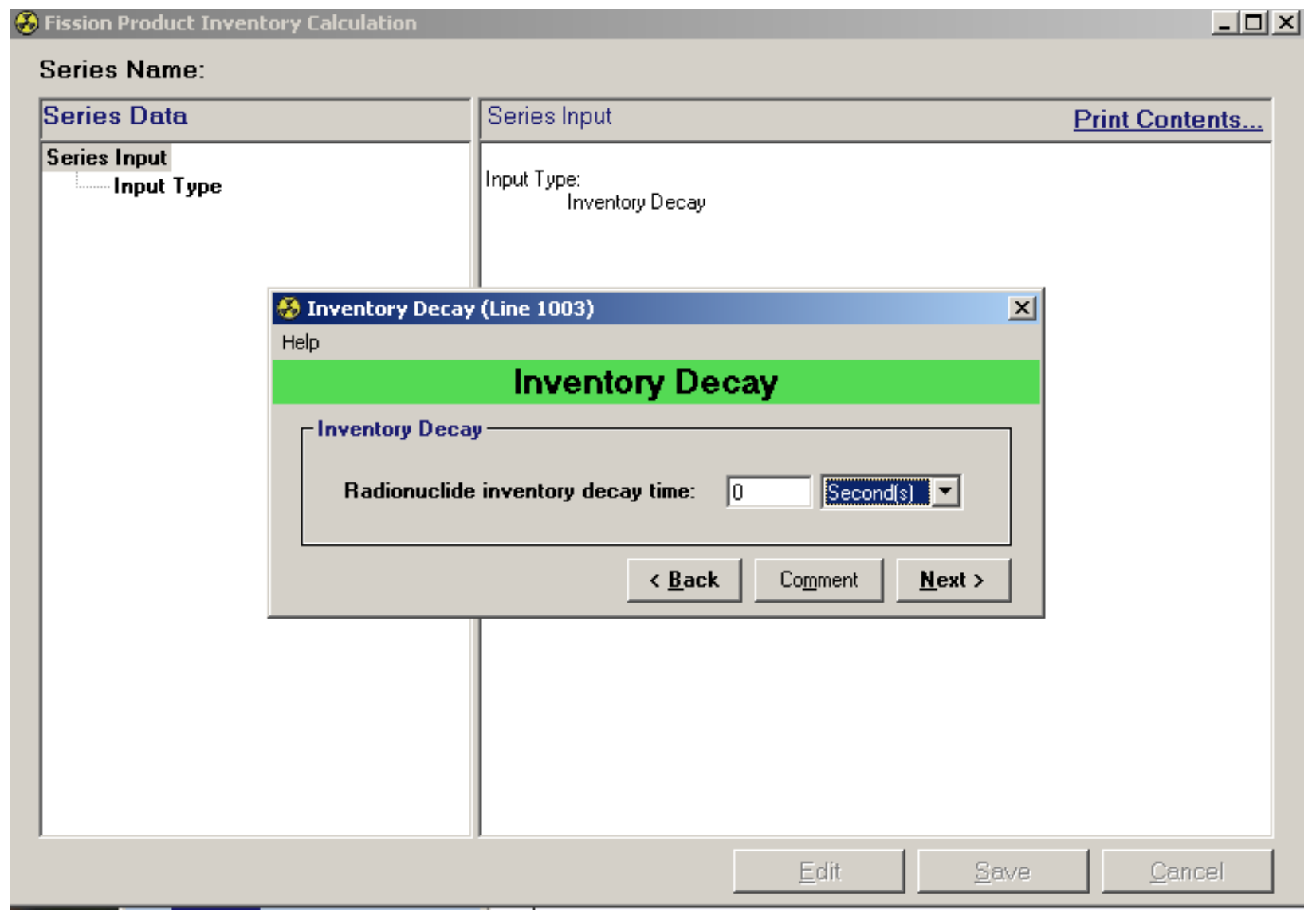

Figure 3-12. Screen 2A (Optional), Inventory Decay. 
Next, notification of input completion for the 1000 series is given (Figure 3-13). Click the OK button to end data entry for the series and review the data input.

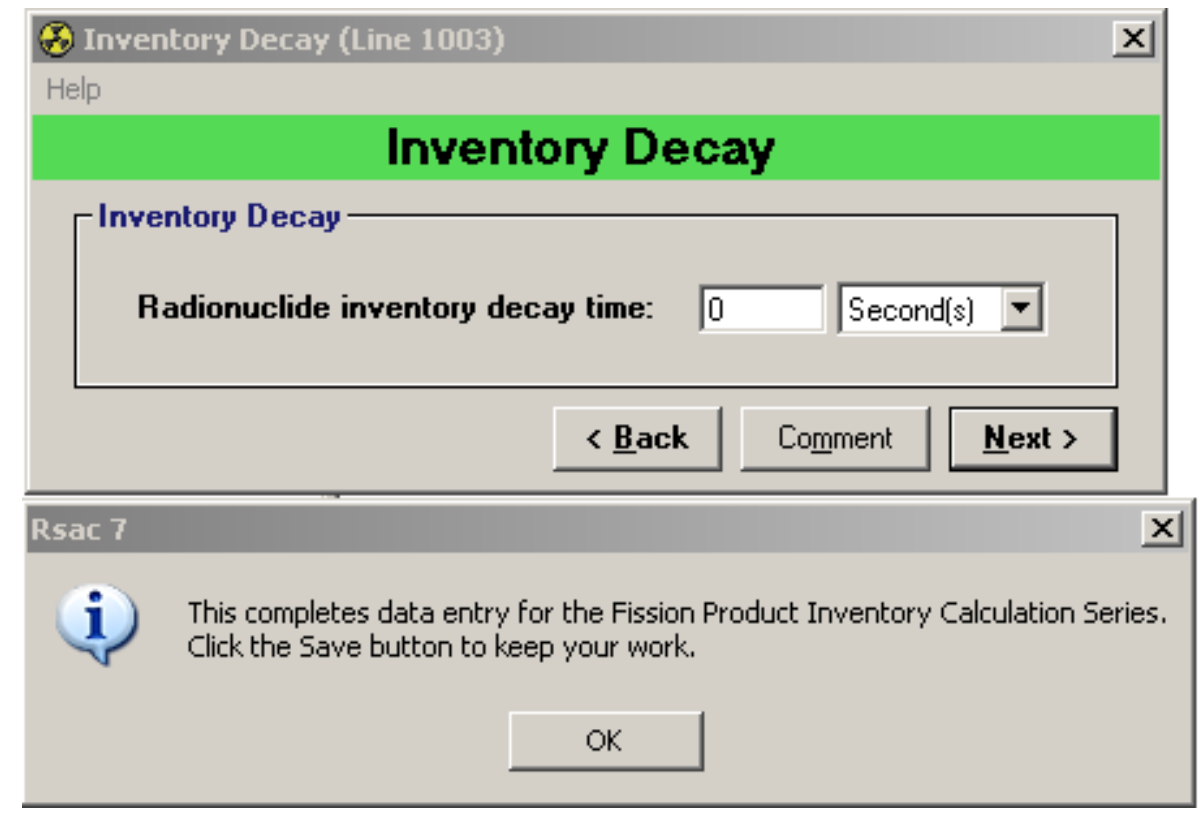

Figure 3-13. Input Completion Notification.

Screen 2B (Optional) - Reactor Operation: Shown only if Reactor Operation is selected on screen 1, see Figure 3-14.

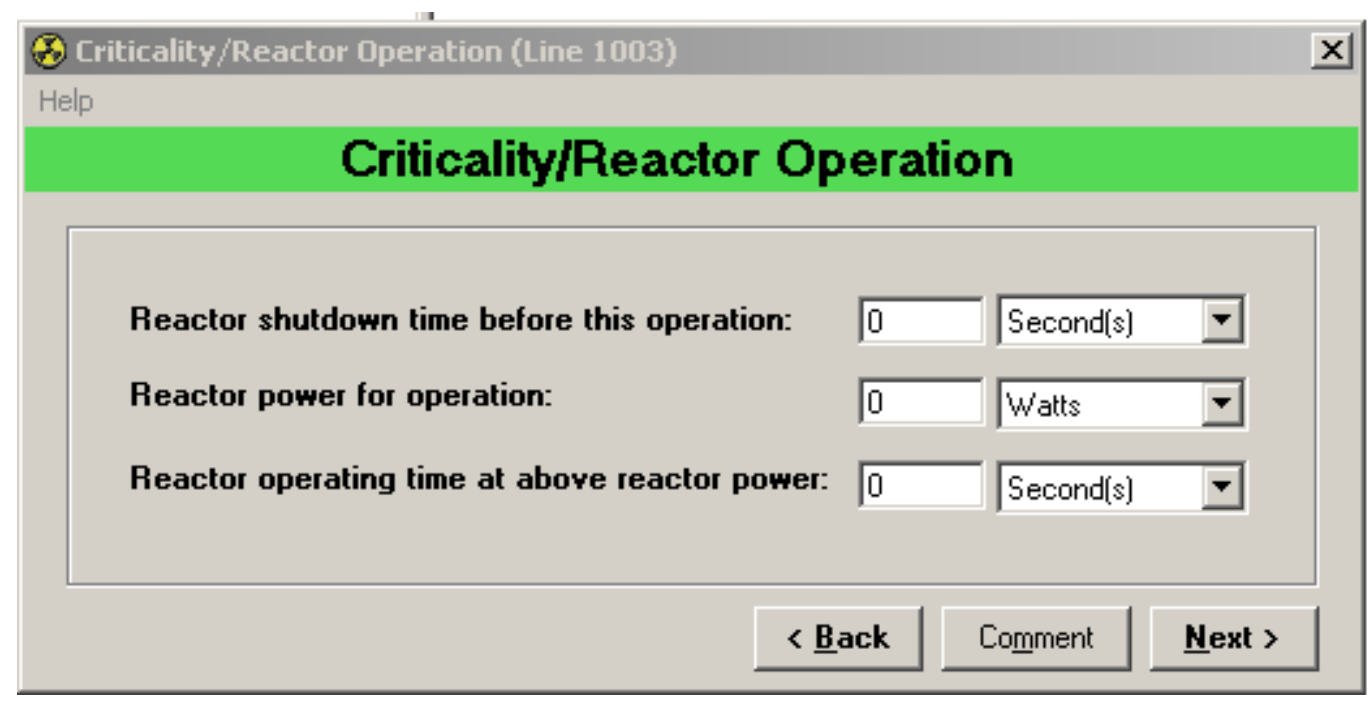

Figure 3-14. Screen 2B (Optional), Reactor Operation. 
Screen 3A - Release During Reactor Operation: Shown after optional screen 2B Reactor Operation (Figure 3-15). If you respond YES, the Release During Fission Product screen will appear next.

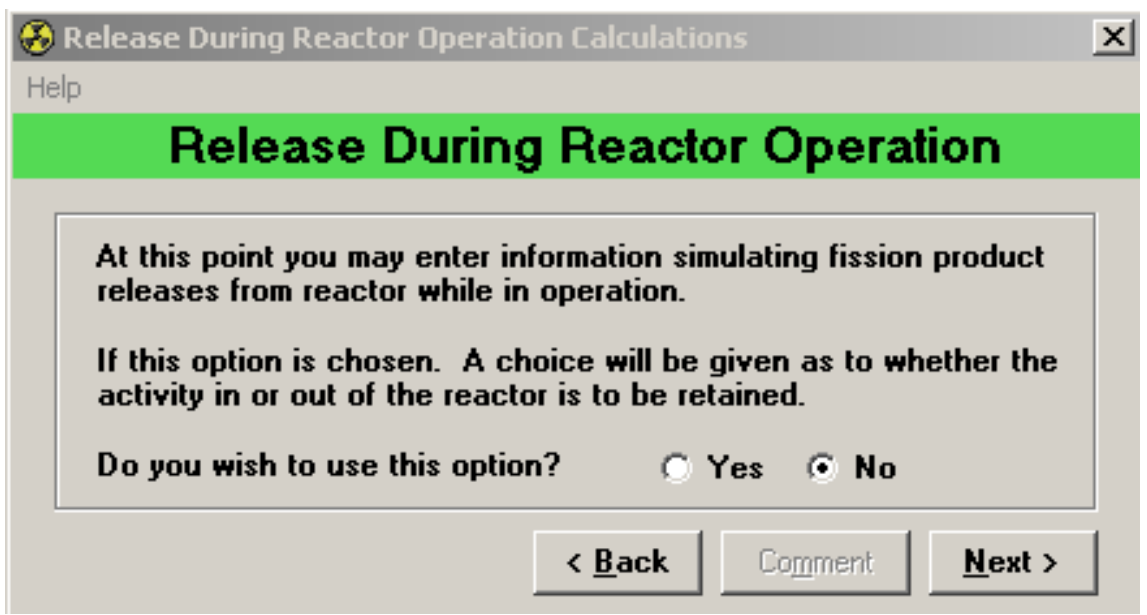

Figure 3-15. Screen 3A, Release During Reactor Operation. 
Screen 4A - Release During Fission Product: On this screen (Figure 3-16), enter the inventory to be retained for subsequent calculations. Specifically, supply the following:

- Number of reactor incremental release steps

- Radionuclide leak rate from the reactor for each of the following: solids, halogens, noble gases, cesium, and ruthenium.

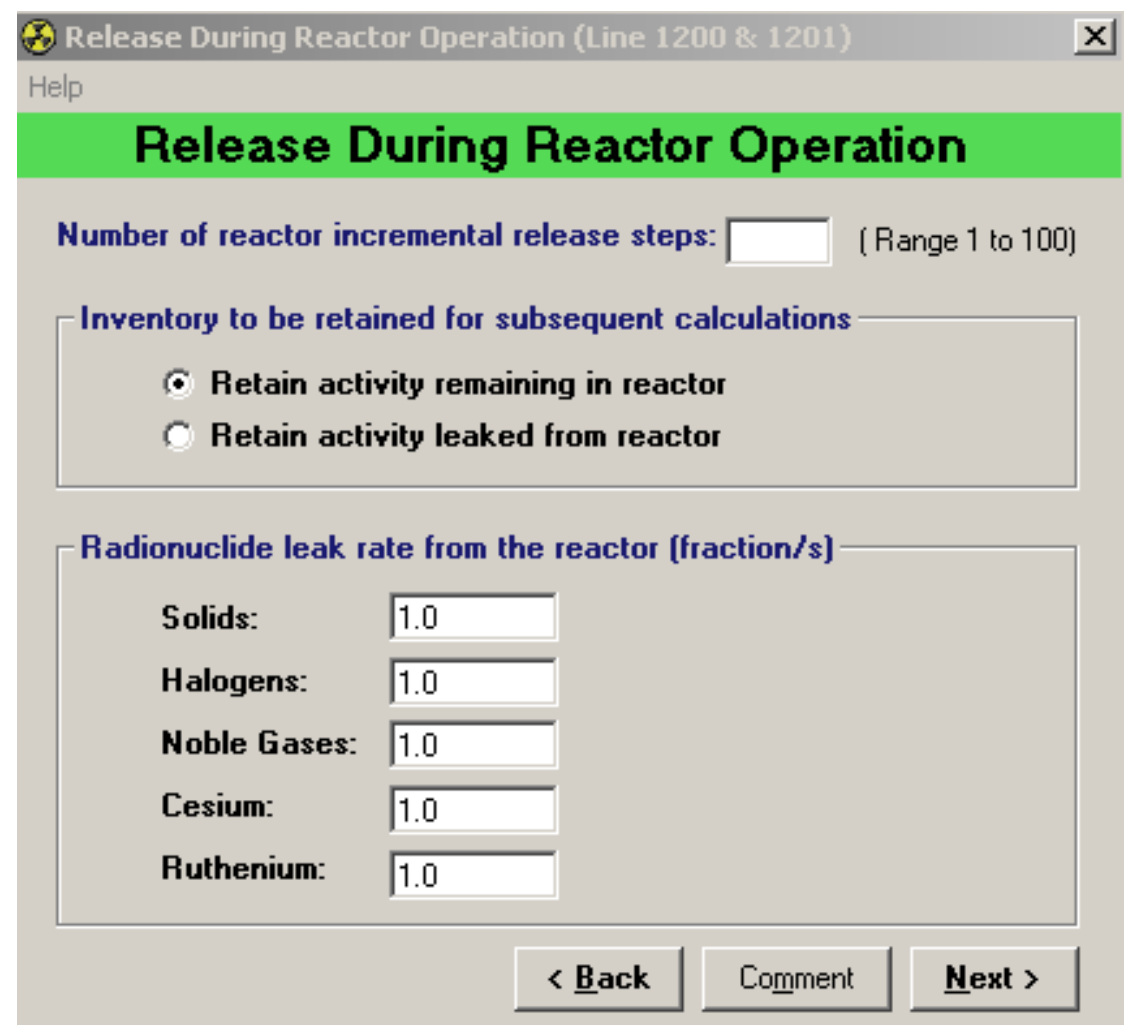

Figure 3-16. Screen 4A, Release During Fission Product.

Screen 2C (Optional) - Fractionate Inventory: Shown only if Fractionate Inventory is selected on screen 1 (Figure 3-17). Select the option of what type of fractionation should be performed.

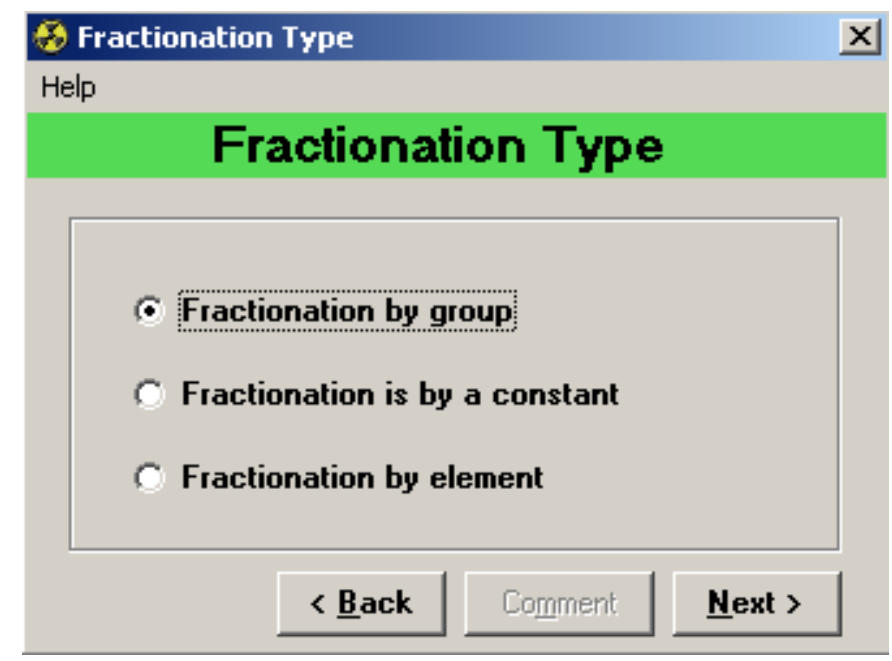

Figure 3-17. Screen 2C (Optional), Fractionate Inventory. 
Screen 3B (Optional) - Fractionation by Group: Shown only if Fractionation by group is selected on the Fractionate Inventory screen 2C (Figure 3-18).

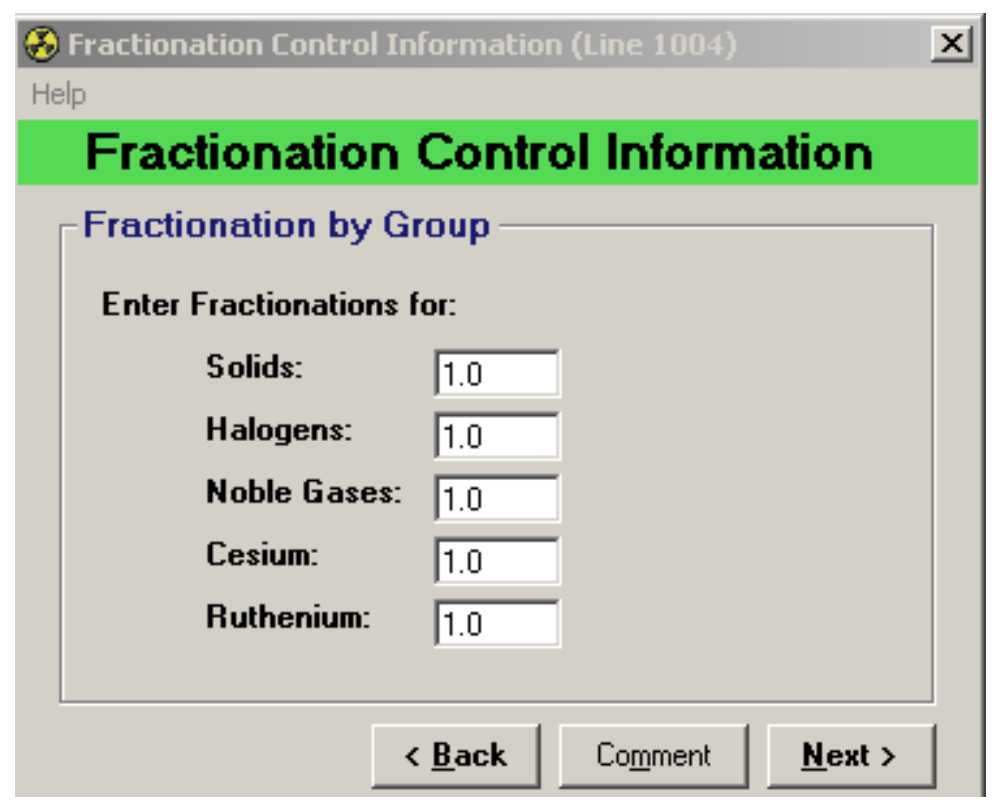

Figure 3-18. Screen 3B (Optional), Fractionation by Group.

Screen 3C(Optional) - Fractionation by Constant: Shown only if Fractionation is by a constant is selected on the Fractionate Inventory screen 2 (Figure 3-19).

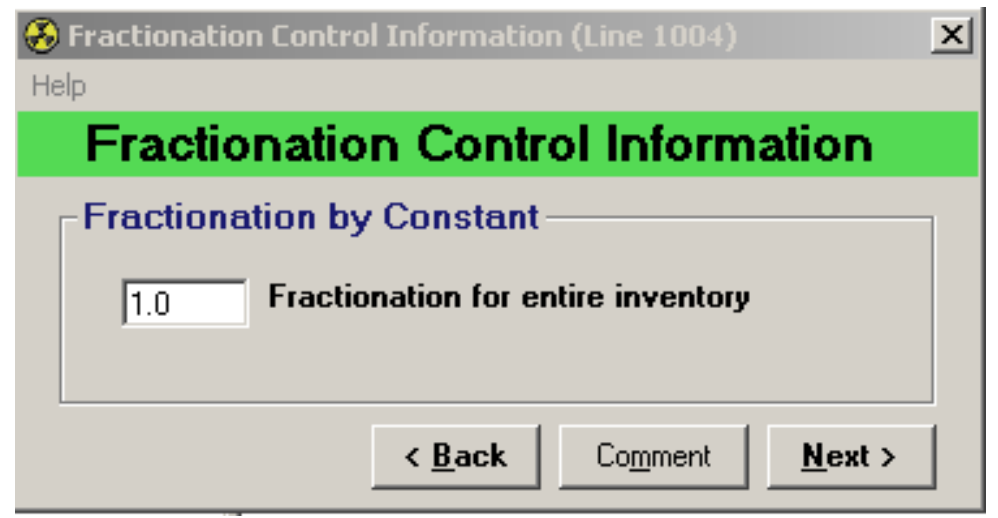

Figure 3-19. Screen 3C (Optional), Fractionation by a Constant. 
Screen 3D (Optional) - Fractionation by Element: Shown only if Fractionation by element is selected on the Fractionate Inventory screen 2C (Figure 3-20). Provide the fractionation for elements that are not individual fractionated on the next screen.

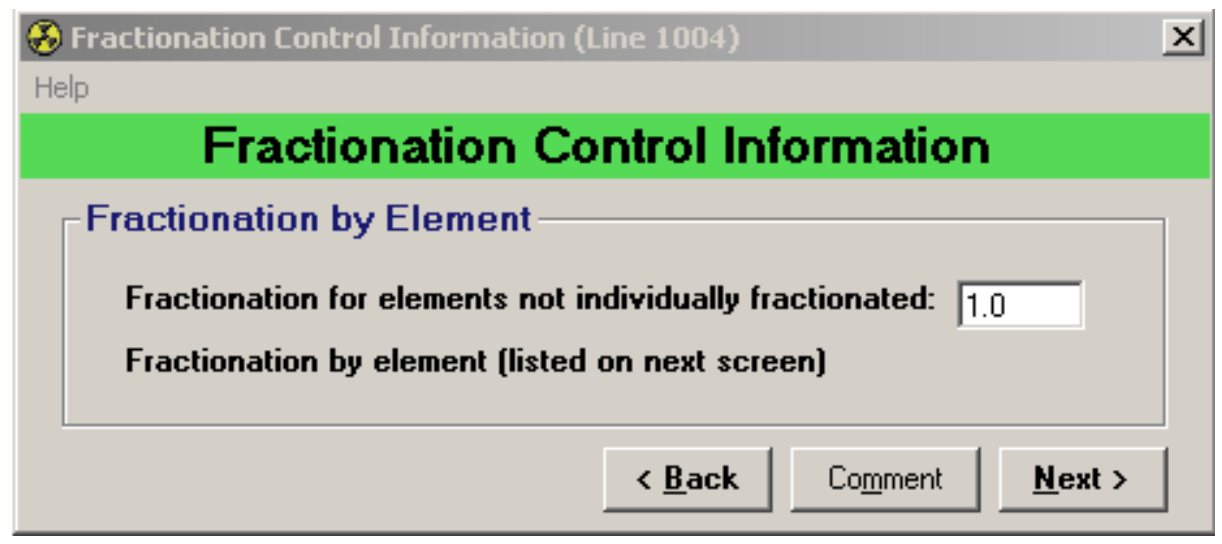

Figure 3-20. Screen 3D (Optional), Fractionation by Element. 
Screen 4B - Element Fractionation Specification: This screen is where individual element fractionations are specified (Figure 3-21). To enter a fractionation for an element use one of the following methods. Use the $\langle\uparrow>$ and $\langle\downarrow\rangle$ to select the desired element in the list; scroll through the list and select the desired element; type the symbol to quickly select the desired element. Then click the Enter Fractionation button below the list or double-click the element to supply a value. Once the value has been supplied click the OK button to accept the value or click the Cancel button to discard the supplied value. Note: To supply the same fractionation to multiple elements hold the $<$ shift $>$ or $<$ ctrl $>$ keys while selecting element then click the Enter Fractionation button. To discard a fractionation already entered, select the element from the list and click the Clear Selected button.

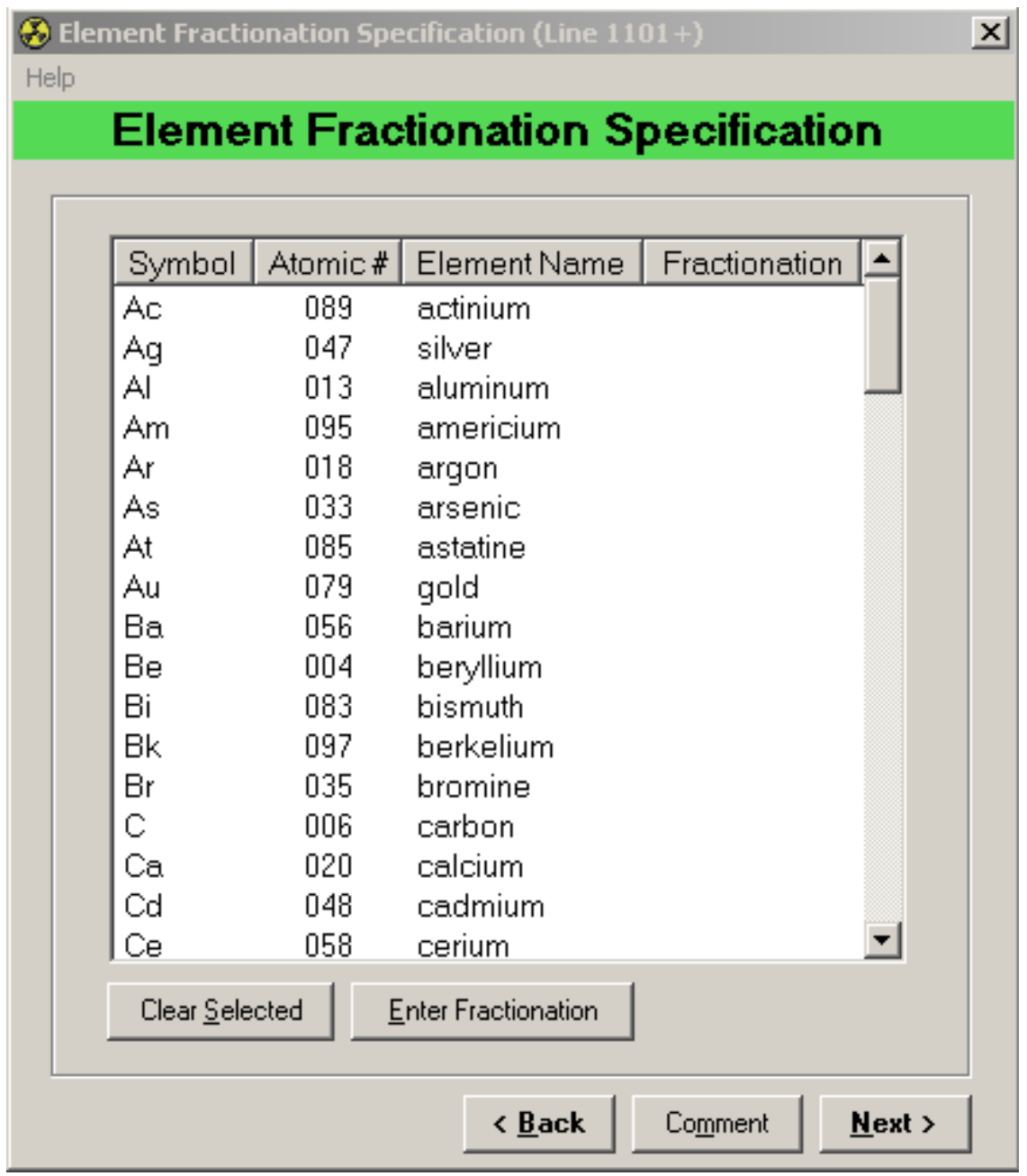

Figure 3-21. Screen 4B, Element Fractionation Specification. 


\subsubsection{Series - Direct Radionuclide Input}

Screen 1 - Series Title: Enter a brief comment about the 2000 Series that is being appended and click on Continue (Figure 3-22). This comment is used to distinguish between series and can make future editing sessions easier. This comment will also appear in the generated RSAC-7 input file.

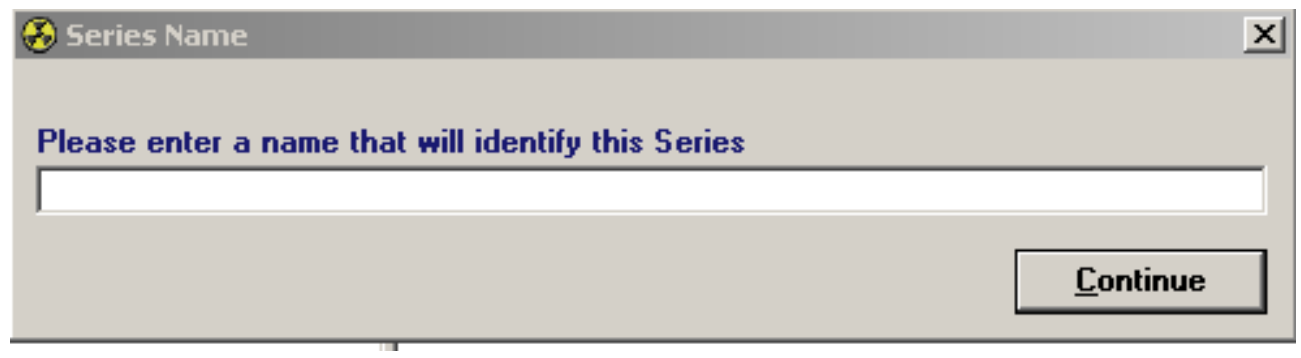

Figure 3-22. Screen 1, Series Title.

Screen 2 - Radionuclide Input Options: Use the mouse to select the appropriate option for your problem (Figure 3-23).

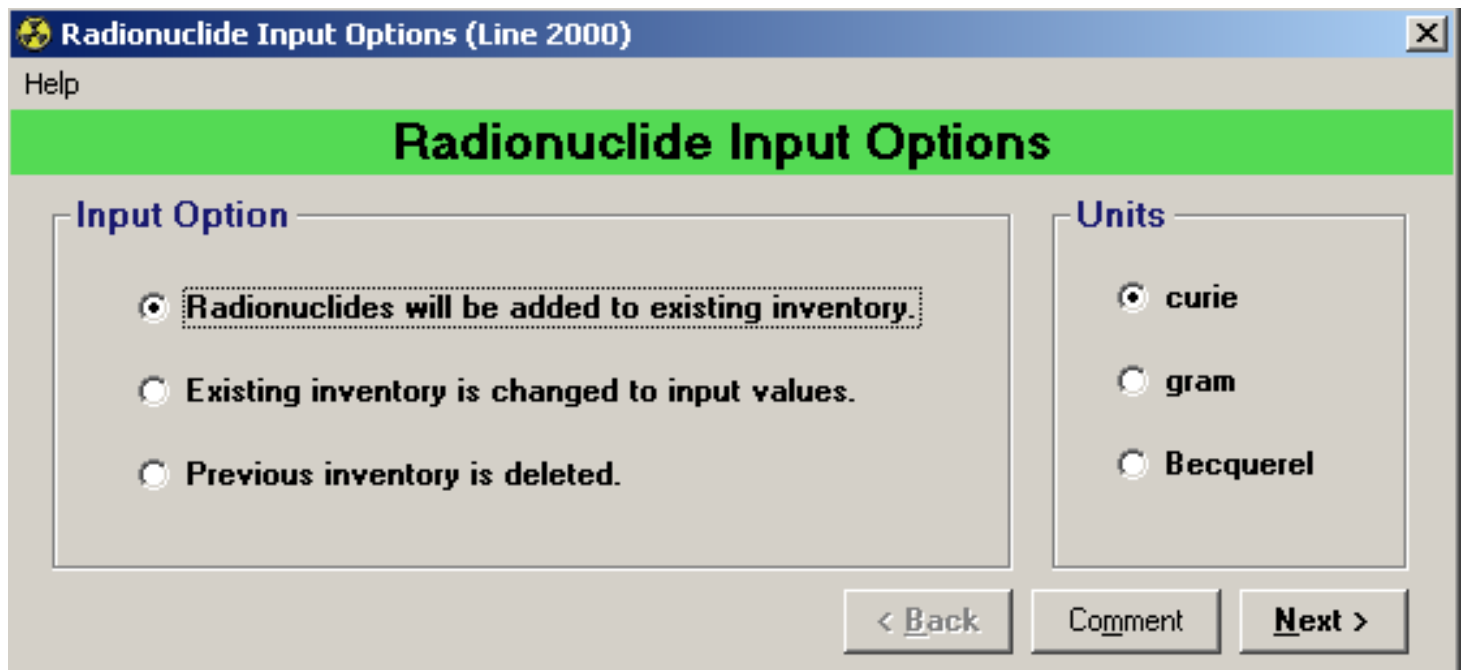

Figure 3-23. Screen 2, Radionuclide Input Options.

- First selection - Retain the previous radionuclide inventory and to add the inventory for the radionuclides selected on the subsequent screens to the previous values.

- Second selection - Retain the previous radionuclide inventory and to change the inventory for the radionuclides selected on the subsequent screens to the new values entered.

- Third selection - Initializes the inventory. You will be entering the radionuclide inventory and any previous radionuclide inventory is deleted. If this option is selected the warning in Figure 3.26 is displayed. It is very important to understand that if a 1000 series was used to generate a fission product inventory previously, this option will delete the inventory from memory. Use this option with caution.

- A new option in RSAC 7 is to allow input in various units. Make sure the appropriate unit of input is selected. 


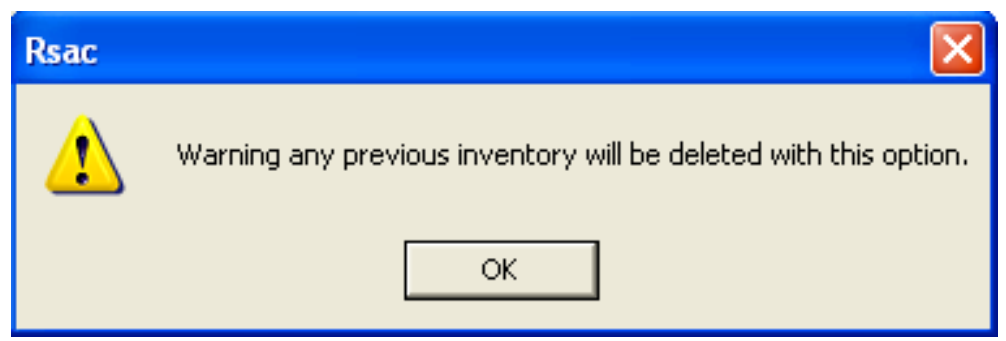

Figure 3-24. Previous Inventory Deleted Warning.

Screen 3 - Direct Radionuclide Input: This screen (Figure 3-25) determines whether the radionuclides will be selected and values input directly or if an external file will be used as the source for radionuclide input.

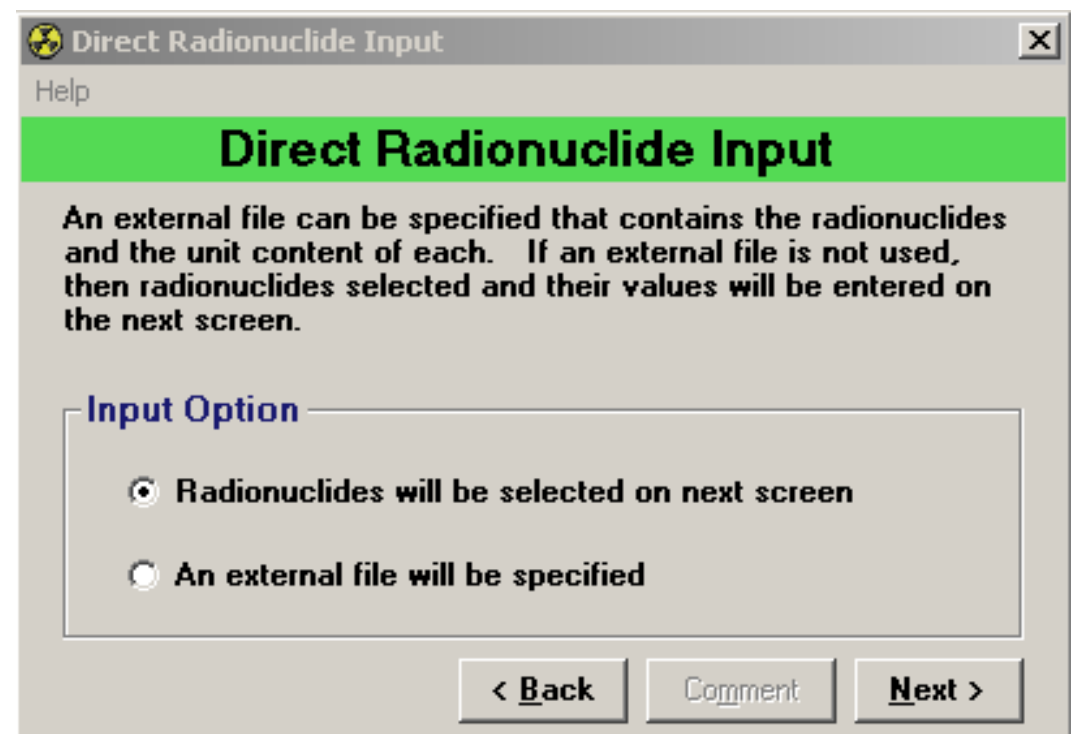

Figure 3-25. Screen 3, Direct Radionuclide Input. 
Screen 4A (Optional) - Radionuclide Curie Input: Shown only when Radionuclides will be selected on next screen is chosen on screen 3. On this screen (Figure 3-26), select the radionuclide and input the activity desired using one of the following methods. Use the $\langle\uparrow\rangle$ and $\langle\downarrow\rangle$ to select the desired radionuclide in the list; scroll through the list and select the desired radionuclide; type the symbol to quickly select the desired radionuclide. Then click the Enter Curie button below the list or double-click the radionuclide to supply a value. Once the value has been supplied click the OK button to accept the value or click the Cancel button to discard the supplied value. Note: To supply the same Curie to multiple radionuclides hold the $<$ shift $>$ or $<$ ctrl $>$ keys while selecting radionuclide then click the Enter Curie button. To discard a Curie already entered, select the radionuclide from the list and click the Clear Selected button. Note: if the selection mode changes from Curies to grams or Becquerel's, the input screen is basically the same other than the name on the enter key.

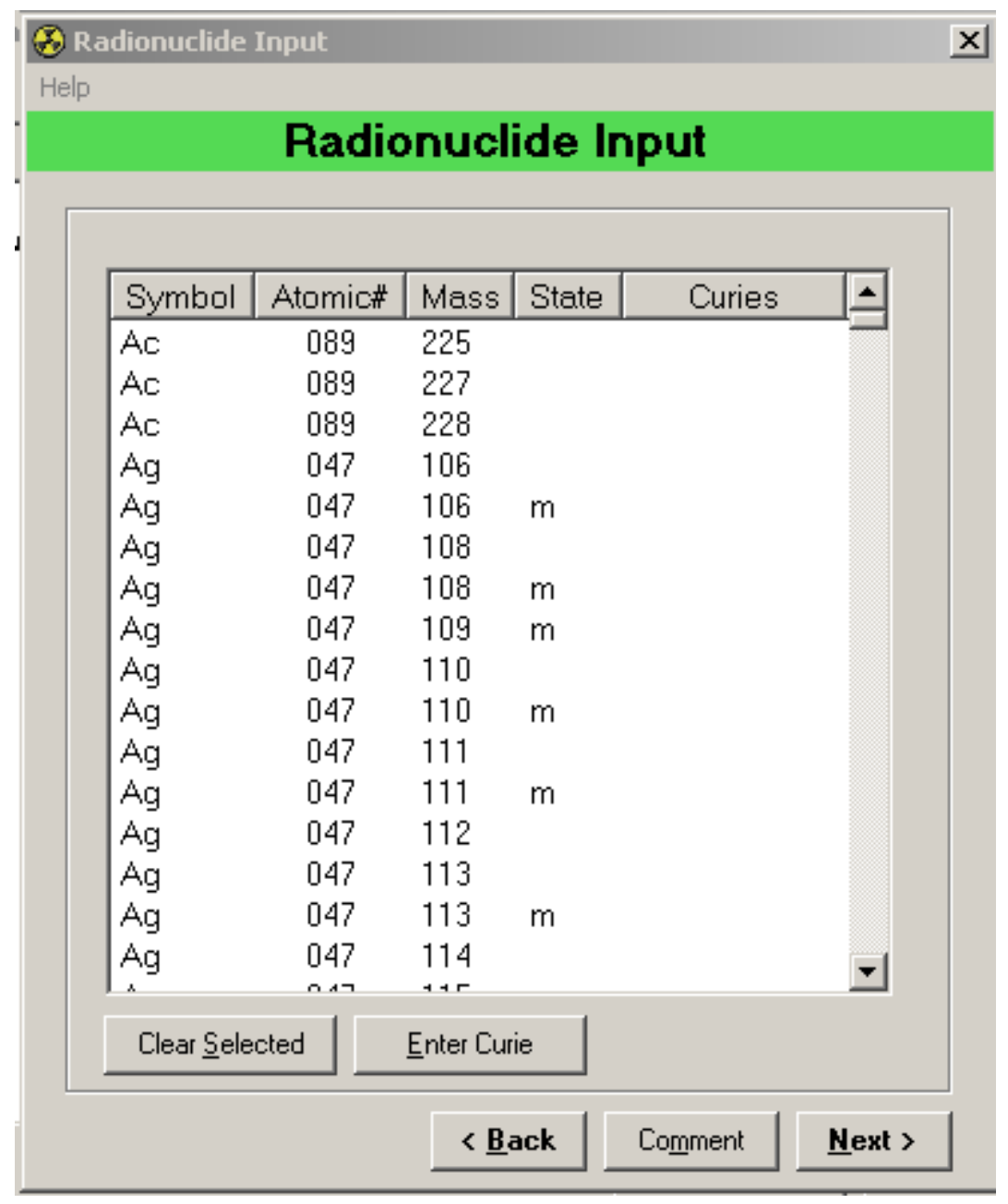

Figure 3-26. Screen 4A (Optional) Radionuclide Curie Input. 
Screen 4B (Optional) - External File for Radionuclide Entry: Shown only when An external file will be specified is chosen on screen 3 (Figure 3-27). Enter the name of the file that contains the list of radionuclides and curie content. Use the Select File button to locate the file.

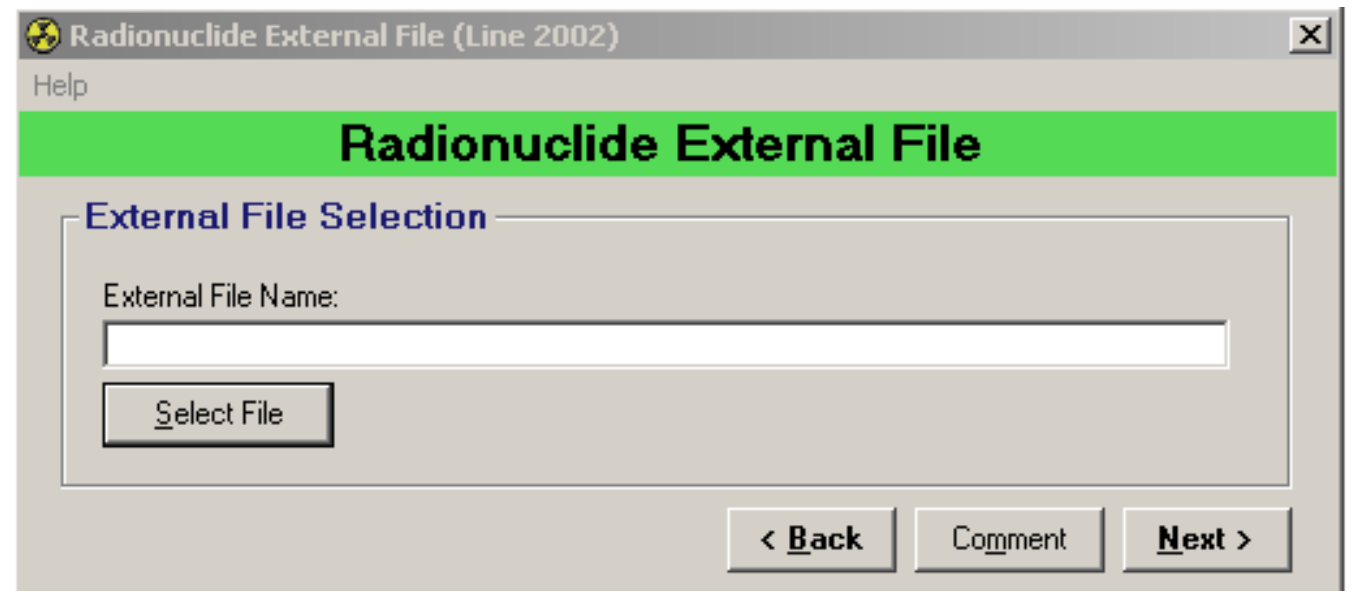

Figure 3-27. Screen 4B (Optional), External File for Radionuclide Entry.

Screen 5 - Series Complete Notification: When finished with the data entry screens, you will be notified that data entry is complete (Figure 3-28). Click OK to return to the series main window (Figure 3.31) to review and save entered data.

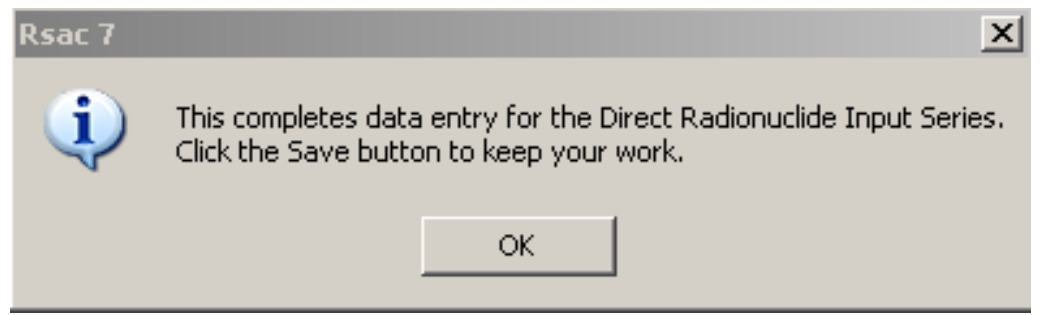

Figure 3-28. Screen 5, Series Complete Notification. 


\subsubsection{Series - Dose Summary Option}

The dose summary option cannot be initialized until meteorological data (5000 Series) has been entered. The initiation of the dose summary option is automatically performed. In addition, downwind distances cannot be changed using subsequent 5000 Series input after the dose summary option has been initiated.

The 3000 series is accessed by clicking on the Reports Tab (Figure 3-29).

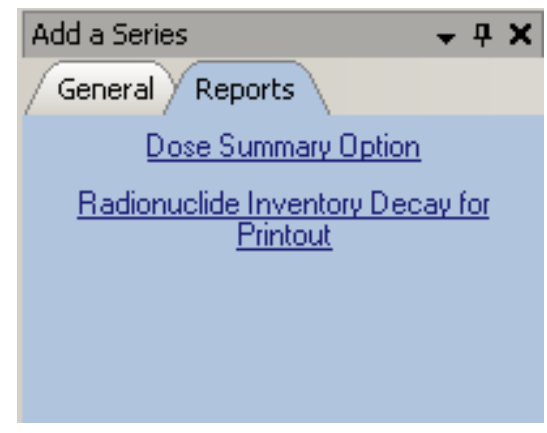

Figure 3-29. Reports Tab.

Screen 2 - Dose Summary Options: After the series title screen is dismissed the following selections are available (Figure 3-30).

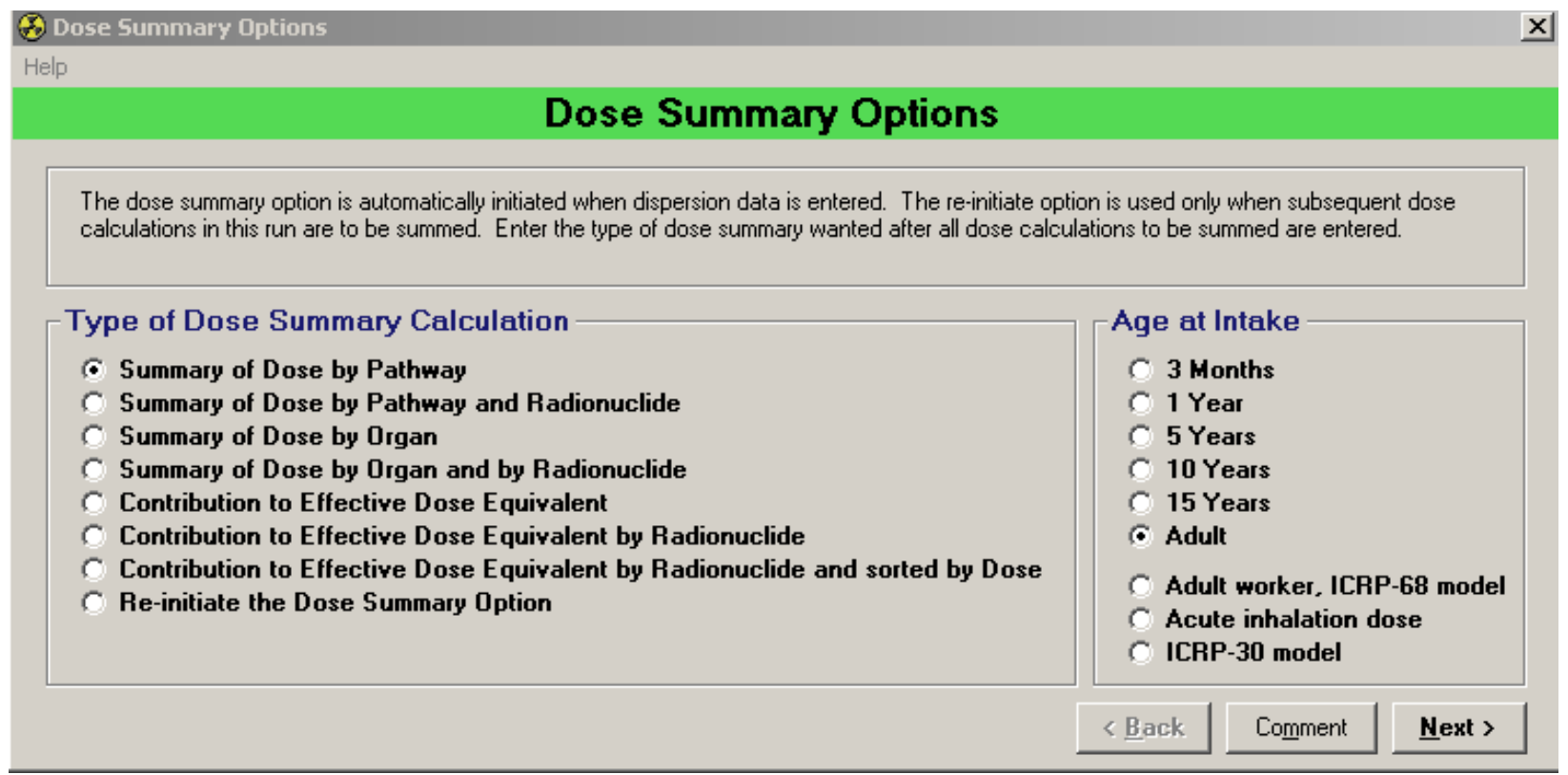

Figure 3-30. Screen 2, Dose Summary Options. 
One or all of the options may be selected and may be selected for a specific age group.

- $\quad$ Summary of Dose by Pathway - Summarizes the CEDE for each pathway and totals the dose.

- $\quad$ Summary of Dose by Pathway and Radionuclide - Summarizes the CEDE for each radionuclide and each pathway. It does not summarize for the plume gamma pathway.

- Summary of Dose by Organ - Requires the selection of organs on optional screen 3 Click the organ in the list to select it and click again to unselect the organ. An X will appear in the selected column to indicate the organ is selected. If you click the Clear Selected button then all organs will be unselected.

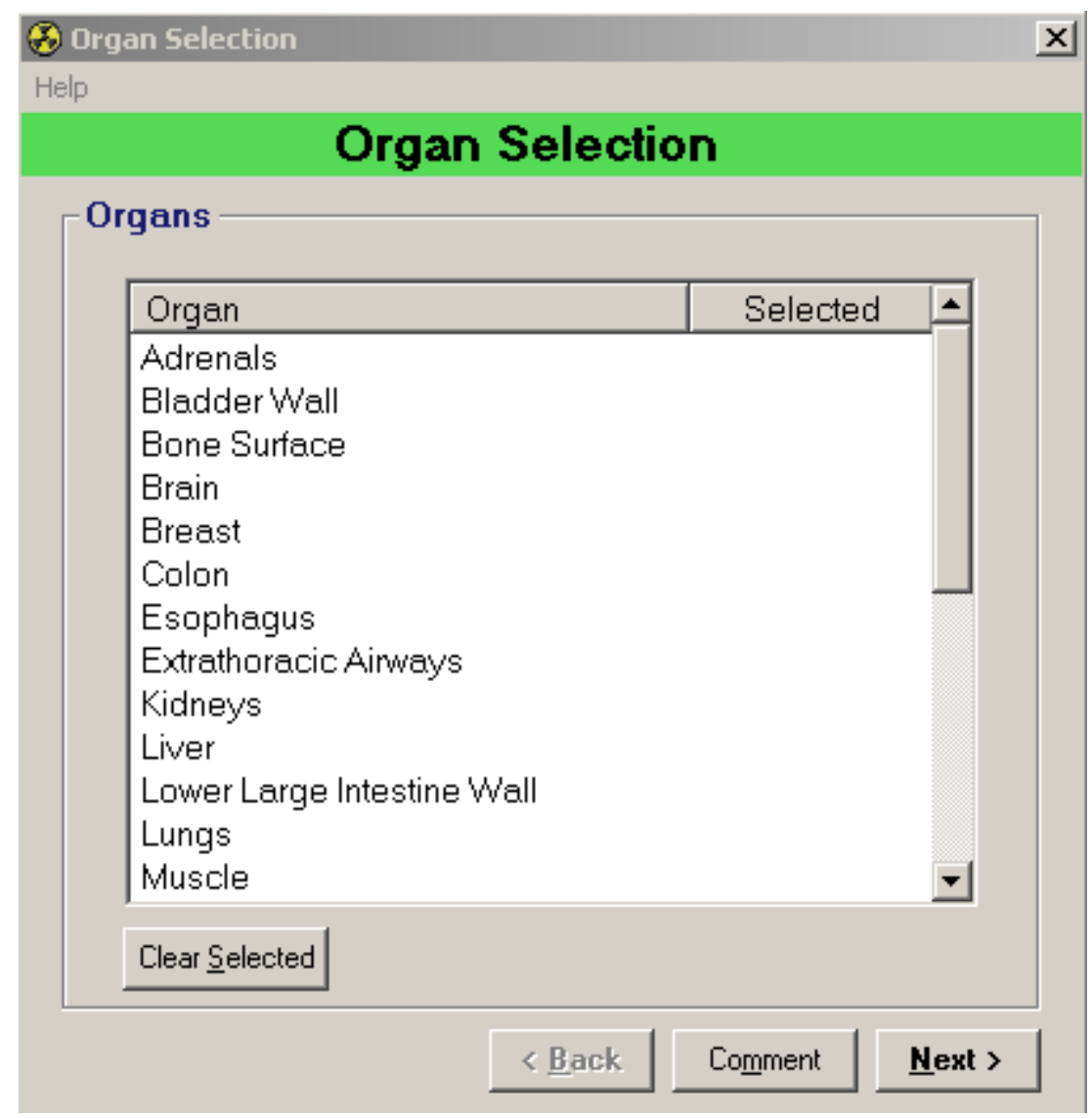

Figure 3-31. Screen 3 (Optional), Organ Selection.

- Summary of Dose by Organ and Radionuclide - Same as previous option but adds the radionuclides to the summary. The organ selection optional screen 3 will be shown with a note that it is summarized by organ and radionuclide

- $\quad$ Summary of Dose from Contribution to Effective Dose Equivalent - this is a summary function that shows in order of distance by pathway to EDE

- $\quad$ Summary of Dose from Contribution to EDE and Radionuclide - Same as previous report sorted alphabetical by radionuclide.

- $\quad$ Summary of Dose from Contribution to EDE and Radionuclide Sorted by Dose - Same as previous report except the order is from highest dose to lowest by radionuclide. 


\subsubsection{Series - Dispersion Control Input}

Screen 2 - Dispersion Options: After the series title screen the Dispersion options screen is displayed (Figure 3-32). Select the type of dispersion control desired and click on the next button.

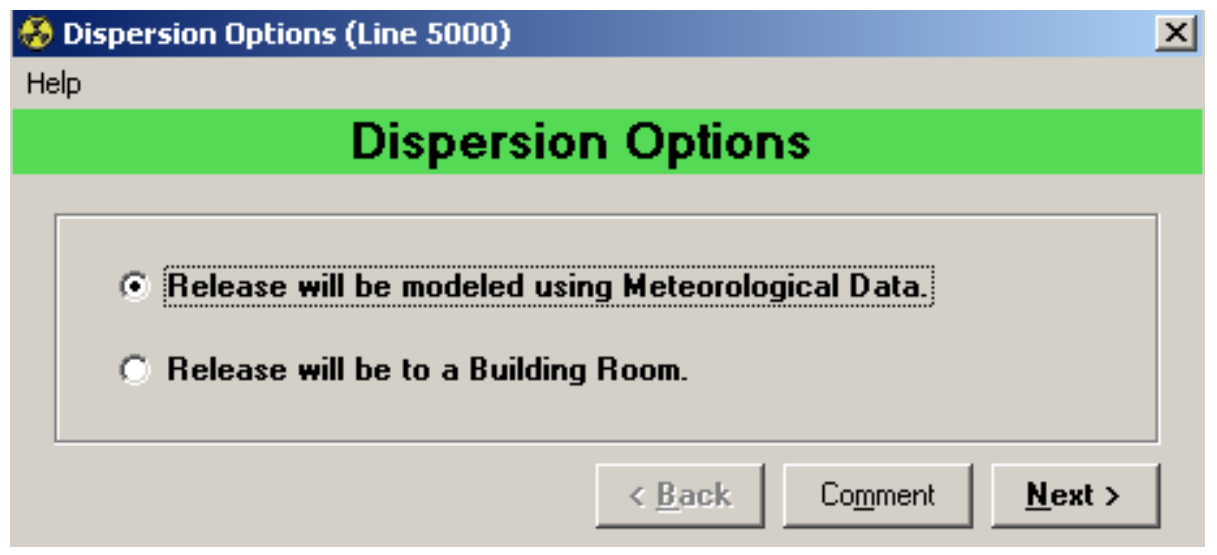

Figure 3-32. Screen 2, Dispersion Options.

- Option 1 - the release will be modeled using meteorological data.

- Option 2 - the release will be to a room. If this option is selected only the inhalation pathway can be evaluated. 
Screen 3 (Optional) - General Meteorological Information: Shown only if option 1 was chosen on screen 2. Enter the Meteorological Conditions and click on next (Figure 3-33). If questions arise on what the inputs are or how the default values were chosen, move your cursor over the item in question and right-click and click on Display Help. Select Help and the information will be displayed (Figure 3-34).

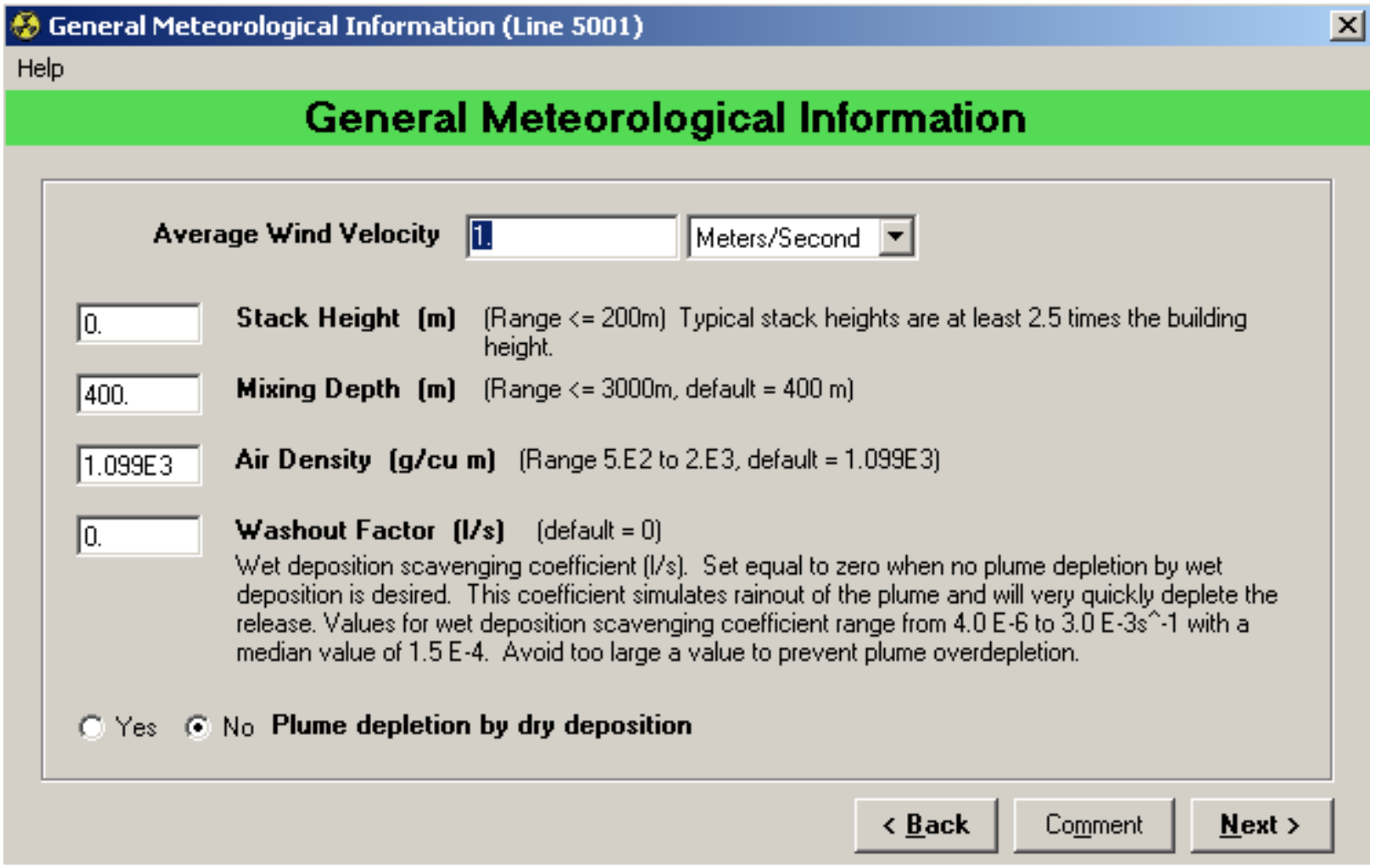

Figure 3-33. Screen 3 (Optional), General Meteorological Information.

Mixing Depth:
The third selection is the mixing depth. This depth acts as an effective
ceiling to the release. Mixing depths are difficult to determine. The default
value is 400 meters. Other values are identified below.
\begin{tabular}{|l|c|c|}
\hline \multicolumn{1}{|c|}{ Season } & Morning & Afternoon \\
\hline Spring & 480 & 2330 \\
\hline Summer & 260 & 2900 \\
\hline Autumn & 330 & 1550 \\
\hline Winter & 400 & 730 \\
\hline Annual & 370 & 2090 \\
\hline
\end{tabular}

Figure 3-34. Help Information. 
Screen 4 (Optional) - Dry Deposition Variables: This screen is only shown when YES has been selected for Plume depletion by dry deposition on screen 3 (Figure 3-35). It is important to understand that if you don't request plume depletion the options for calculation of ingestion and ground surface dose will not be available. If the RSAC-7 default variables are chosen the then Deposition Velocities will be those defined in Figure 3-35.

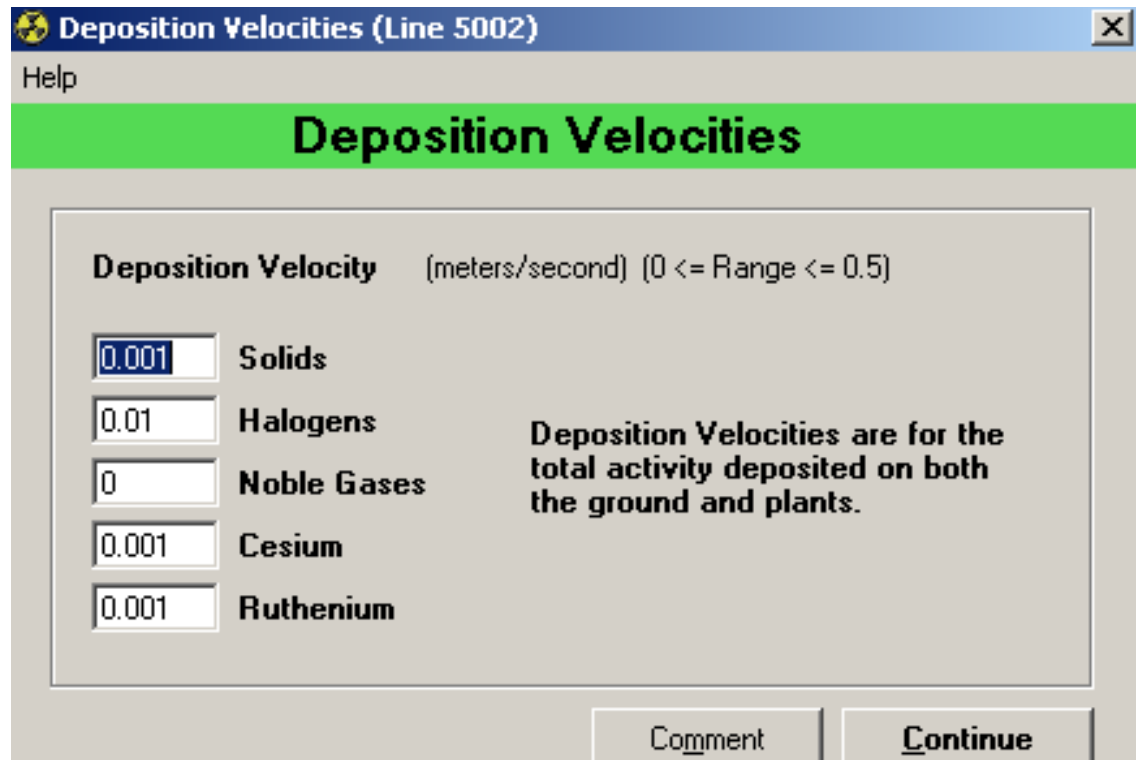

Figure 3-35. Screen 4 (Optional), Dry Deposition Variables. 
Screen 5 - Downwind Distances: Enter one or more unique downwind distances (Figure 3-36). If a duplicate distance is entered, you will be alerted and the field in error will automatically be highlighted. Be careful when editing downwind distances because the direct input of $\chi / \mathrm{Q}$ values and the direct input of standard deviations must correspond to downwind distances.

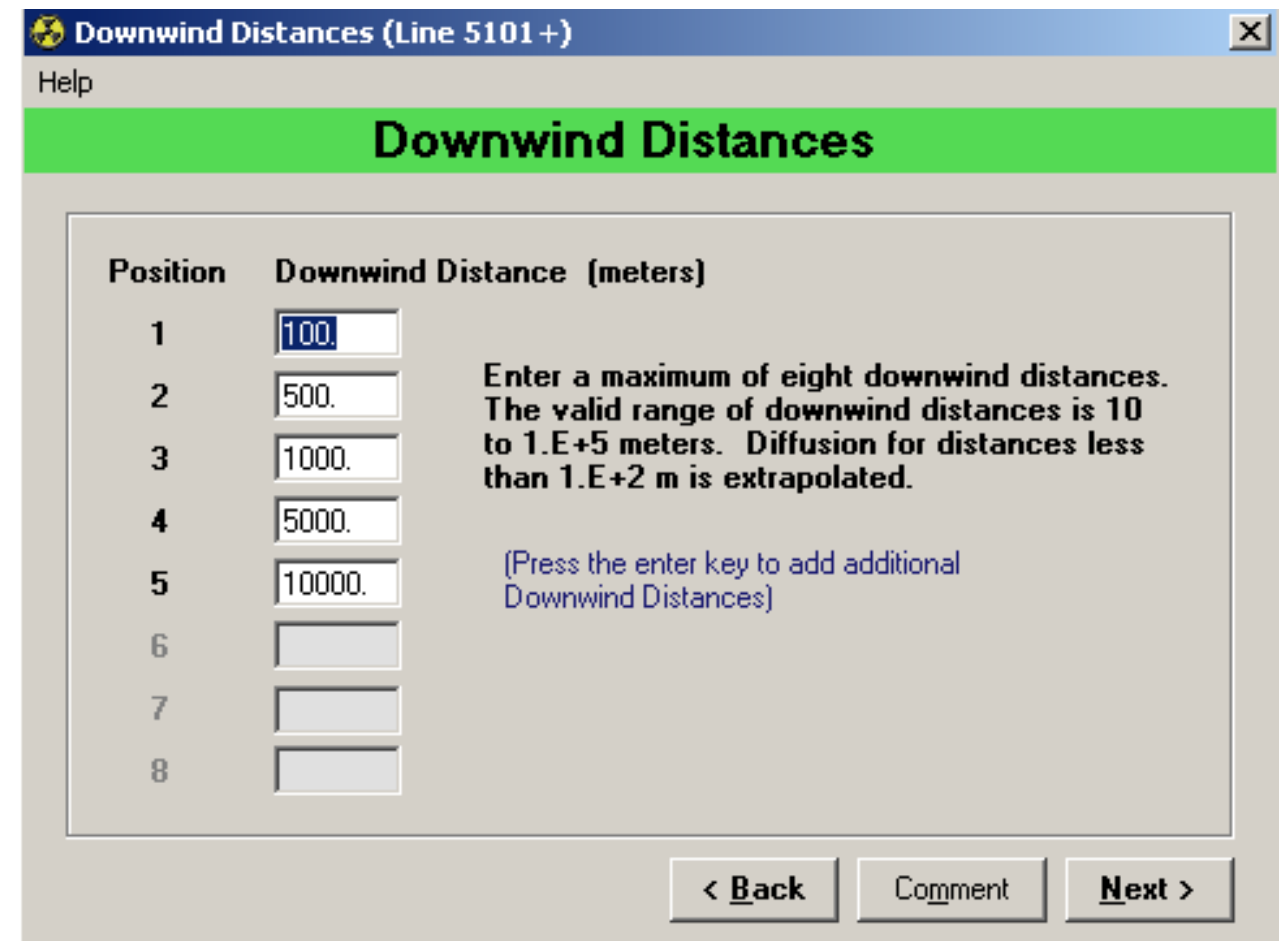

Figure 3-36. Screen 5, Downwind Distances. 
Screen 6 - Leakage Decay Constants: Enter linear or exponential constants (s) (Figure 3-37). Up to 10 sets of constants can be entered. The leakage decay constants must be entered in sets of two.

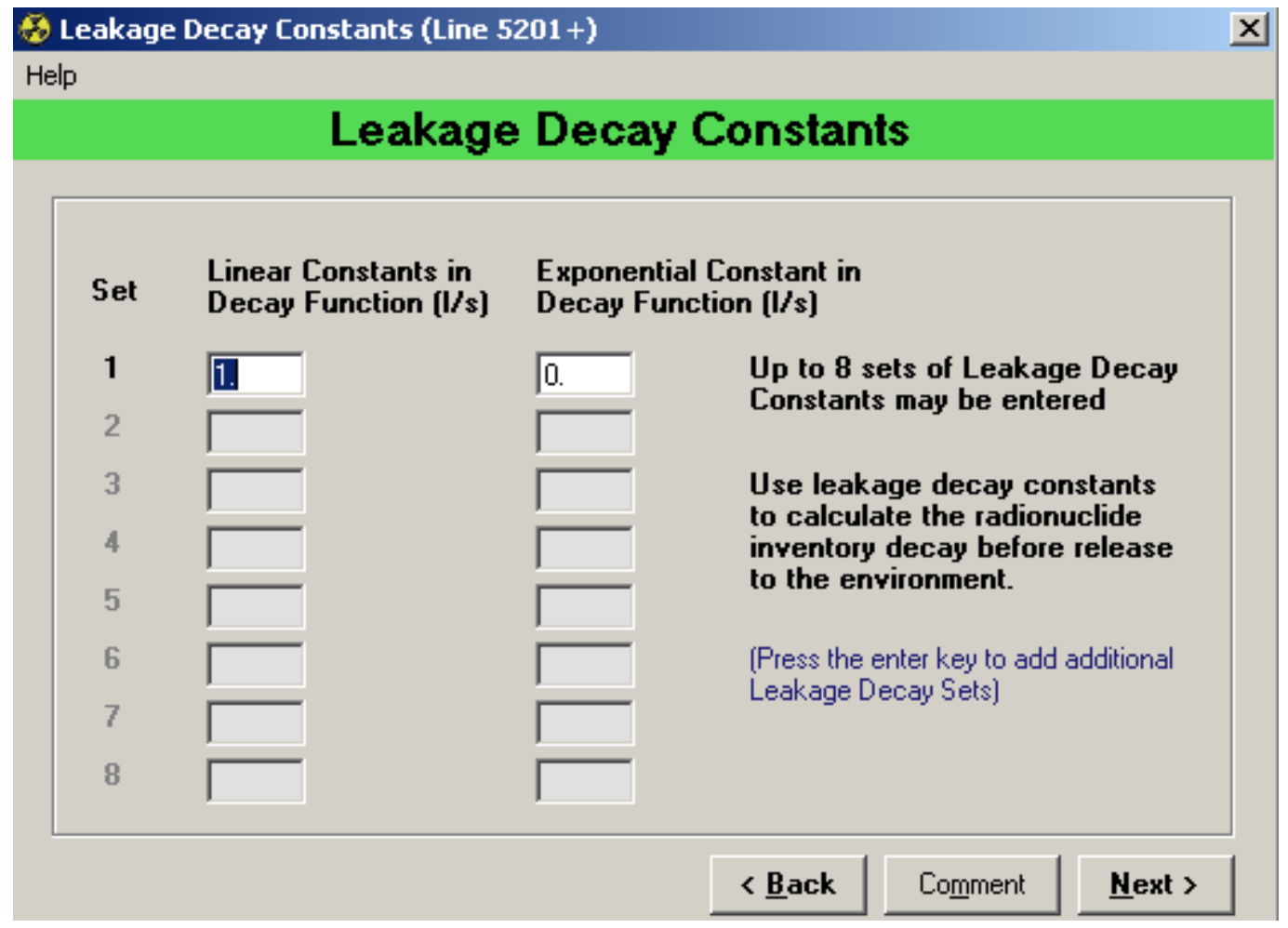

Figure 3-37. Screen 6, Leakage Decay Constants. 
Screen 7 - Crosswind Distance: Select Yes if you want to enter crosswind distances; otherwise, select No (Figure 3-38). If yes is selected, the input fields will become active allowing up to 15 crosswind distances to be entered.

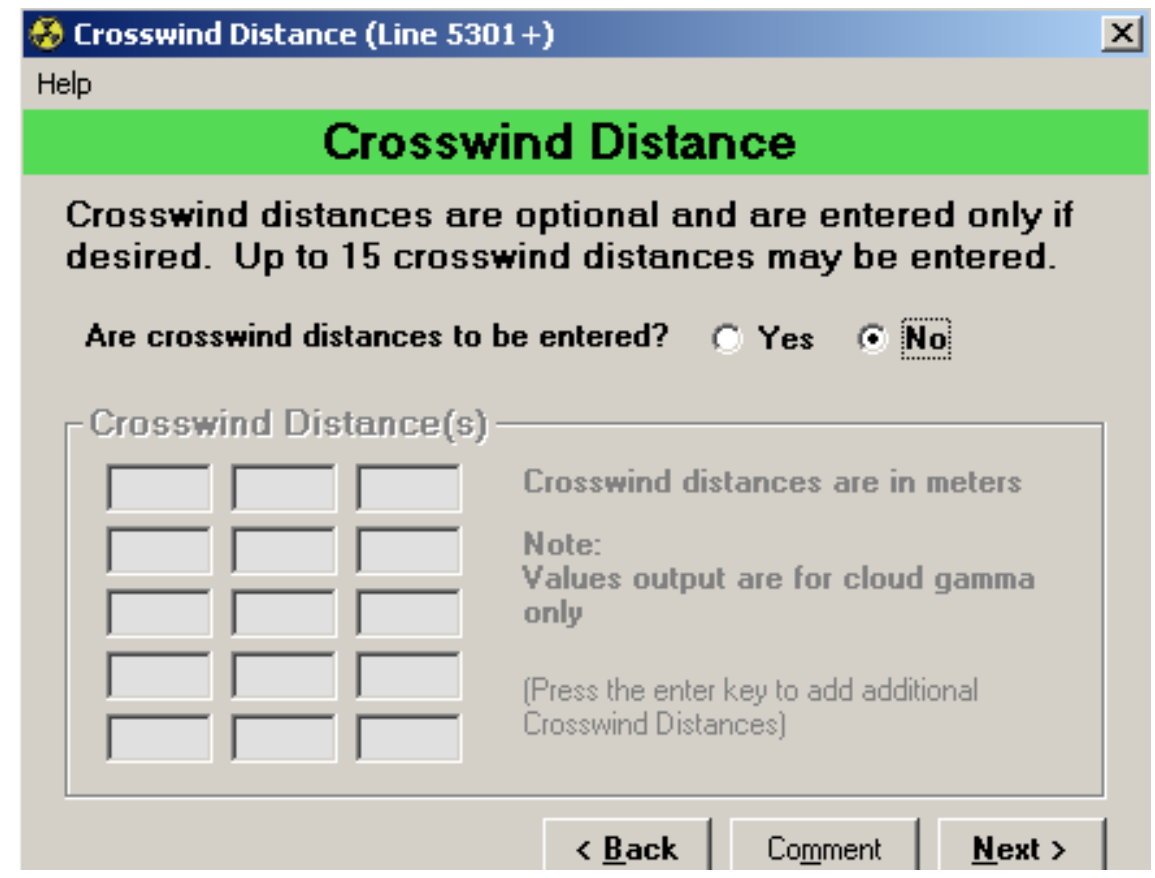

Figure 3-38. Screen 7, Crosswind Distance. 
Screen 7 - Diffusion Coefficient Control: The following options are available for diffusion coefficient control (Figure 3.52):

- If you select option 1, then the Coefficient of Standard Deviation screen will appear next. Enter the values for $\sigma_{\mathrm{y}}$ and $\sigma_{\mathrm{z}}$. Standard deviations must be entered in sets of two.

- If you select option 2, then the Plume Standard Deviation Control screen will appear next. Enter the type of sigma weather class and plume rise indicator on a sequence of input screens.

- If you select option 3, then the Direct $\chi / Q$ Input screen will appear next. Enter the $\chi / Q$ associated with the downwind distance.

Note: Building wake control is only available if stack height was equal to zero on screen 3 (Figure 3-39).

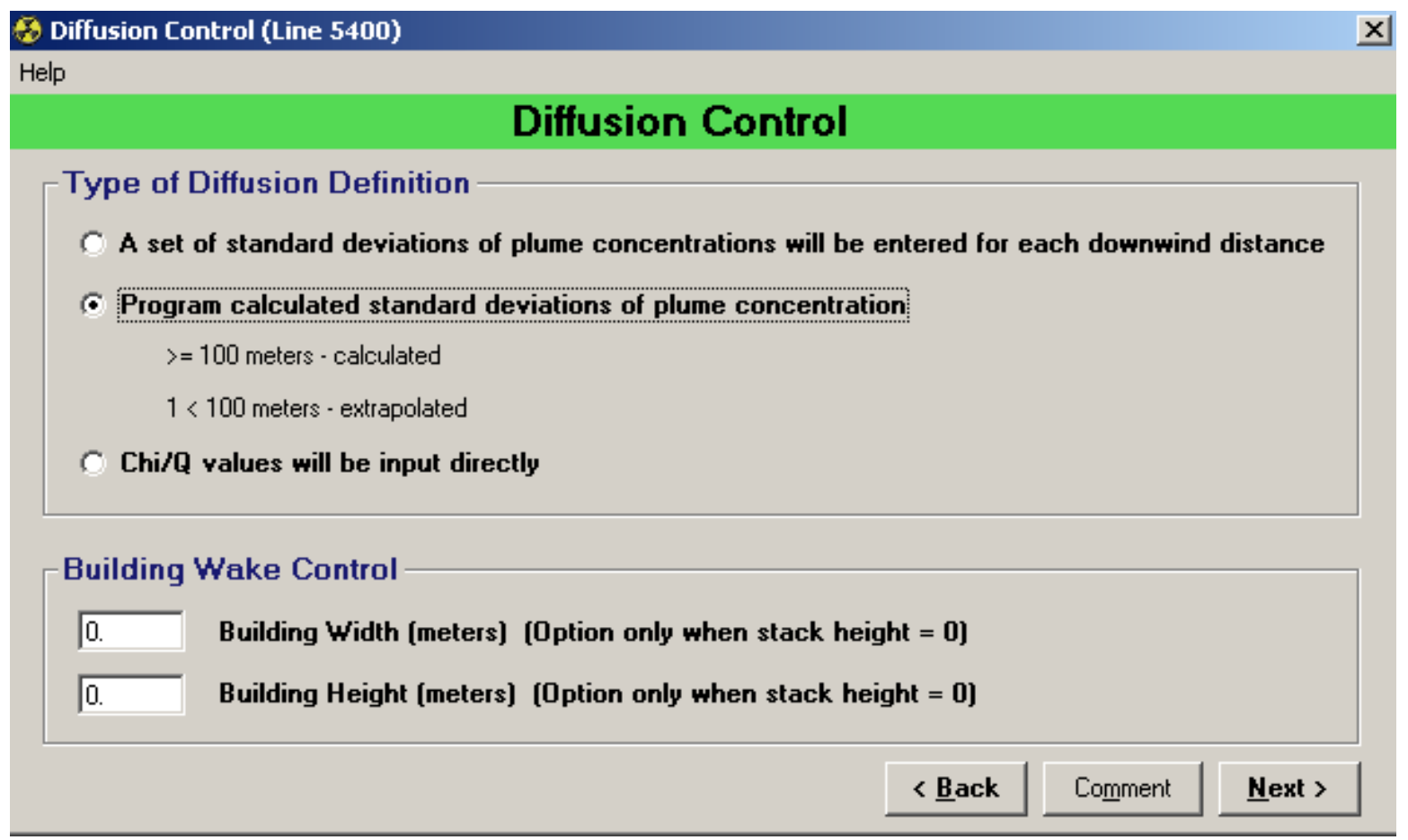

Figure 3-39. Screen 8, Diffusion Coefficient Control. 
Screen 10A (Optional) - Coefficient of Standard Deviation: Shown only if option 1 was chosen on screen 9 (Figure 3-40).

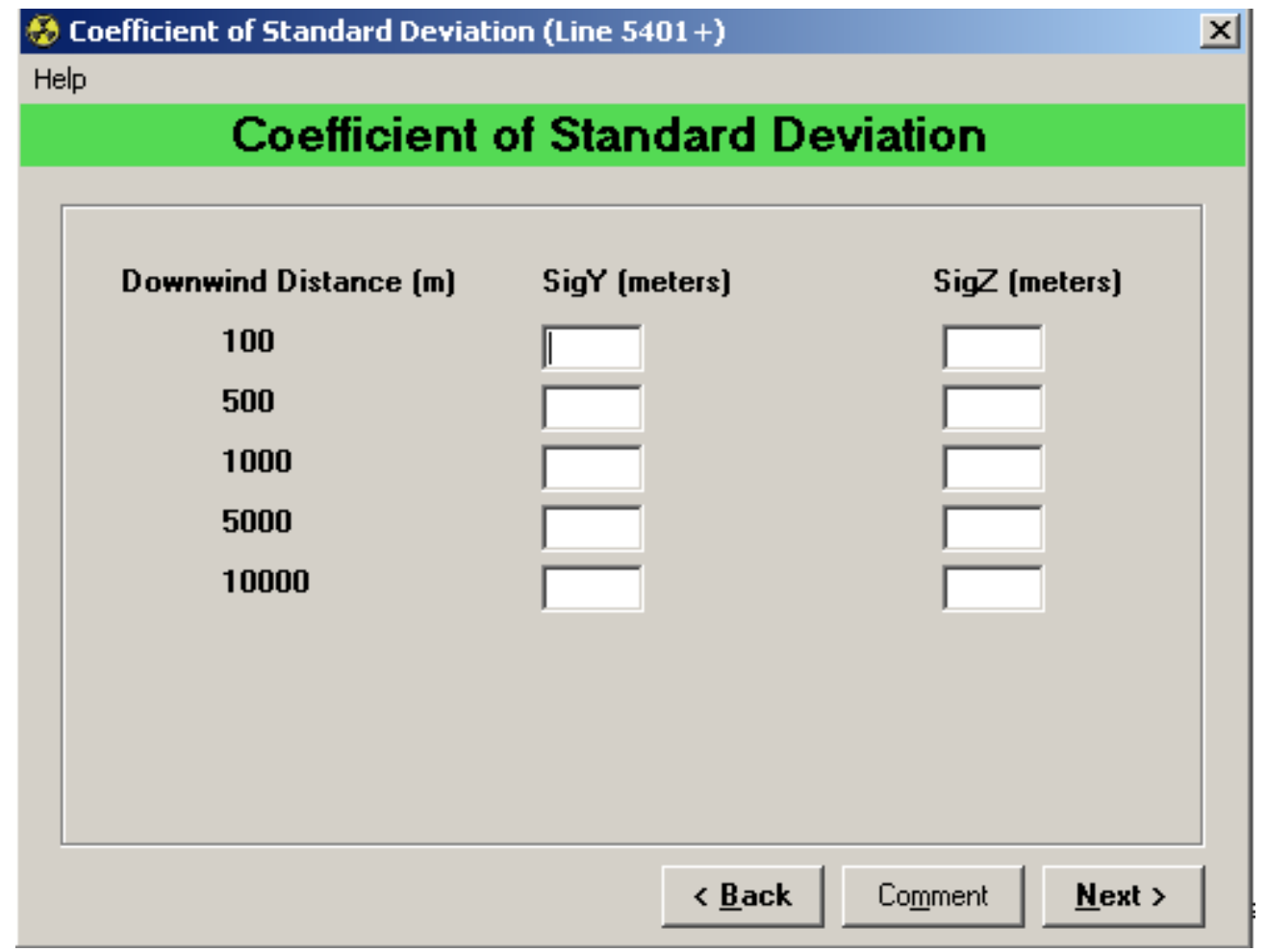

Figure 3-40. Screen 10A (Optional), Coefficient of Standard Deviation. 
Screen 10B (Optional) - Plume Standard Deviation Control: Shown only if option 2 was chosen on screen 9 (Figure 3-41).

NOTE: Weather class F Extremely Stable (Fumigation) is only available if stack height was equal to zero on screen 3. Plume meander is a factor that allows for additional spreading of the plume. Also known as a spreading ratio it is a factor greater than 1 that adjusts the calculated Chi/Q values to account for very low wind speed spreading.

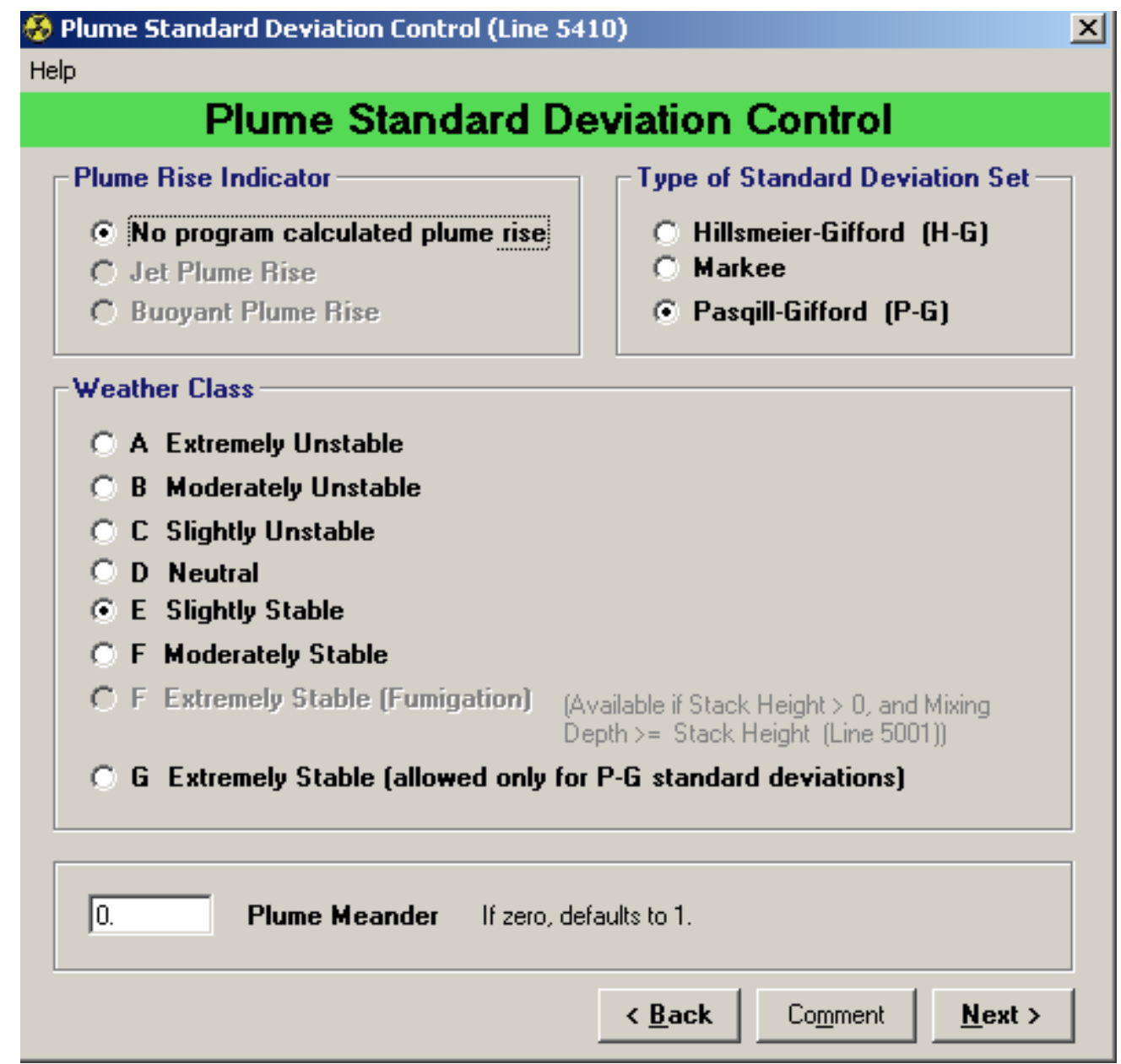

Figure 3-41. Screen 10B (Optional), Plume Standard Deviation Control. 
Screen 10C (Optional) - Direct Chi/Q Input: Shown only if option 3 was chosen on screen 9 (Figure 3-42).

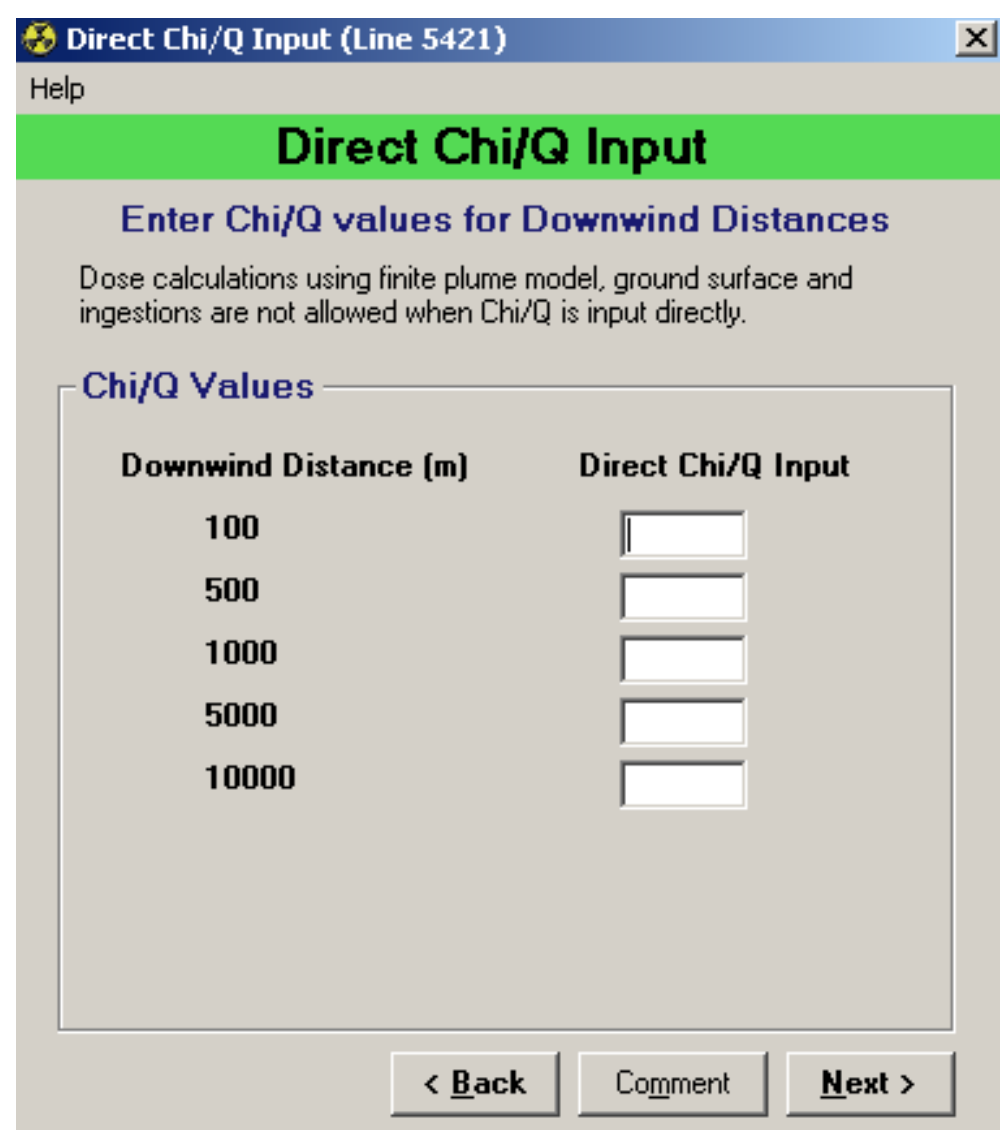

Figure 3-42. Screen 10C (Optional), Direct Chi/Q Input.

Screen 11A (Optional) - Jet Plume Rise Parameters: Shown only if Jet Plume Rise was chosen on Plume Standard Deviation Control screen 10B (Figure 3-43).

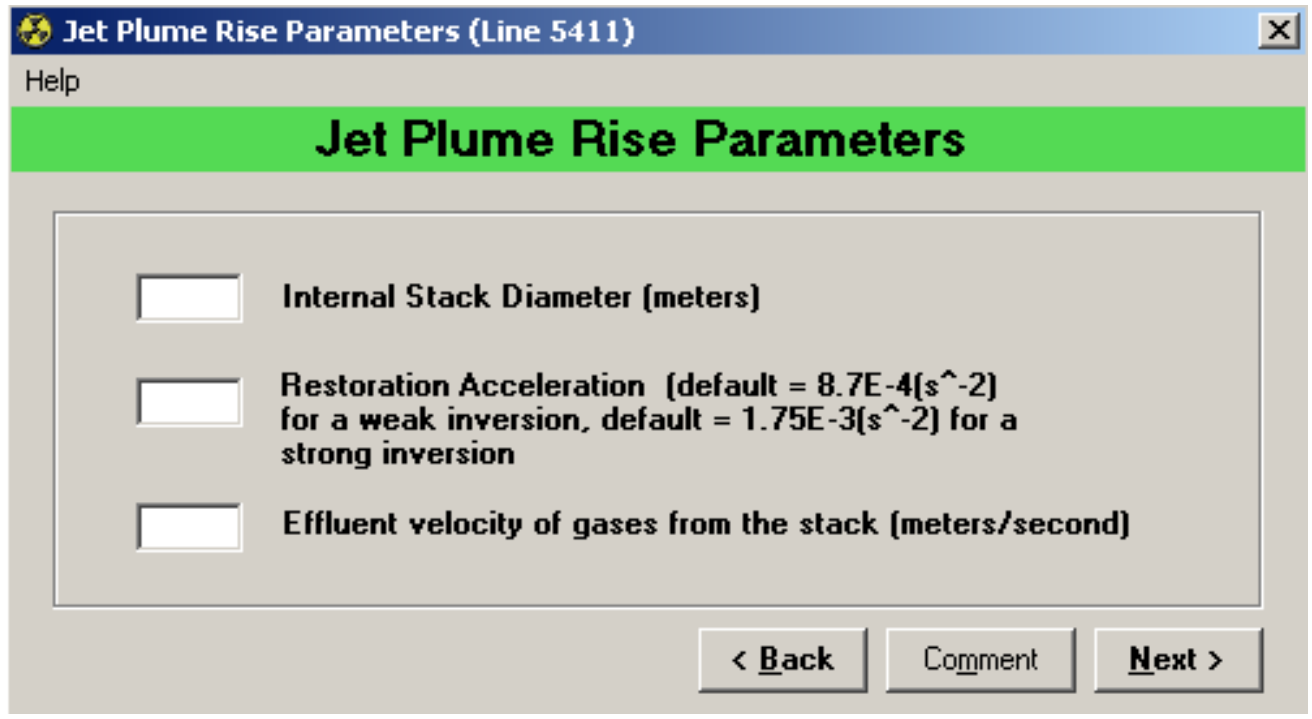

Figure 3-43. Screen 11A (Optional), Jet Plume Rise Parameters. 
Screen 11B (Optional) - Buoyant Plume Rise Parameters: Shown only if Buoyant Plume Rise was chosen on Plume Standard Deviation Control screen 10B (Figure 3-44).

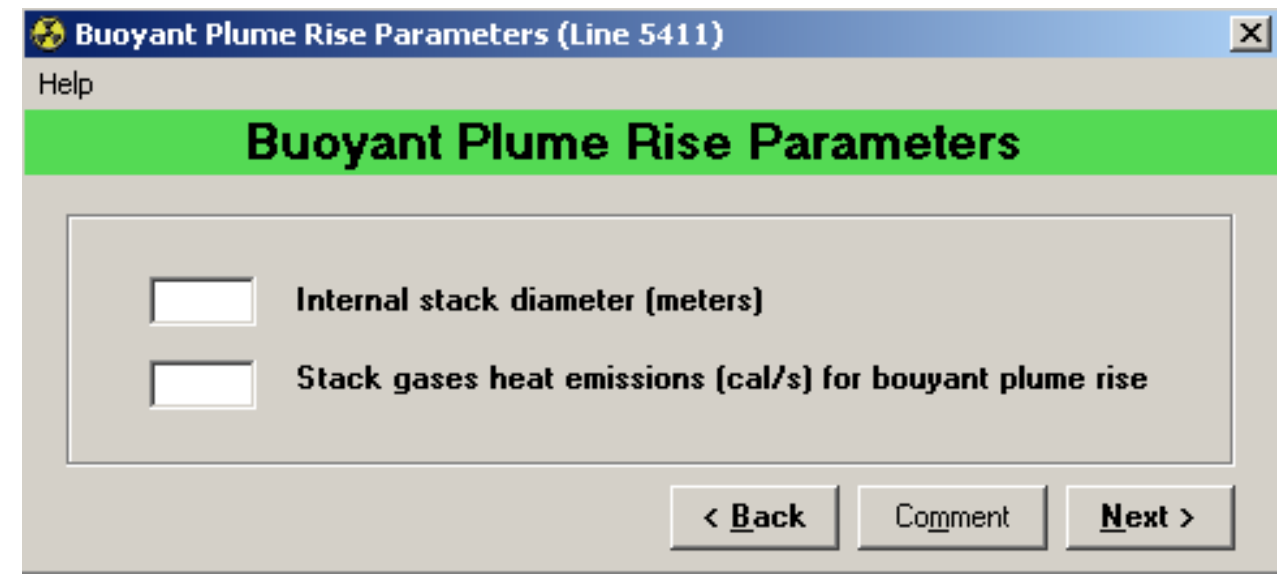

Figure 3-44. Screen 11B (Optional), Buoyant Plume Rise Parameters.

\subsection{5 $\quad 6000$ Series - Radionuclide Inventory Decay and Printout}

To append a new 6000 series in the current file click on the Reports tab (Figure 3-45).

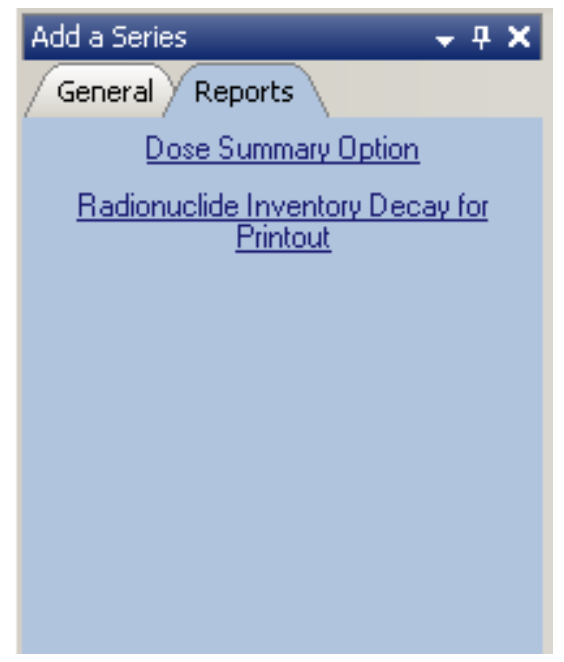

Figure 3-45. Reports Tab. 
Screen 2 - Radionuclide Decay Control: This screen is shown after the series title screen for the 6000 series (Figure 3-46). In this data entry screen sequence you will be asked to provide the following information:

- If all or selected radionuclide decay will be calculated

- If inventories are to be printed

- Which units of measure

- If the exponential leakage decay option is desired

\section{Radionuclide Decay Control (Line 6000) \\ Help \\ Radionuclide Decay Control \\ Radionuclides to be decayed \\ c. All radionuclides in the library will be decayed \\ $C$ Only radionuclides that are selected on an upcoming screen will be decayed}

-Inventory Printout Options

(- No individual radionuclide inventories are printed

Print all fission products; and any activation products, actinides and daughters of actinides with positive values

Same as above option except suppress short-lived fission products which have no available dose conversion factors

C Print inventory of radionuclides that have positive values at or following first decay time
-Units
c. Curies
C MeV/s [gamma only]
$C$ Grams
C Becquerel

\section{Exponential Leakage}

C No exponential leakage corrections are included

C Corrections for exponential leakage decay will be manually entered

Figure 3-46. Screen 2, Radionuclide Decay Control. 
Screen 3 (Optional) - Exponential Leakage Decay: Shown only if Corrections for exponential leakage decay will be manually entered was chosen on screen 2 (Figure 3-47). Enter the decay time(s) for the exponential decay function. After clicking next a prompt will appear asking if you want to change the Leakage Decay constants (Figure 3-48). If the constants have been previously entered and do not need to be changed, click on No to proceed; otherwise click Yes to change the Leakage Decay constants.

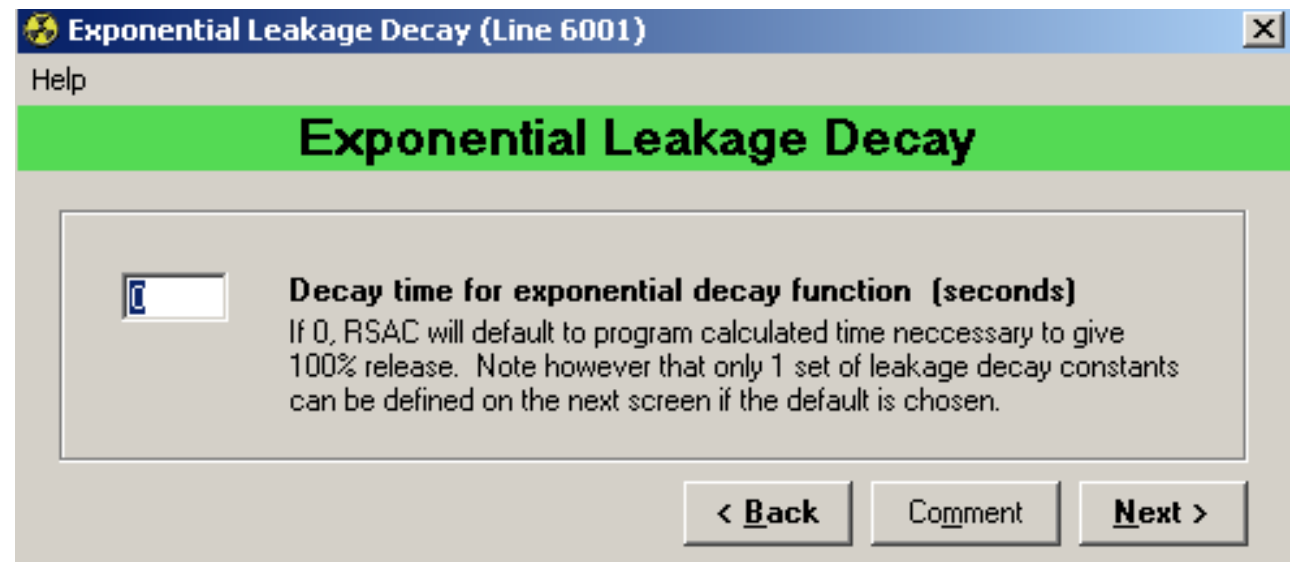

Figure 3-47. Screen 3 (Optional), Exponential Leakage Decay.

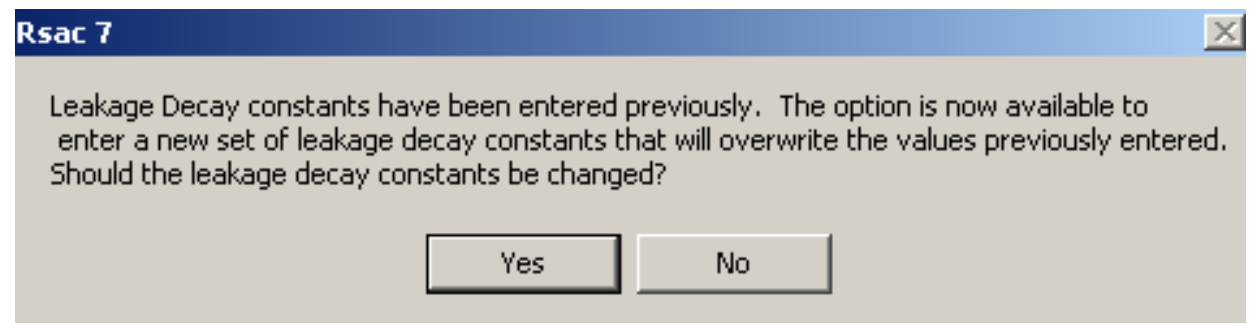

Figure 3-48. Leakage Decay Constants Prompt. 
Screen 4 (Optional) - Leakage Decay Constants: If Yes was chosen on the Leakage Decay Constants Prompt then the screen in Figure 3-49 will be shown to enter linear and exponential constants $\left(\mathrm{s}^{-1}\right)$. Up to 8 sets of constants can be entered. After entering a set of constants, press the $<$ enter $>$ key to allow entry of another set.

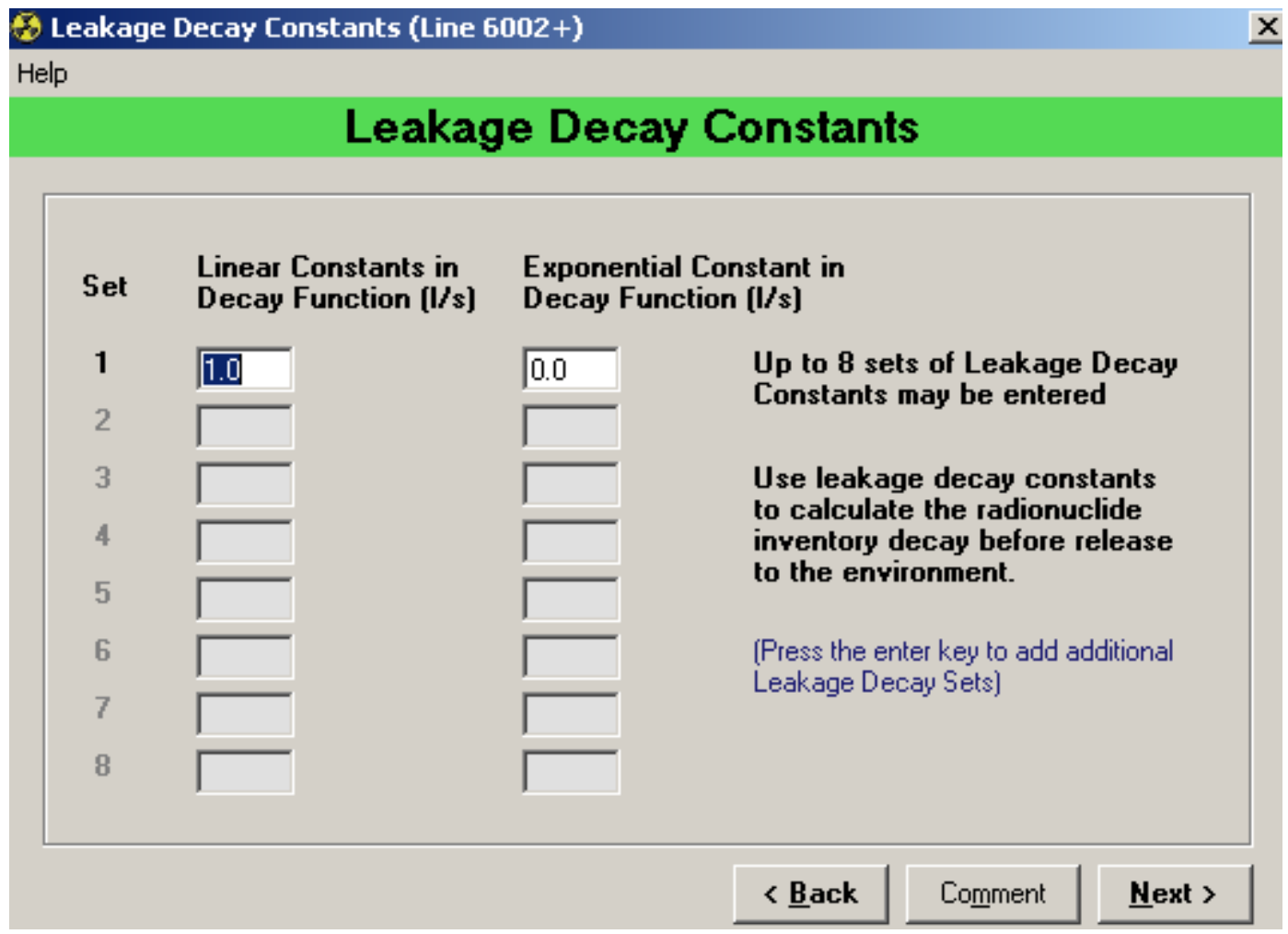

Figure 3-49. Screen 4 (Optional), Leakage Decay Constants. 
Screen 5 (Optional) - Radionuclide Selection: Shown only if Only radionuclides that are selected on an upcoming screen will be decayed was chosen on screen 2. On this screen (Figure 3-50), select the radionuclide using one of the following methods. Scroll through the list and click on the desired radionuclide; type the symbol to quickly select the desired radionuclide. To unselect a radionuclide click it in the list a second time. To clear all selected, click the Clear Selected button.

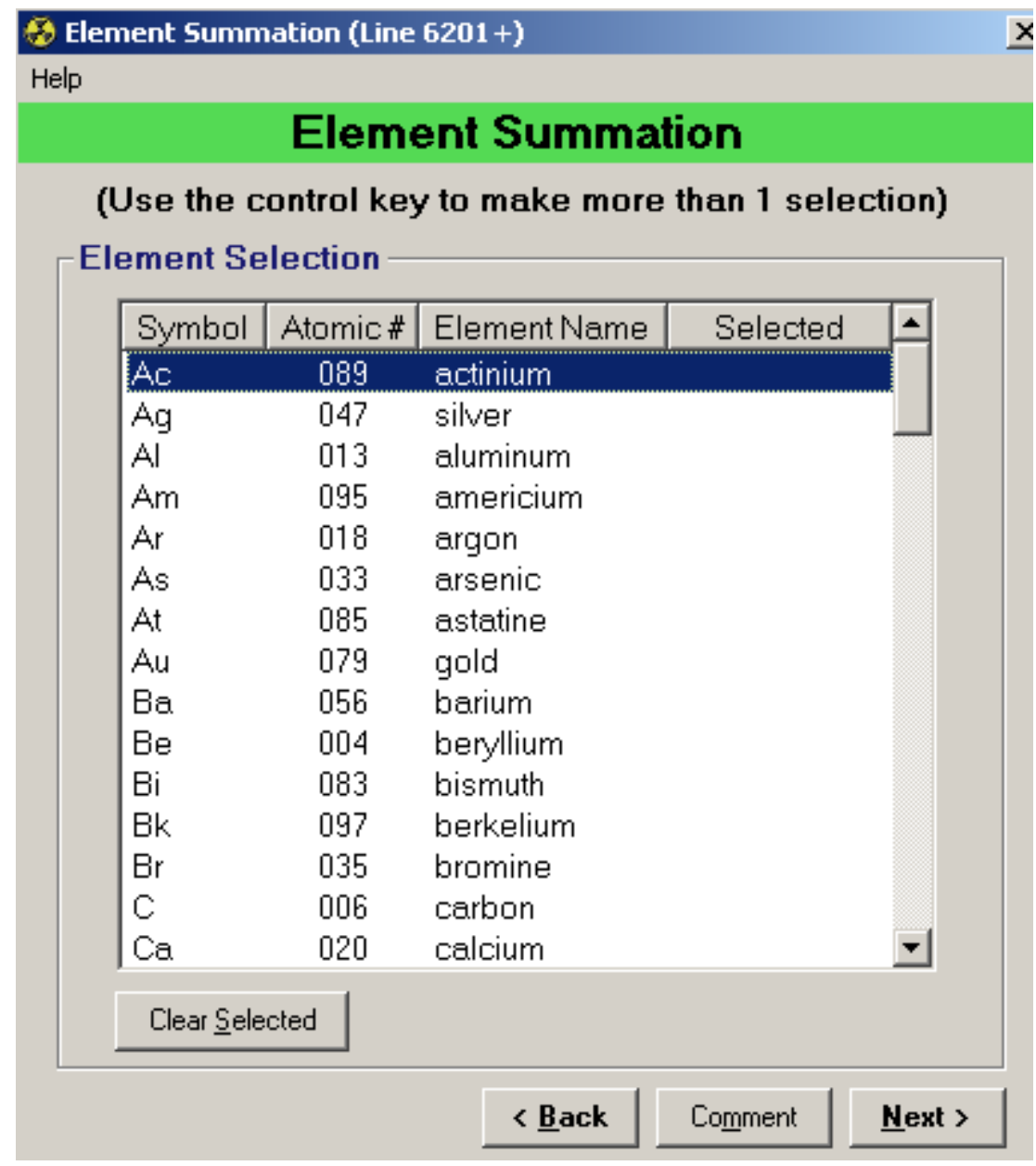

Figure 3-50. Screen 5 (Optional), Radionuclide Selection. 
Screen 6 - Decay Times: The screen asks if you want to enter decay times directly (Figure 3-51). If Yes is selected, the decay times input section will be enabled allowing input of decay times. A maximum of eight decay times can be entered. However, when you want to see all of the output data on an unshifted screen or printed on a standard 80-column page, enter a maximum of three decay times.

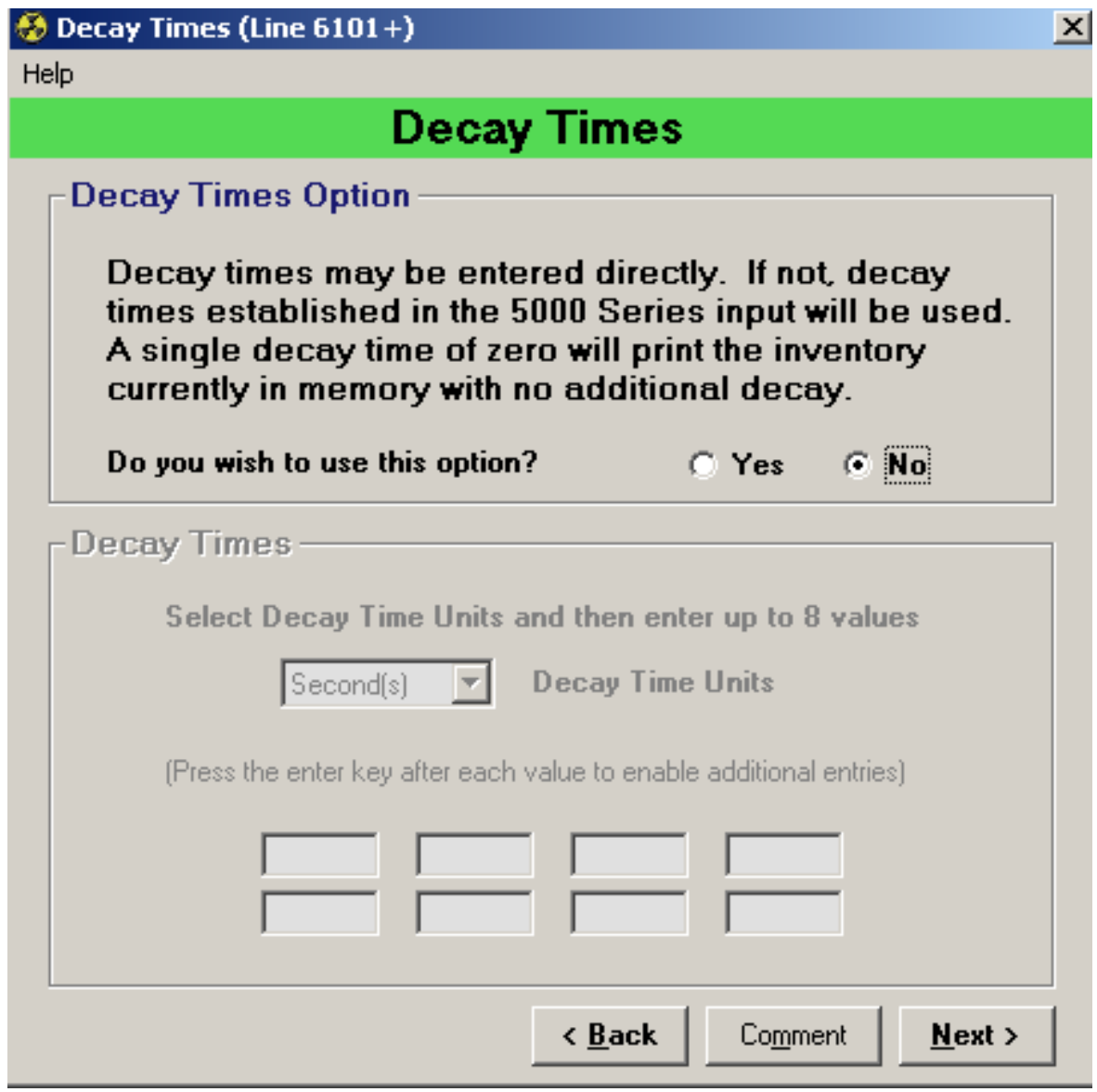

Figure 3-51. Screen 6, Decay Times. 
Screen 7 (Optional) - Summation Control: Shown only if All radionuclides in the library will be decayed was chosen on screen 2. This screen (Figure 3-52) will determine if you would like a summation of the radionuclide inventory by group (solids, halogens, noble gases, cesium, and ruthenium) and if the radionuclide inventory should be summed by element.

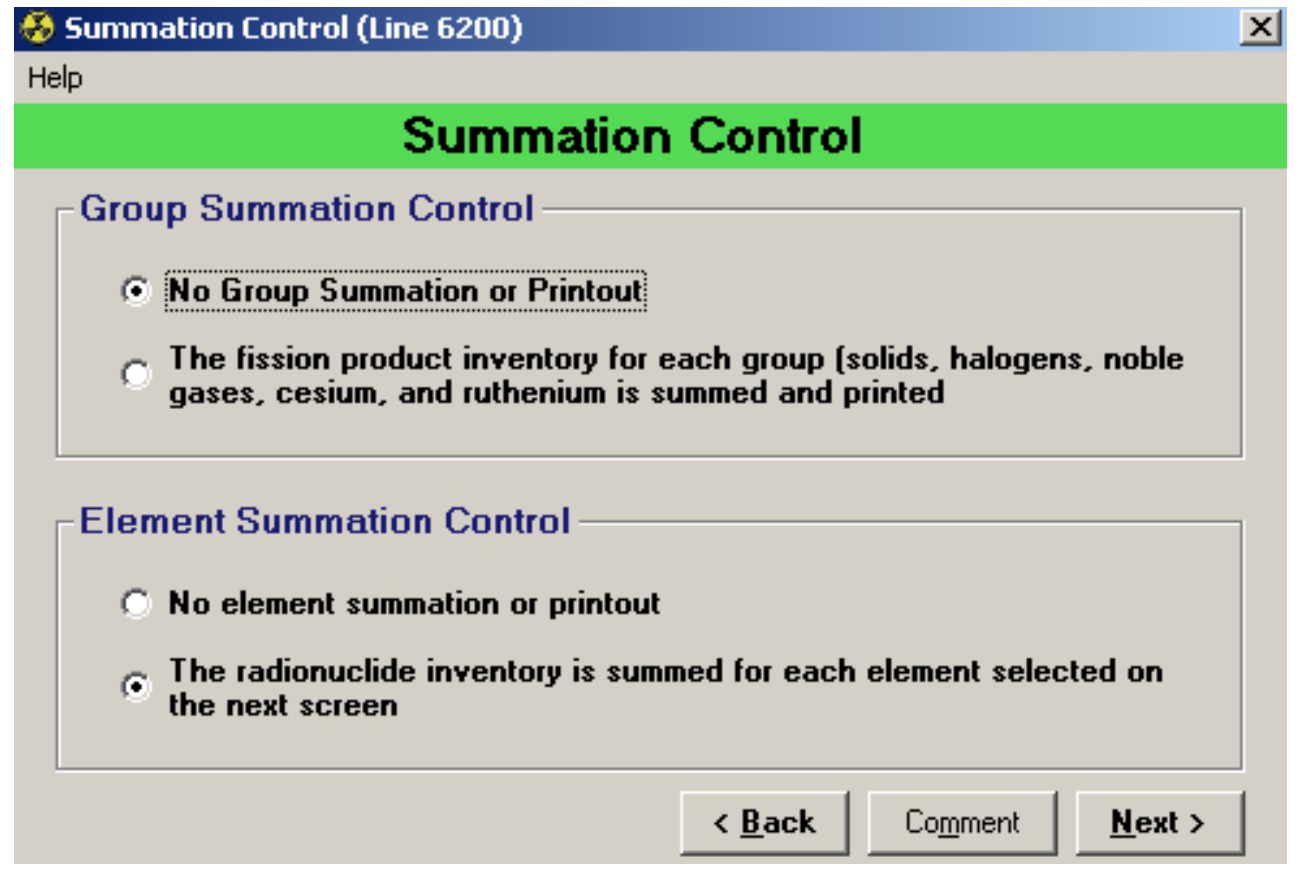

Figure 3-52. Screen 7 (Optional), Summation Control. 
Screen 8 (Optional) - Element Summation: Shown only if The radionuclide inventory is summed of each element selected on the next screen is chosen on screen 7. On this screen (Figure 3-53), select the element using one of the following methods. Scroll through the list and click on the desired element; type the symbol to quickly select the desired element. To unselect an element click it in the list a second time. To clear all selected, click the Clear Selected button.

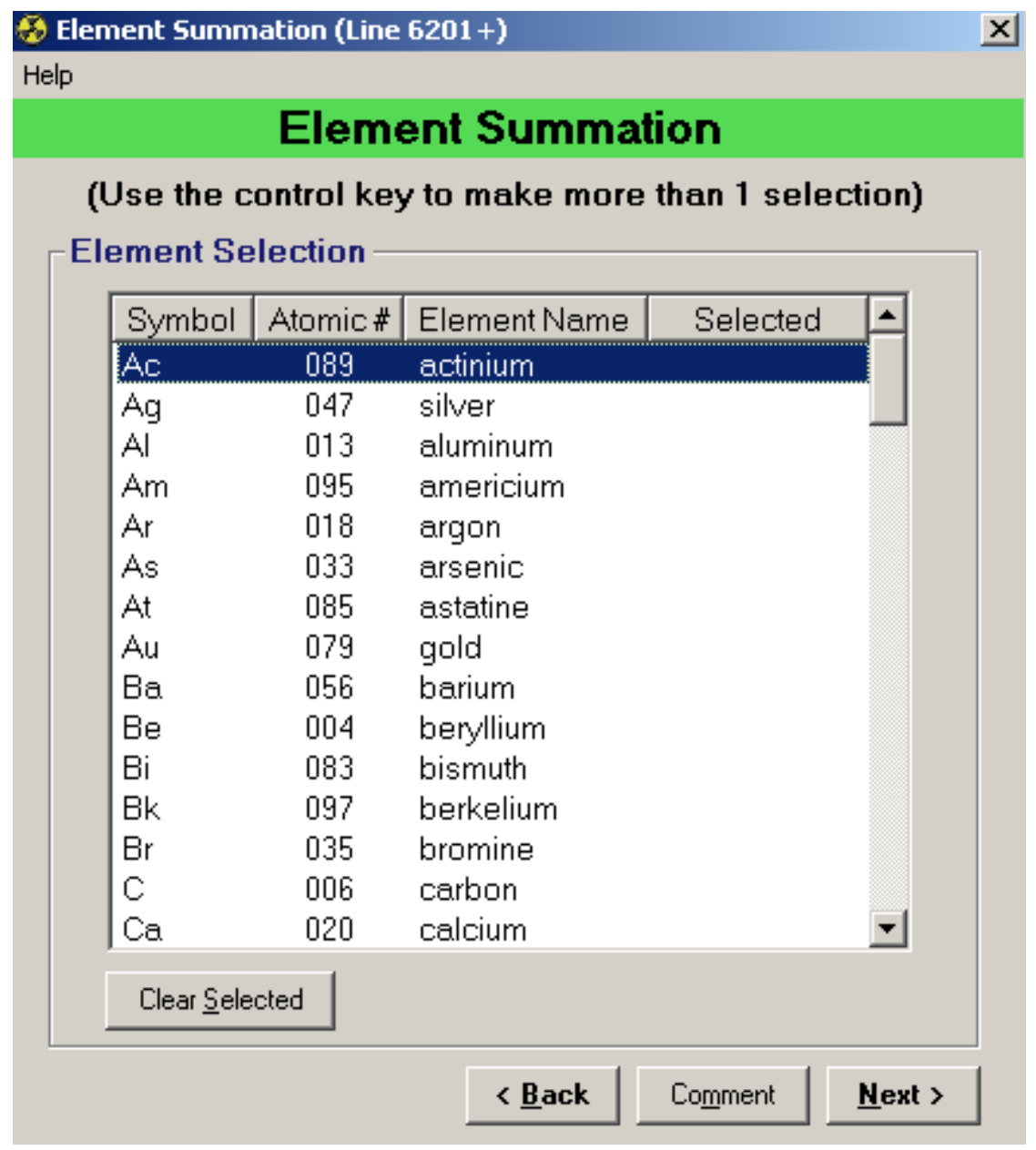

Figure 3-53. Screen 8 (Optional), Element Summation. 


\subsubsection{Series - Internal/External Dose Calculation}

Screen 2 - Dose Control Selection: After the series title screen the Dose Control Calculation screen is displayed (Figure 3-54). In this data entry screen you will be asked to provide select the type of dose calculation or risk evaluation in accordance with Federal Guidance Report 13.

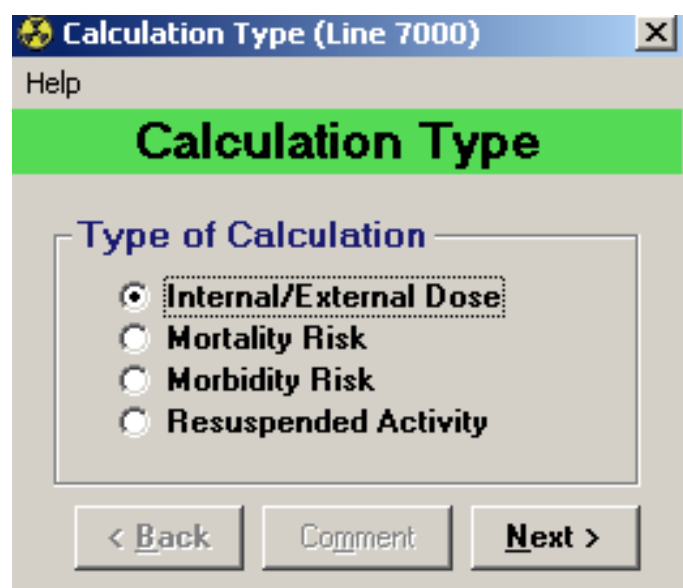

Figure 3-54. Dose Selection Screen. 
Based on the type of calculation chosen, a different screen sequence will be presented.

- Type of dose calculation - Internal/External

- Amount of printed output

- Dose unit

- If all elements are to be used in the calculation

- If all organs are to be included in the dose calculation

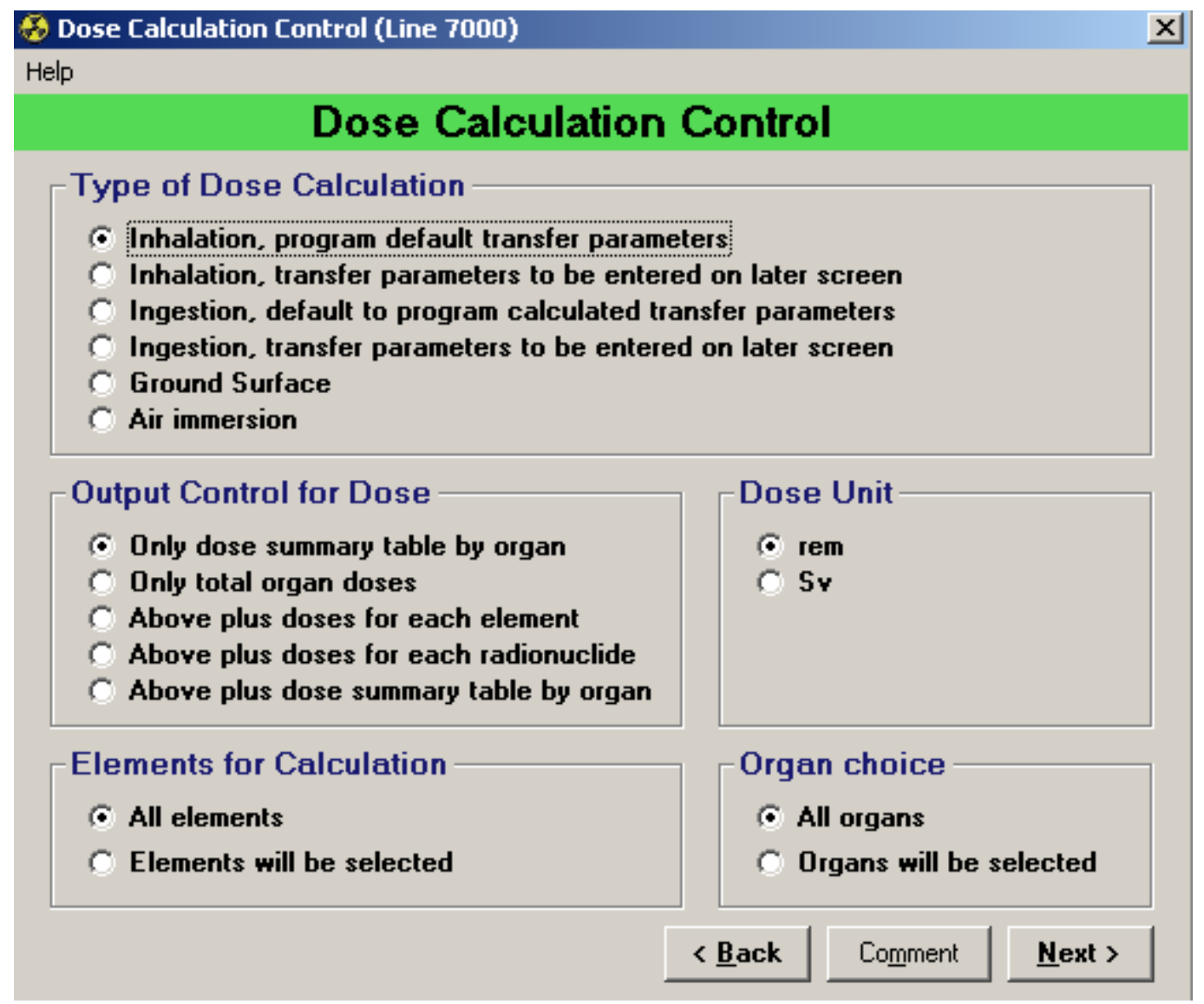

Figure 3-55. Screen 2, Dose Control Calculation. 
Screen 3A (Optional) - Inhalation Dose Control: Shown only when option 1, 2, 7, or 8 is chosen for the Type of Dose Calculation on screen 2. Enter the breathing rate $\left(\mathrm{m}^{3} / \mathrm{s}\right)$ and decay time $(\mathrm{s})$ for exponential decay function (Figure 3-56).
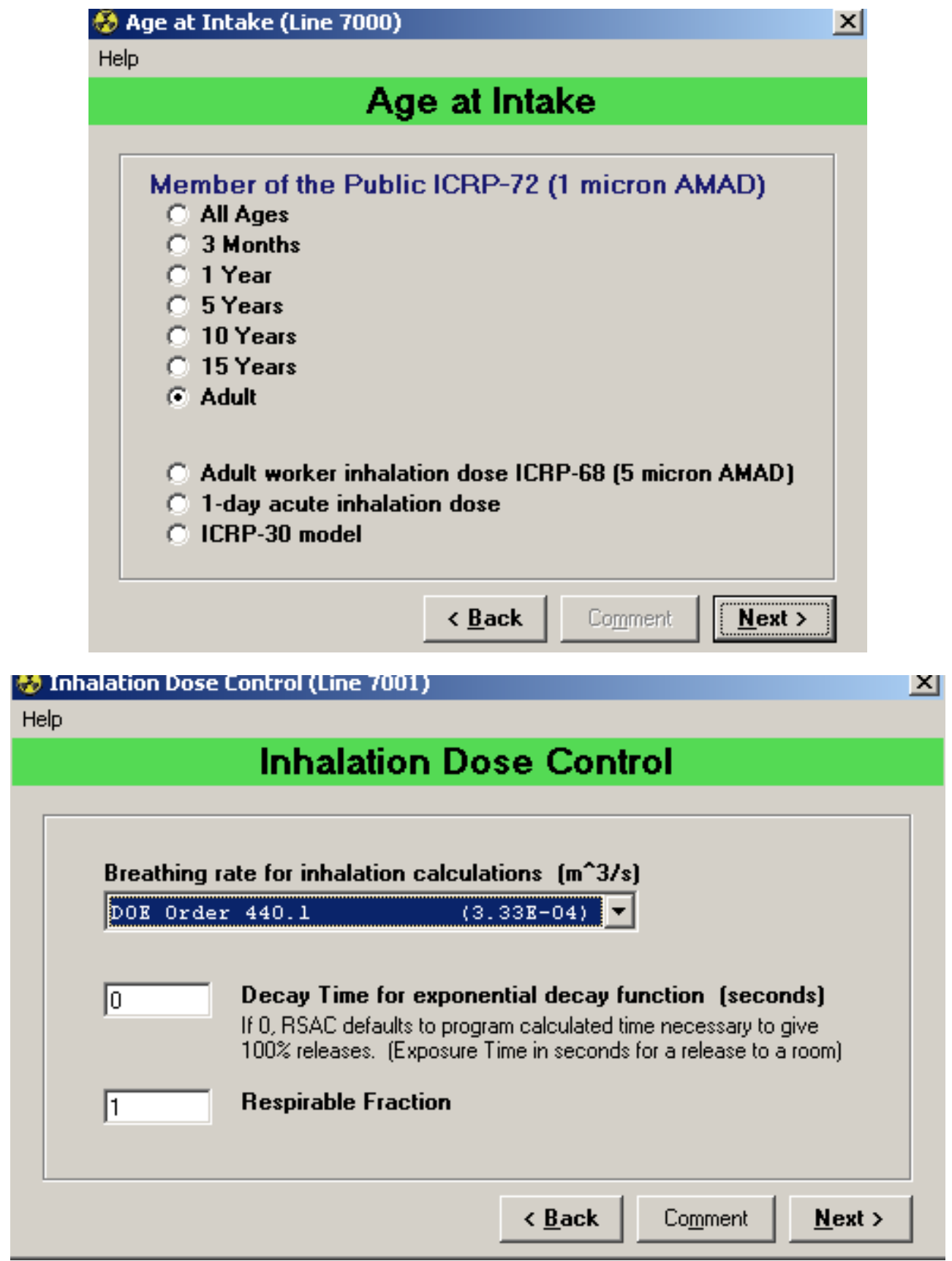

Figure 3-56. Screen 3A (Optional), Inhalation Dose Control. 
Screen 4A (Optional) - Inhalation Parameters Dose Calculation: Shown only if option 2 or 8 is chosen for the Type of Dose Calculation on screen 2. Enter activity median aerodynamic diameter (AMAD) $(\mu)$ and whether default lung clearance classes are to be used (Figure 3-57). If user input of lung clearance classes is chosen, the Clearance Class Entry screen will appear next.

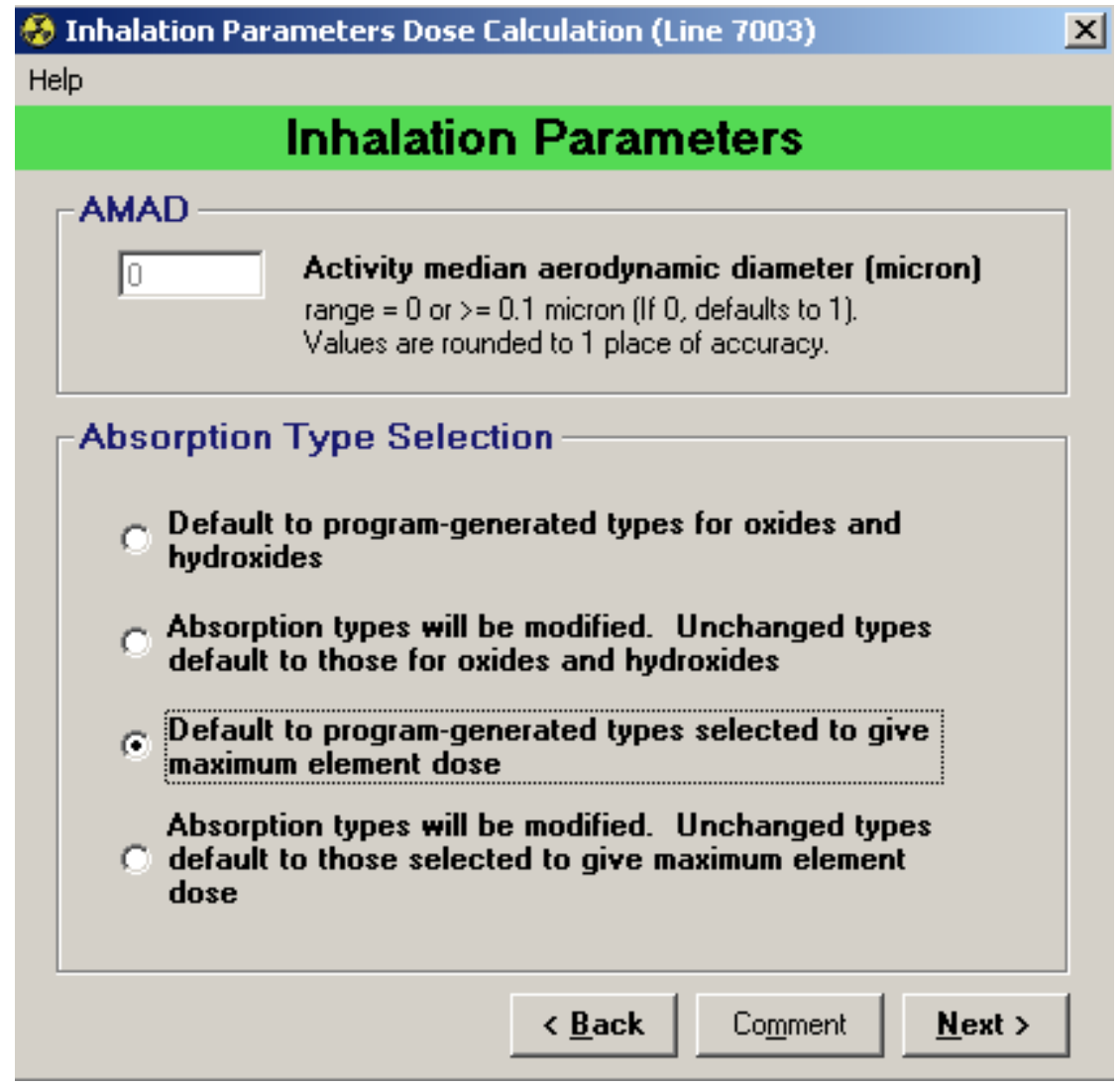

Figure 3-57. Screen 4A (Optional), Inhalation Parameters Dose Calculation. 
Screen 5A (Optional) - Absorption Type Entry: Shown only if option 2 or 4 is chosen for Absorption Type Entry on screen 4A (Figure 3-58). Scroll through the list and click on the desired element. A pop-up screen will appear showing the valid lung clearance classes for the chosen element. Select the desired lung clearance class and click on Continue.

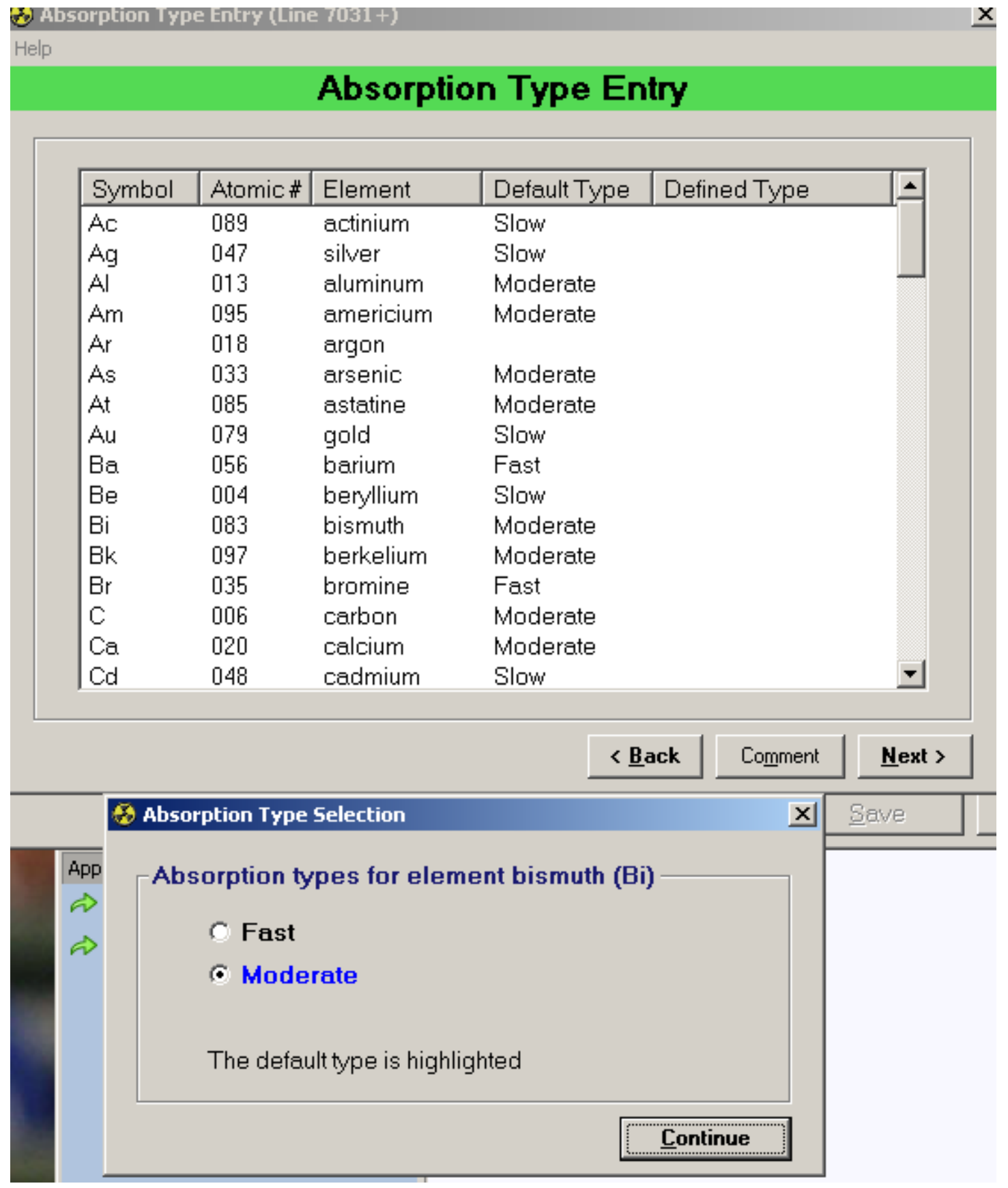

Figure 3-58. Screen 5A (Optional), Clearance Class Entry. 
Mortality Risk Calculation- Shown when mortality risk is selected on the opening screen.

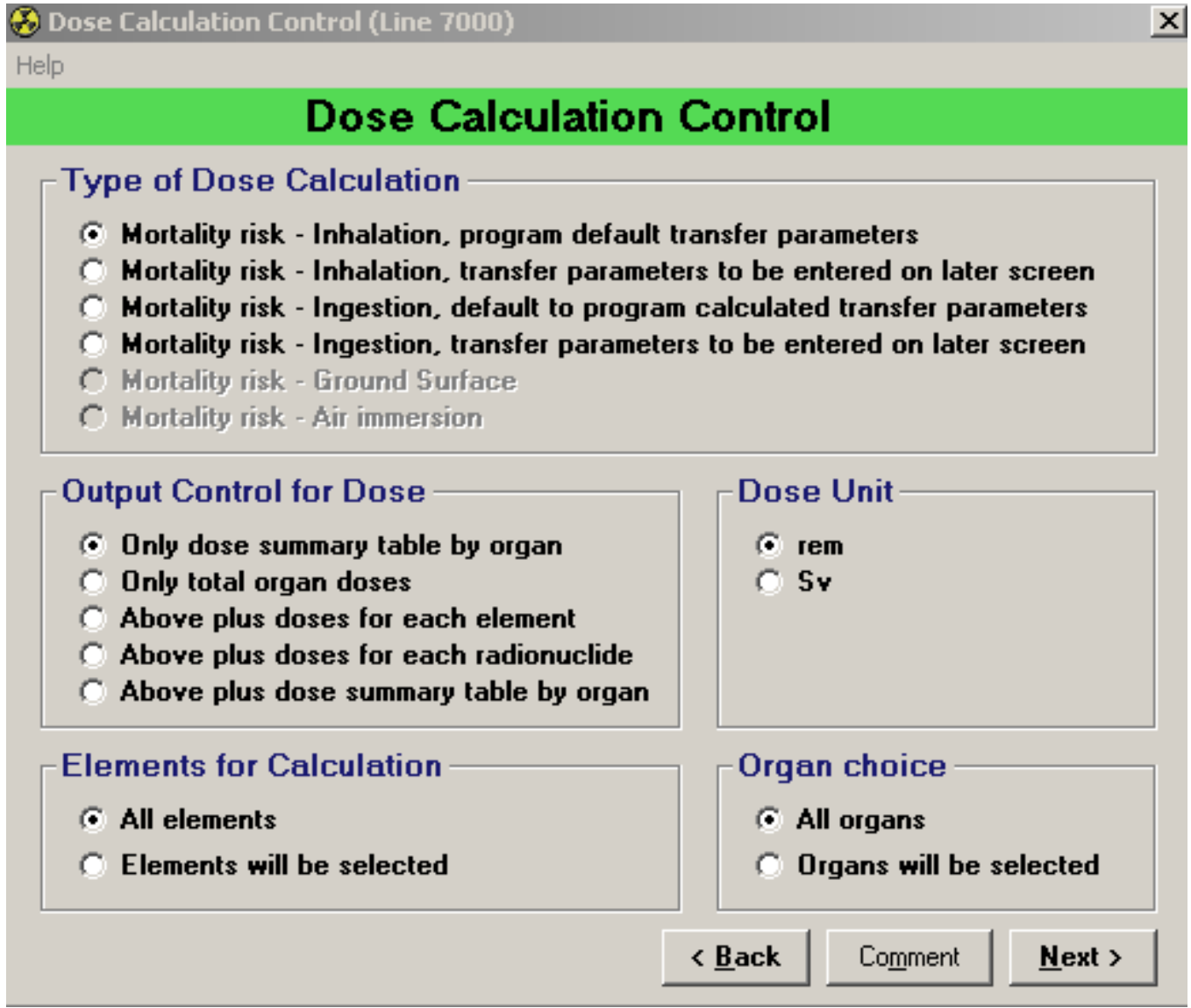

All optional screens for inhalation/ingestion transfer parameters and output control are generated and controlled the same as for dose calculation. The primary difference is that summary output controls are specific to the risk calculation function and should be calculated separate from a dose calculation. 
Morbidity Risk Calculation- Shown when mortality risk is selected on the opening screen.

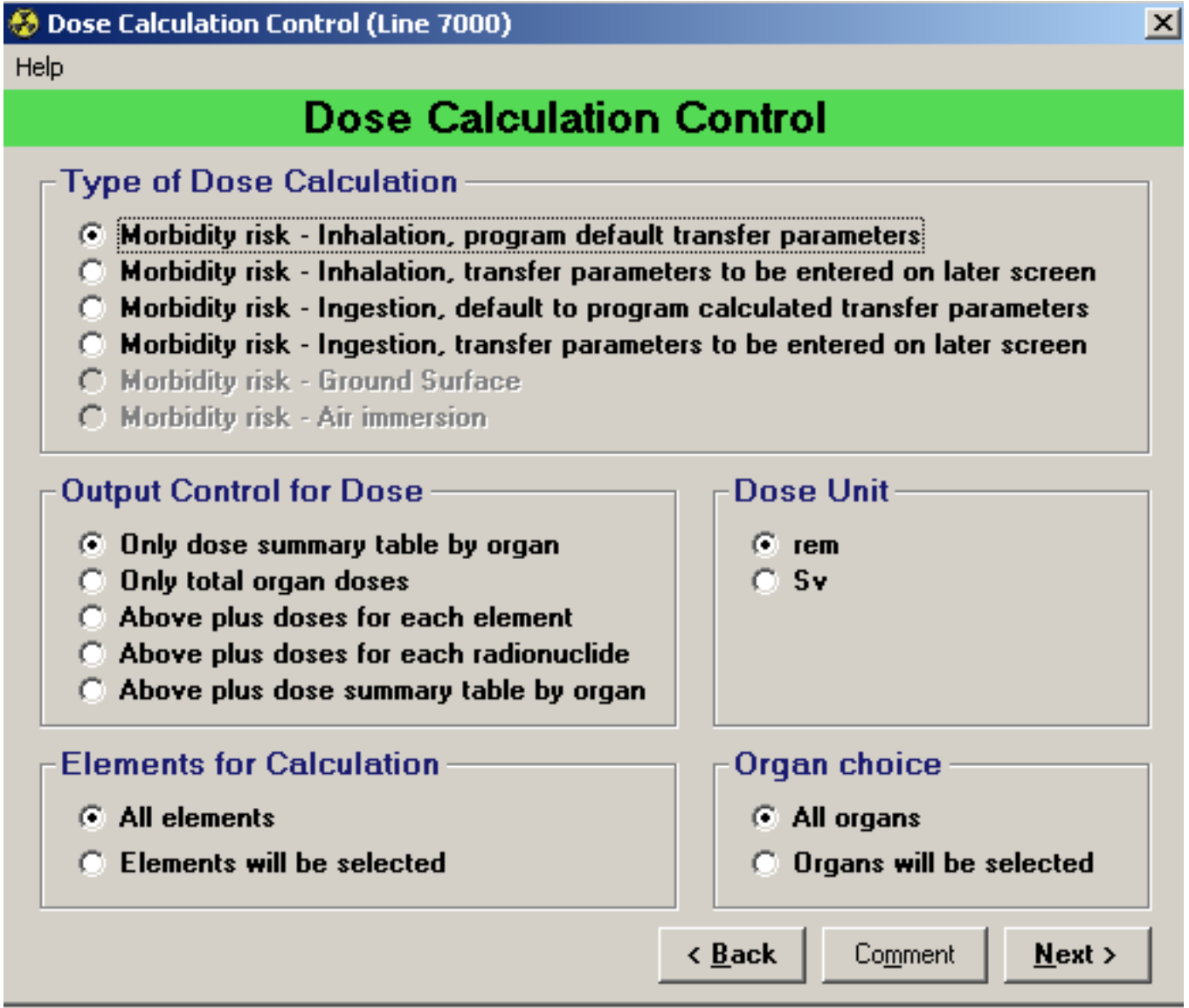


Screen 6 (Optional) - Resuspension of Activity: Only shown if option 7 or 8 is chosen for Type of Dose Calculation on screen 2 (Figure 3-59).

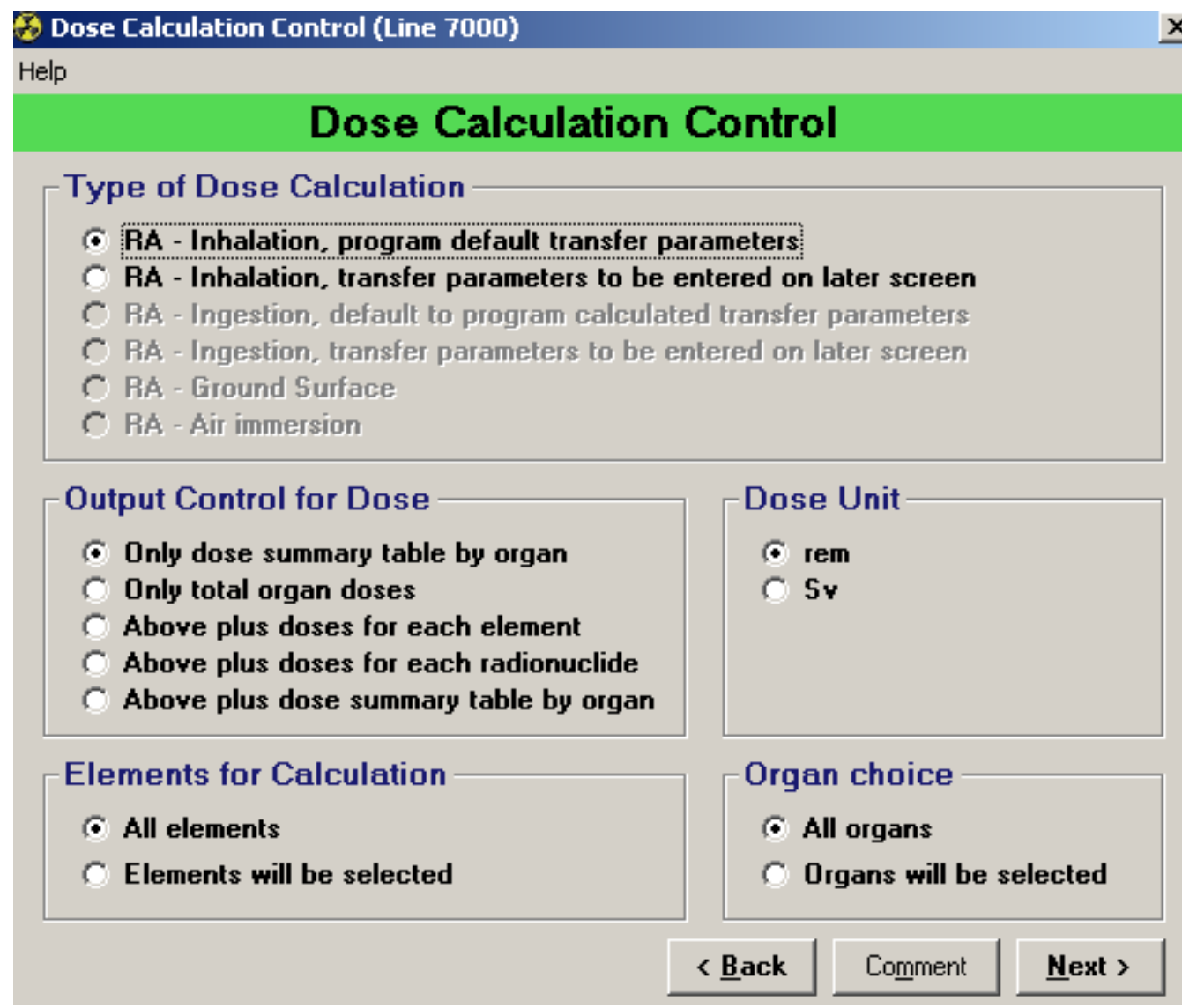

Figure 3-59. Screen 6 (Optional), Resuspension of Activity. 
Screen 3B (Optional) - Ingestion Dose Parameters: Shown only if option 3 or 4 is chosen for Type of Dose Calculation on screen 2 (Figure 3-60). Enter decay time (s) for exponential decay function and the plant midpoint of operating life (y).

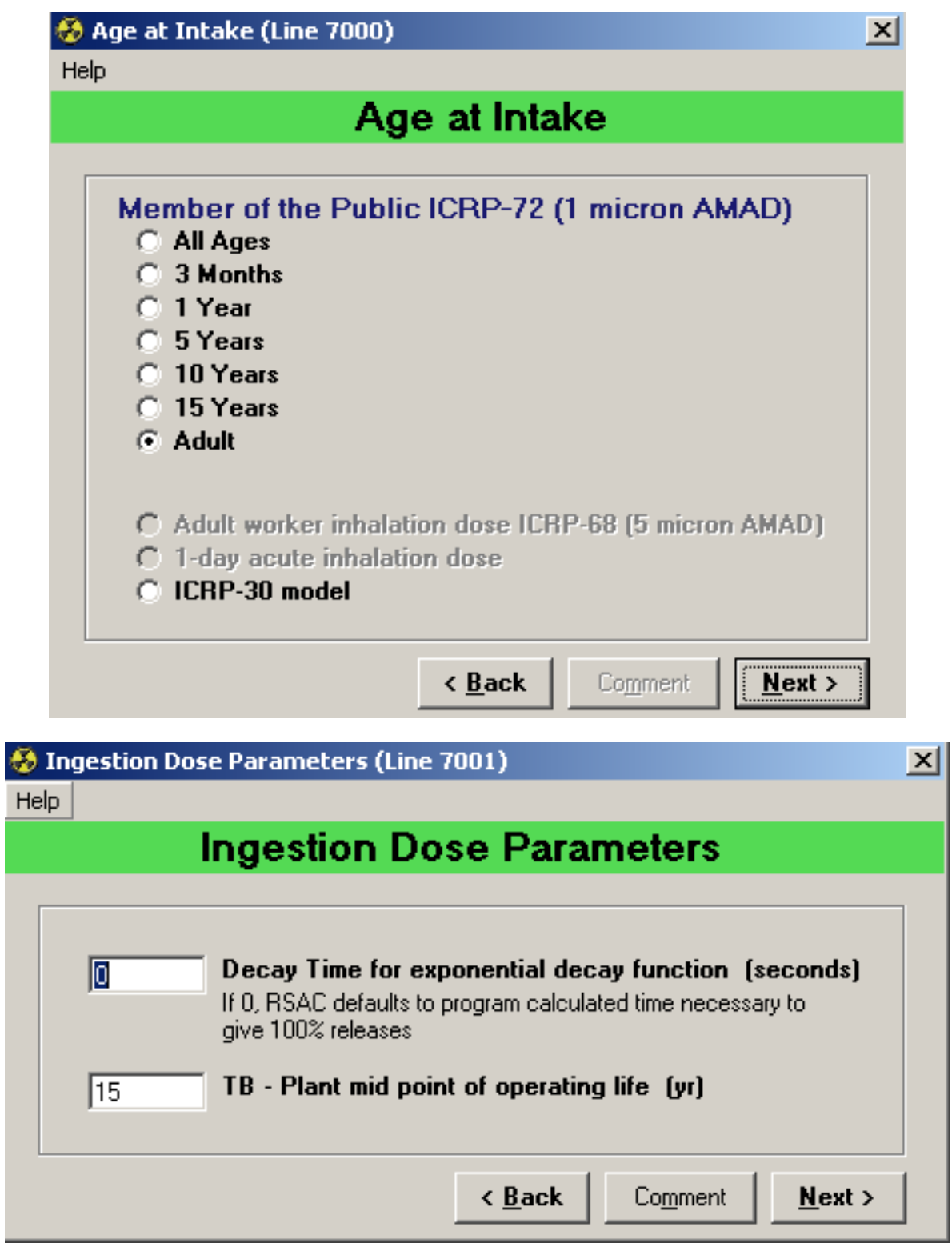

Figure 3-60. Screen 3B (Optional) - Ingestion Dose Parameters. 
Screen 4B (Optional) - Ingestion Dose Control: Shown only if option 4 is chosen for Type of Dose Calculation on screen 2 (Figure 3-61). Use this sequence of screens to choose whether to use default ingestion transfer parameters; whether the release is chronic, acute, or if ingestion parameters are to be user entered; the time period crops are exposed to contamination during the growing season when the release is not chronic; and the harvest duration period following the end of an acute release period. When you select to enter ingestion parameters, a series of screens will appear that contain the RSAC-7 default ingestion parameters.

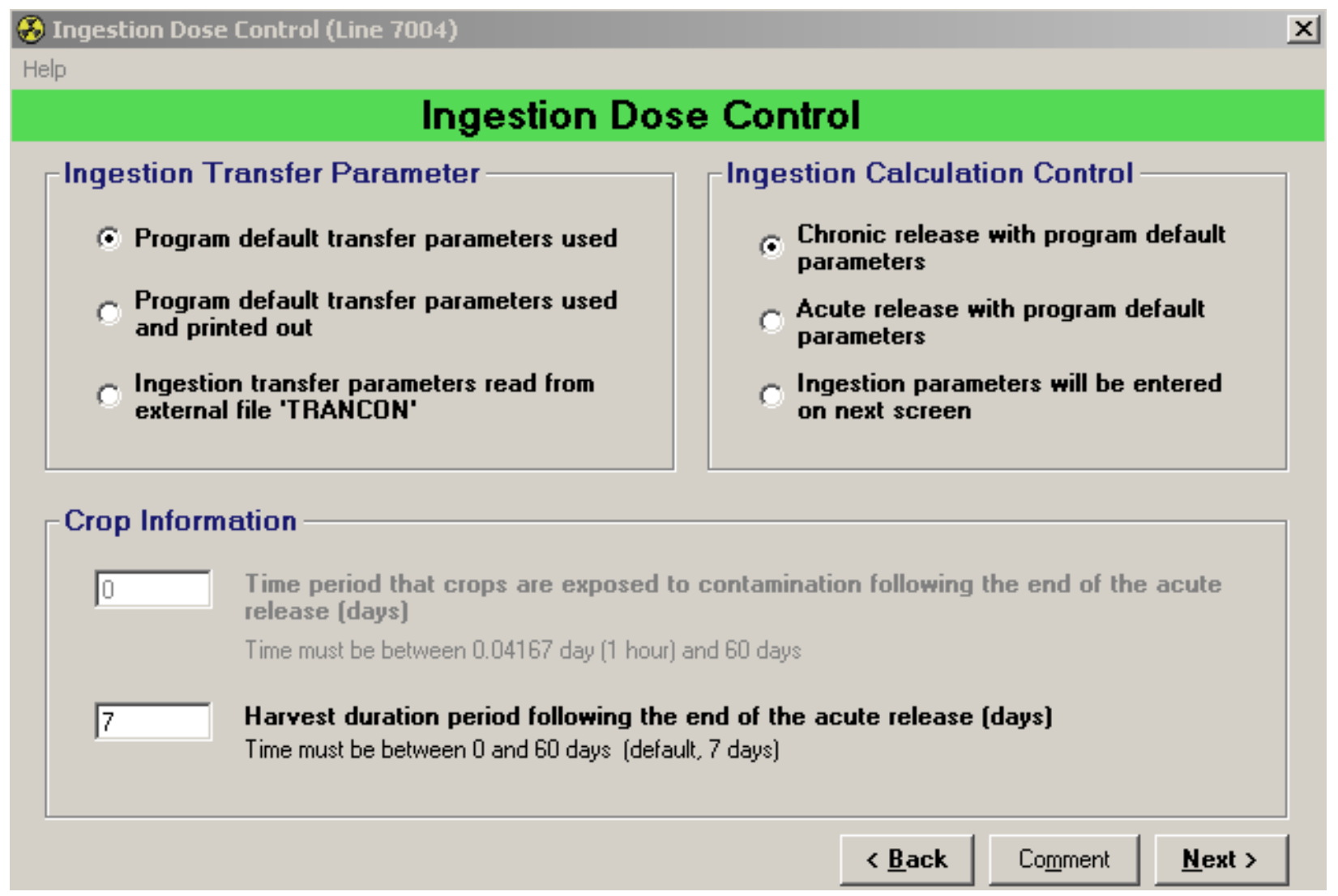

Figure 3-61. Screen 4B (Optional), Ingestion Dose Control. 
Screen 5B (Optional) - Ingestion Dose Constants: Shown only if Ingestion parameters will be entered on next screen is chosen on screen 4B (Figures 3-62, 3-63, 3-64, 3-65, and 3-66). Note: All tabs will need to be reviewed before continuing.

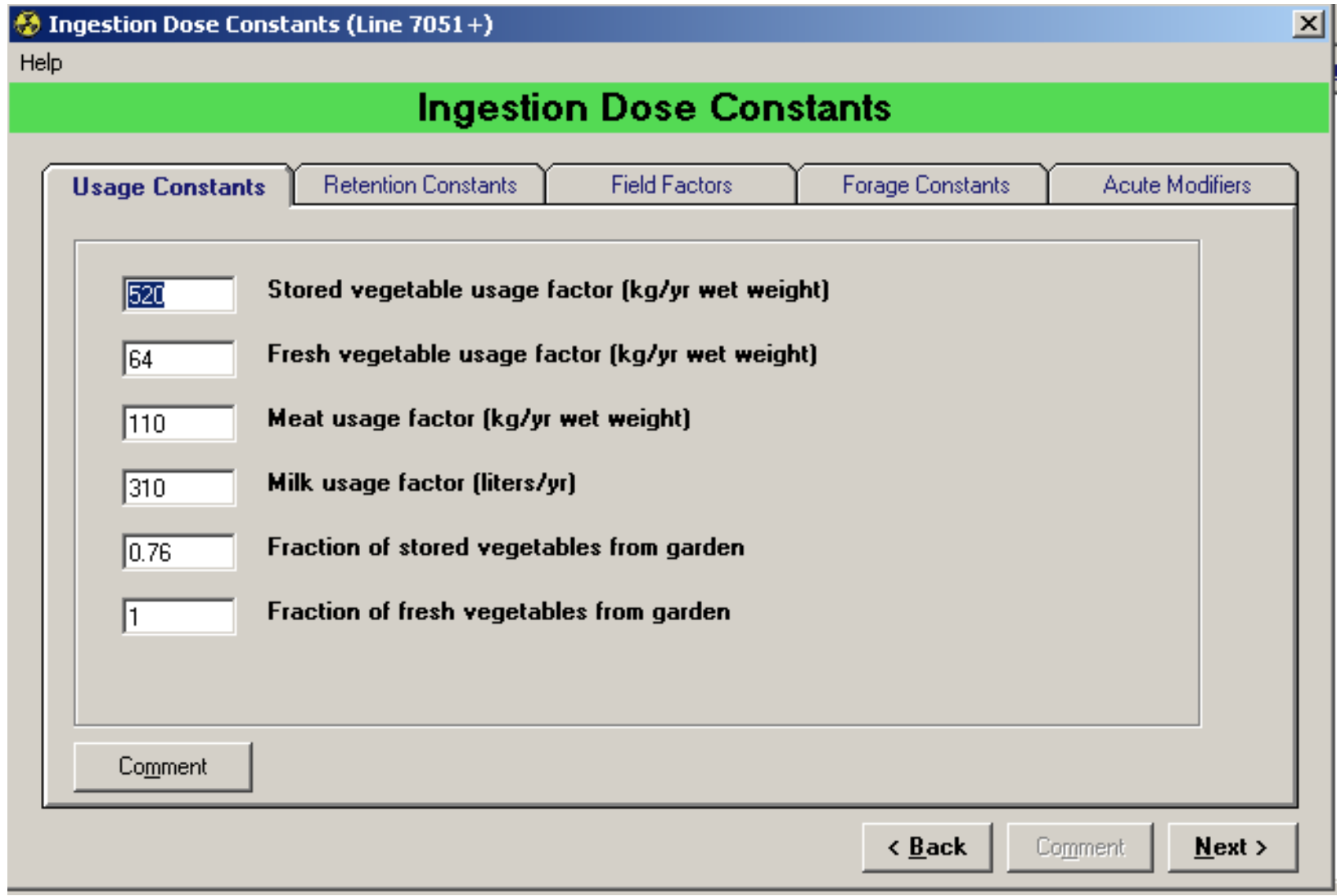

Figure 3-62. Screen 5B (Optional), Usage Constants Tab. 


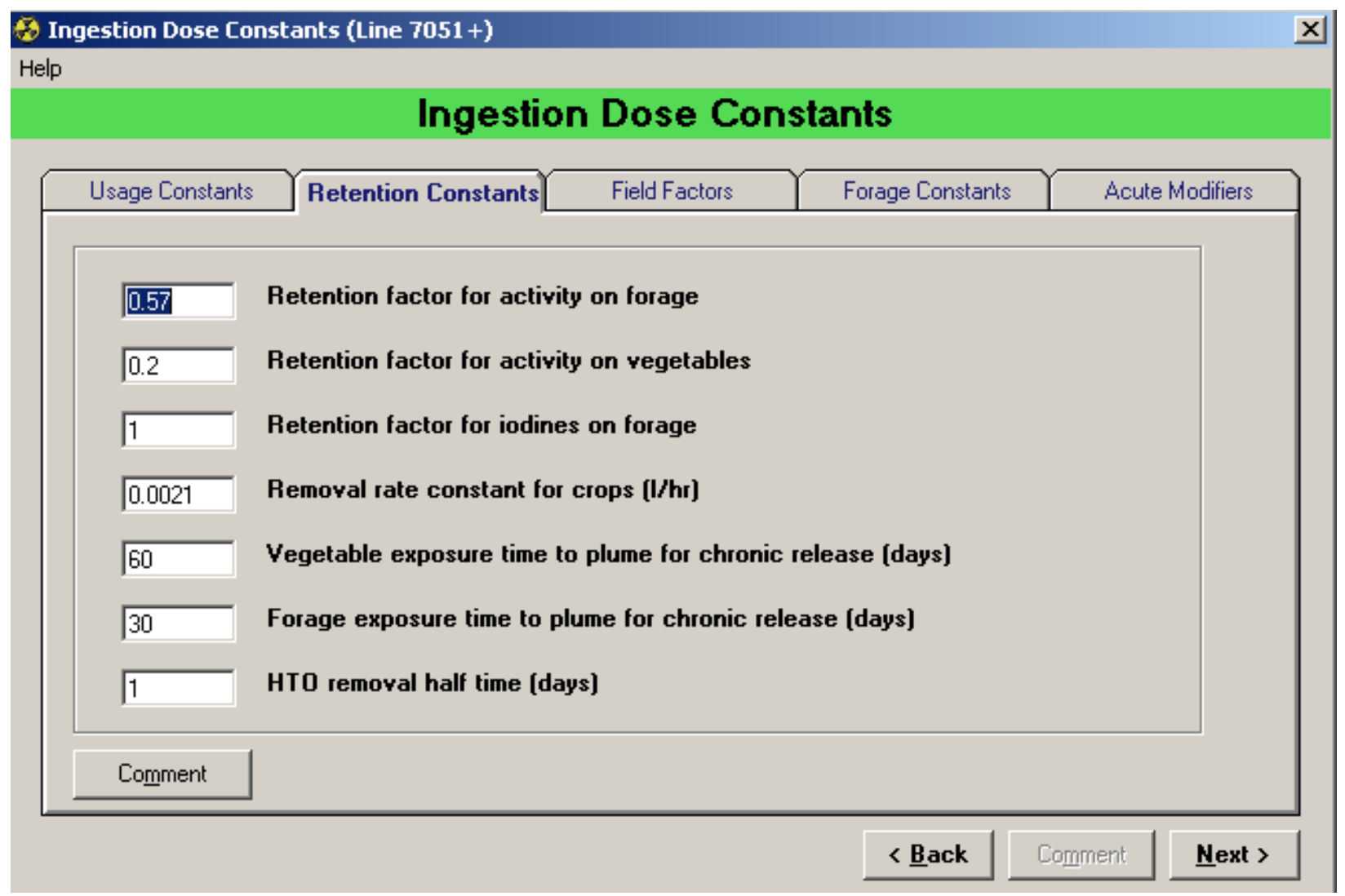

Figure 3-63. Screen 5B (Optional), Retention Constants Tab. 


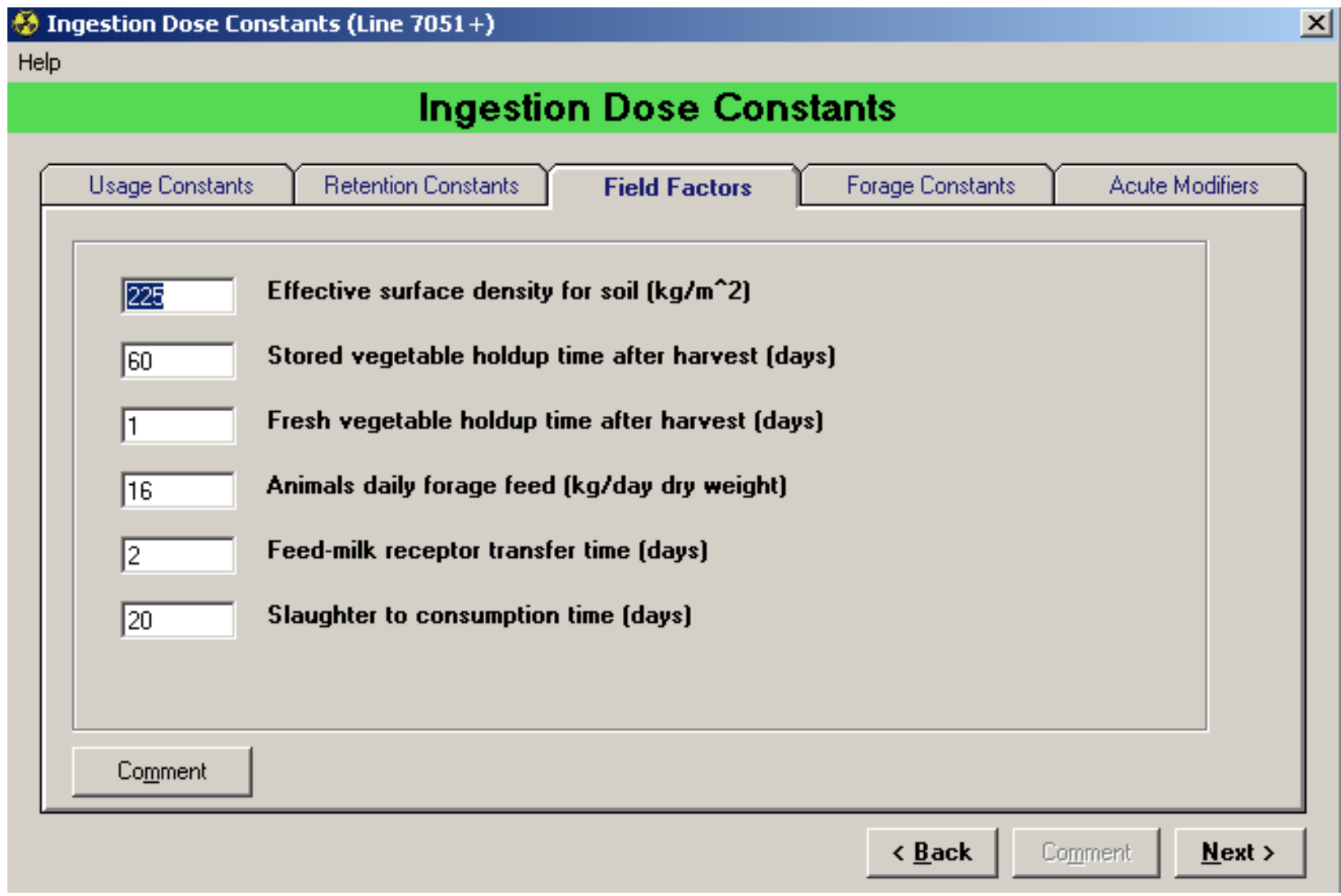

Figure 3-64. Screen 5B (Optional), Field Factors Tab. 
Help

\section{Ingestion Dose Constants}

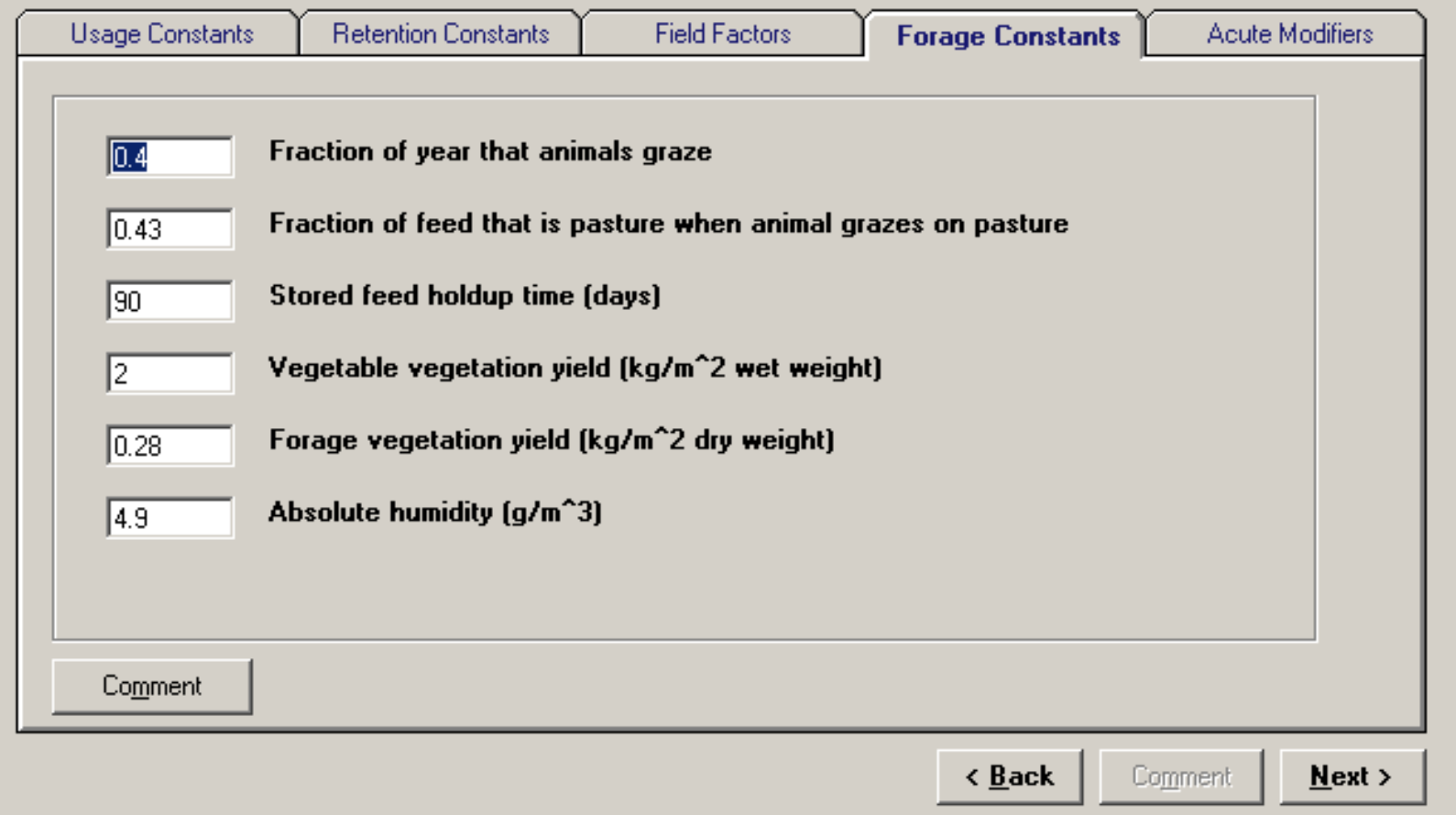

Figure 3-65. Screen 5B (Optional), Forage Constants Tab. 


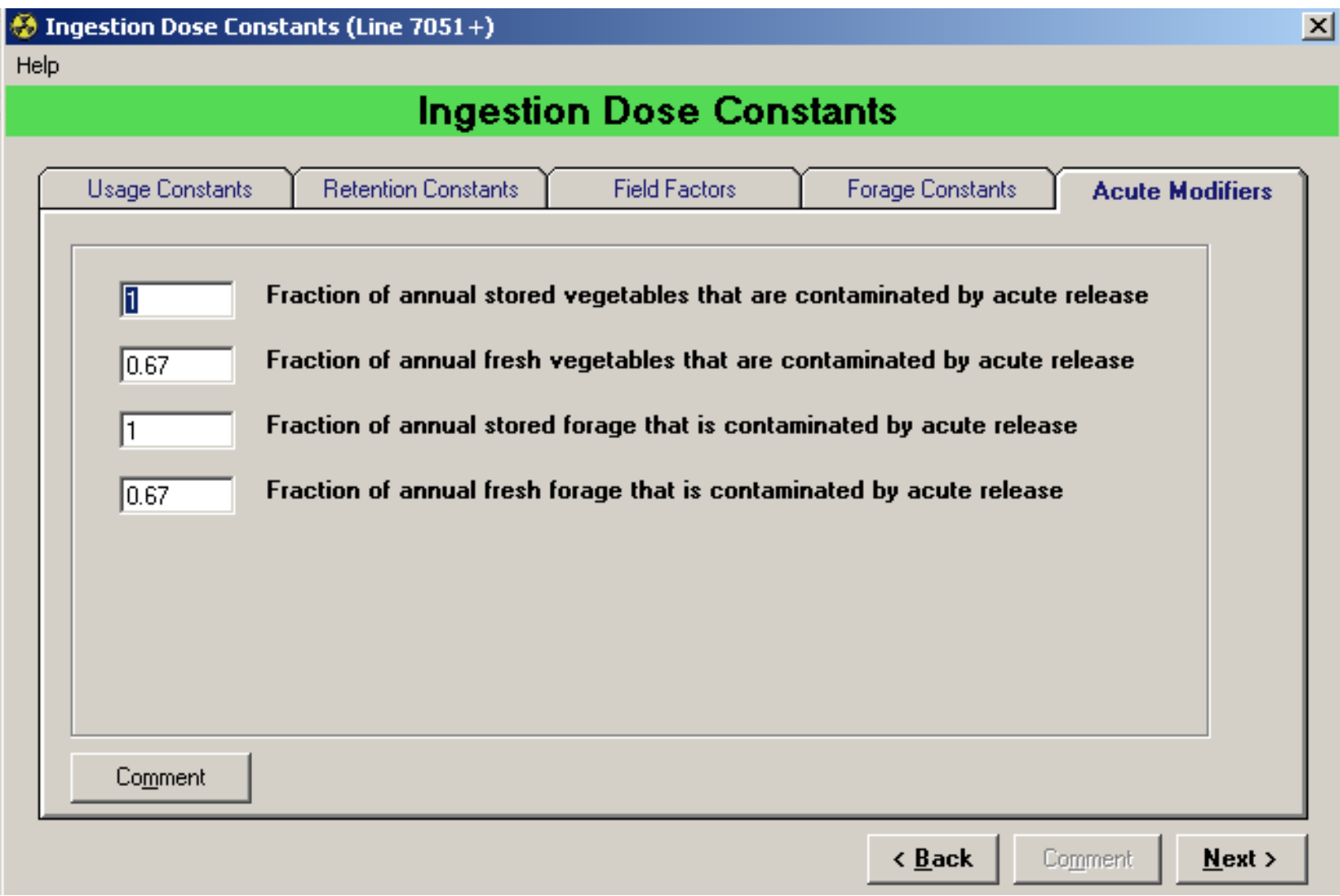

Figure 3-66. Screen 5B (Optional), Acute Modifiers. 
Screen 3C (Optional) - Ground Surface Dose Parameters: Shown only if option 5 is chosen for Type of Dose Calculation on screen 2. Enter the decay time (s) for exponential calculations, exposure time of the receptor to contaminated ground surface, and the building shielding factor (Figure 3-67).

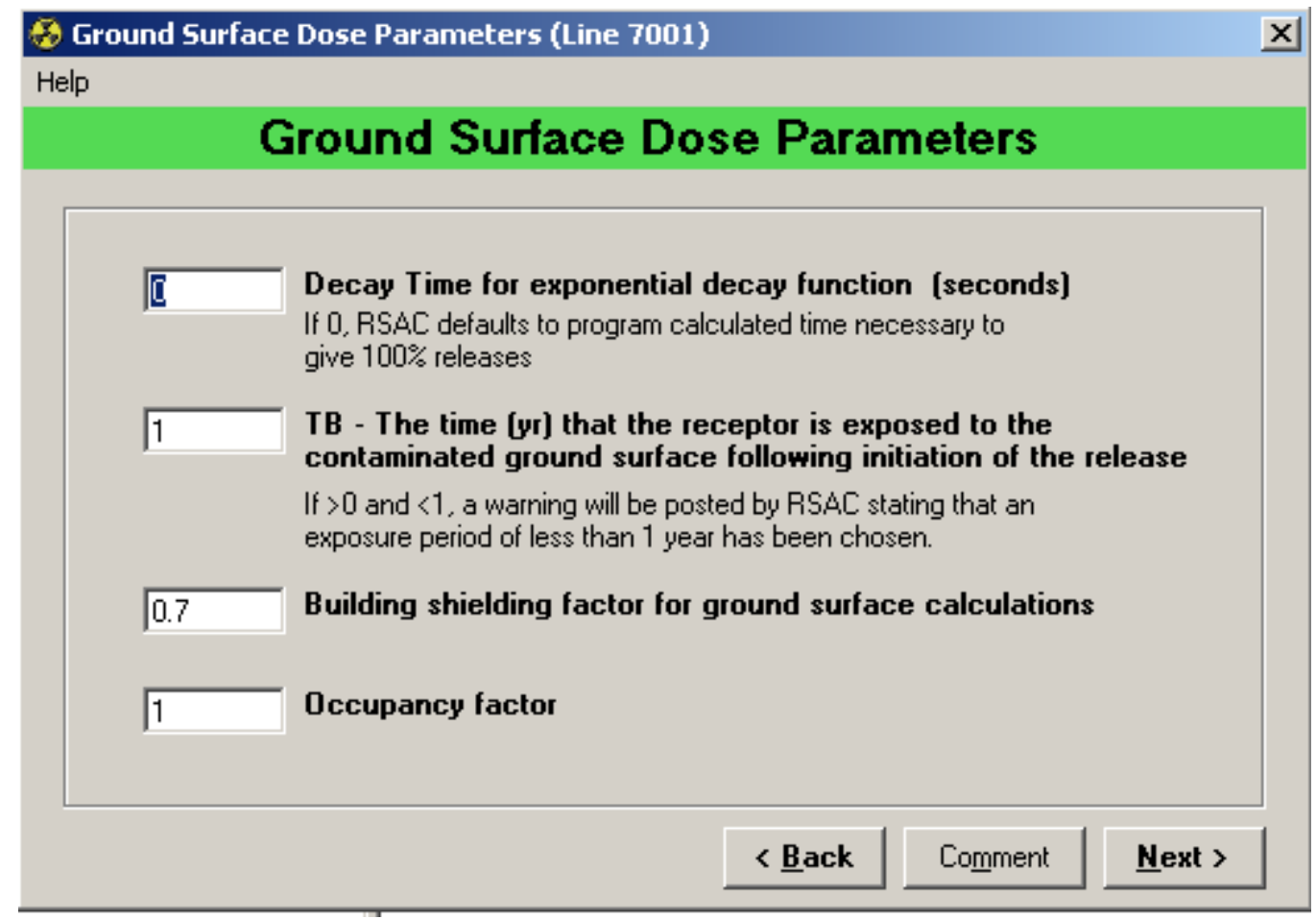

Figure 3-67. Screen 3C (Optional), Ground Surface Dose Parameters.

Screen 3D (Optional) - Air Immersion Dose Parameters: Shown only if option 6 is chosen for Type of Dose Calculation on screen 2. Enter decay time (s) for exponential decay functions (Figure $3-68)$.

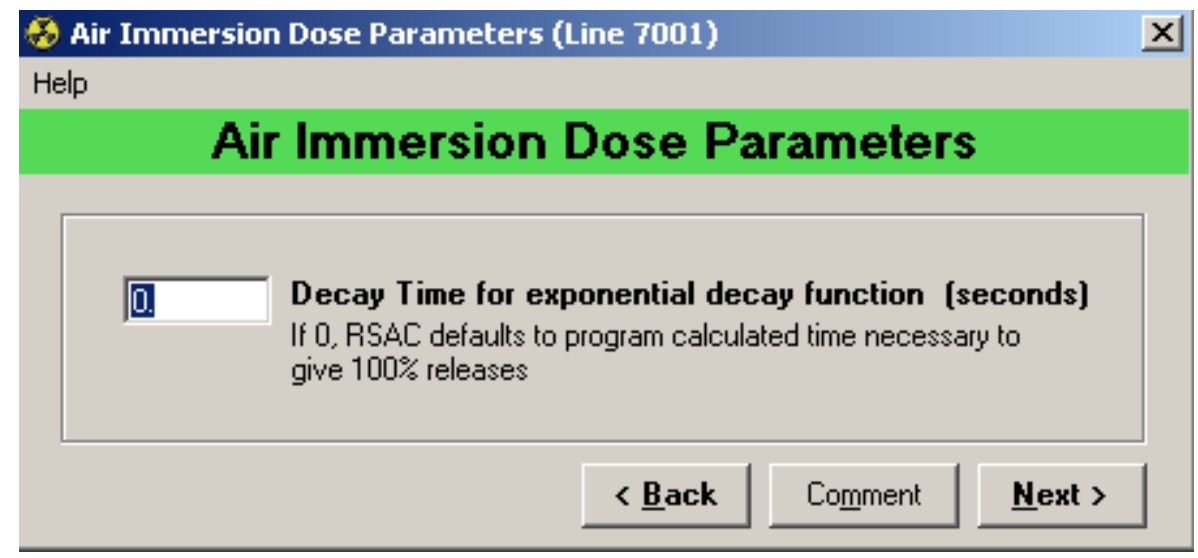

Figure 3-68. Screen 3D (Optional), Air Immersion Dose Parameters. 
Screen (Optional) - Internal/External Organ Selection: Shown only if Organs will be listed on a upcoming screen is chosen on screen 2. On this screen (Figure 3-69), select the organ using one of the following methods. Scroll through the list and click on the desired organ; type the organ name to quickly select the desired organ. To unselect an organ click it in the list a second time. To clear all selected, click the Clear Selected button.

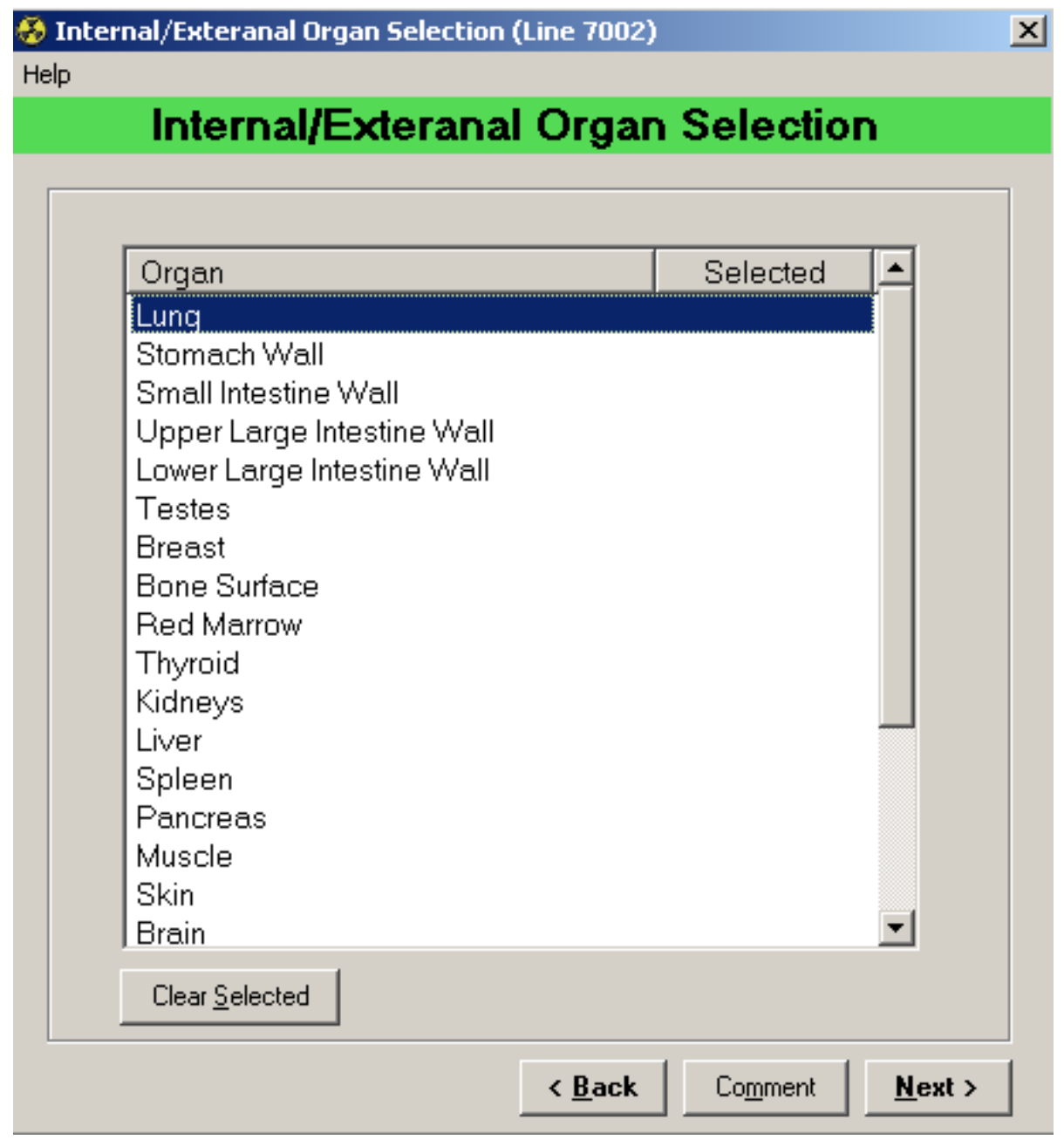

Figure 3-69. Screen (Optional), Internal/External Organ Selection. 
Screen (Optional) - Element Selection: Shown only if Elements will be listed on a upcoming screen is chosen on screen 2. On this screen (Figure 3-70), select the element using one of the following methods. Scroll through the list and click on the desired element; type the symbol to quickly select the desired element. To unselect an element click it in the list a second time. To clear all selected, click the Clear Selected button.

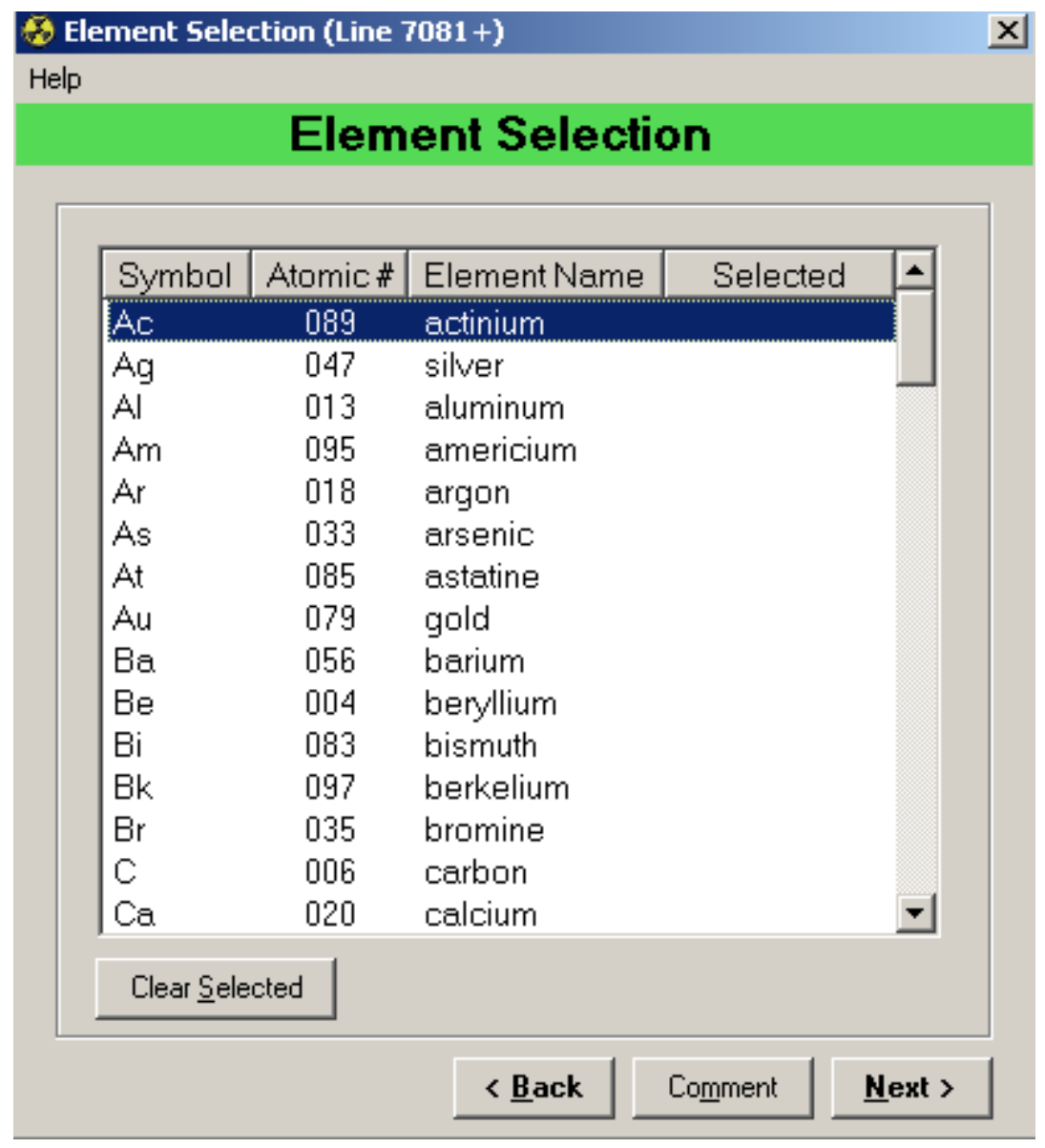

Figure 3-70. Screen (Optional), Element Selection. 


\subsubsection{Series - Cloud Gamma Dose Calculation}

Screen 2 - Cloud Gamma Dose Calculation: After the series title screen the cloud gamma does calculation screen appear asking whether calculations are to be made using the finite or semi-infinite plume model (Figure 3-71). By checking which calculation should be used the inputs for the exponential decay function will be enabled.

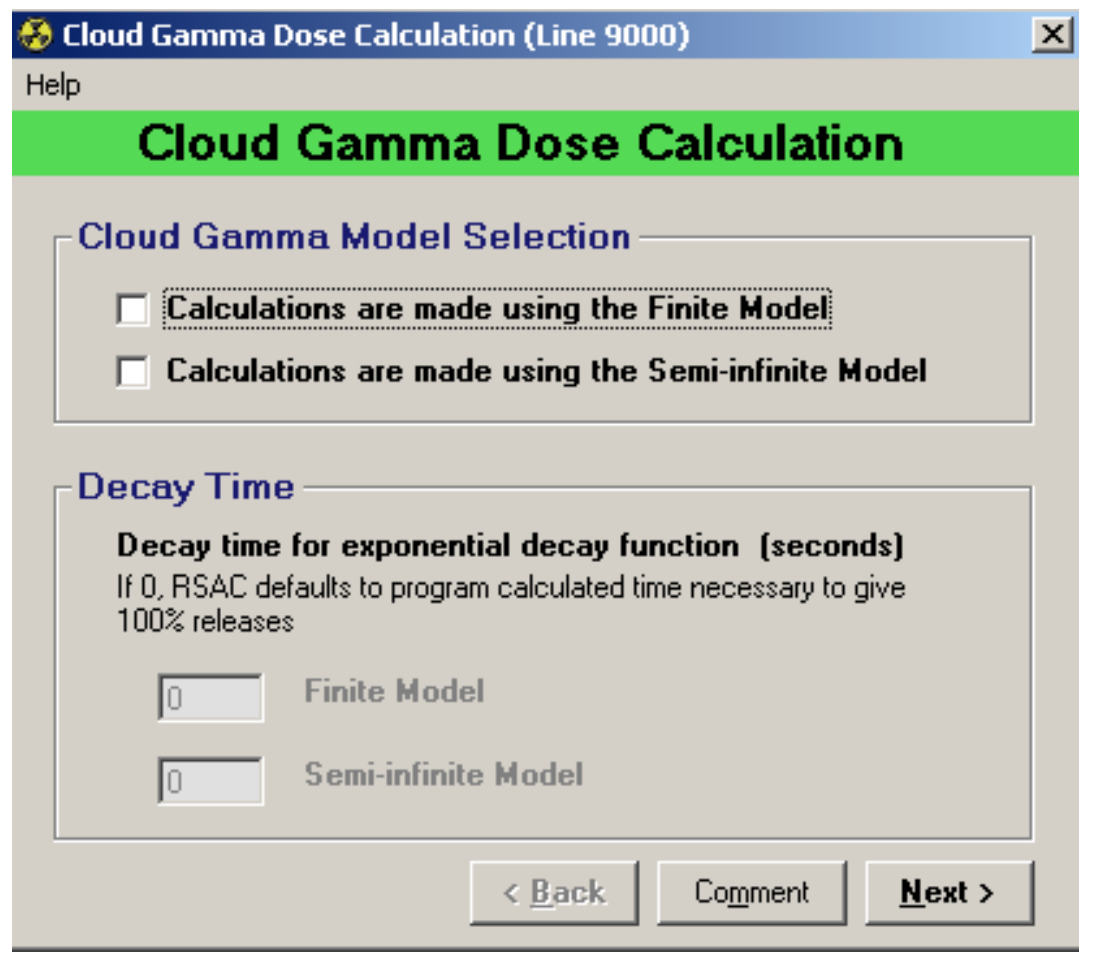

Figure 3-71. Screen 2, Cloud Gamma Dose Control.

\subsection{Critdos Subroutine}

CRITDOS calculates the prompt neutron doses using the Nuclear Regulatory Commission (NRC) Regulatory Guide 3.33 (RG 3.33) equations. Both unshielded and shielded direct doses are calculated based on the total fission yield of the postulated criticality, the distance from the criticality to the receptor, equivalent concrete thickness of the shield, and the system being analyzed (i.e., neutron escape fraction based on the system size).

The gamma and neutron attenuation factors given in RG 3.33 vary according to the thickness of the concrete. That is, the first few inches of concrete are not as effective at attenuating radiation as the remaining thickness of concrete. Equations have been derived and put into CRITDOS that take this into account. In addition, the equations for concrete shielding that is less than $12 \mathrm{in}$. thick have been modified to make them more realistic (i.e., best estimate rather than conservative).

The equations for calculating a dose, in rem, from NRC Regulatory Guide 3.33 (RG 3.33) are based on $10 \%$ of the neutrons escaping from the system. The equations in CRITDOS have been modified to allow the user two additional options for neutron escaping from the system. In addition to the 0.10 escape fraction, which is representative of a large moderated system, the user can choose a moderated system with an escape fraction of 0.30 or a small unreflected metal system with an escape fraction of 0.70 . 
To run the Critdos subroutine click on the Critdos tab and click the Launch Critdos link (Figure 3-72).

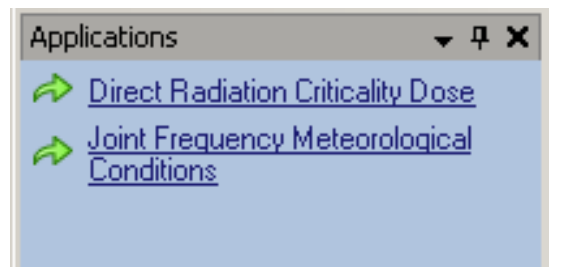

Figure 3-72. Applications Tab.

Screen 1 - Data Input: Use this screen to supply the following information (Figure 3-73): Title that will appear on each page of output; The total fissions; Distance in feet; Concrete thickness in inches; and the system type.

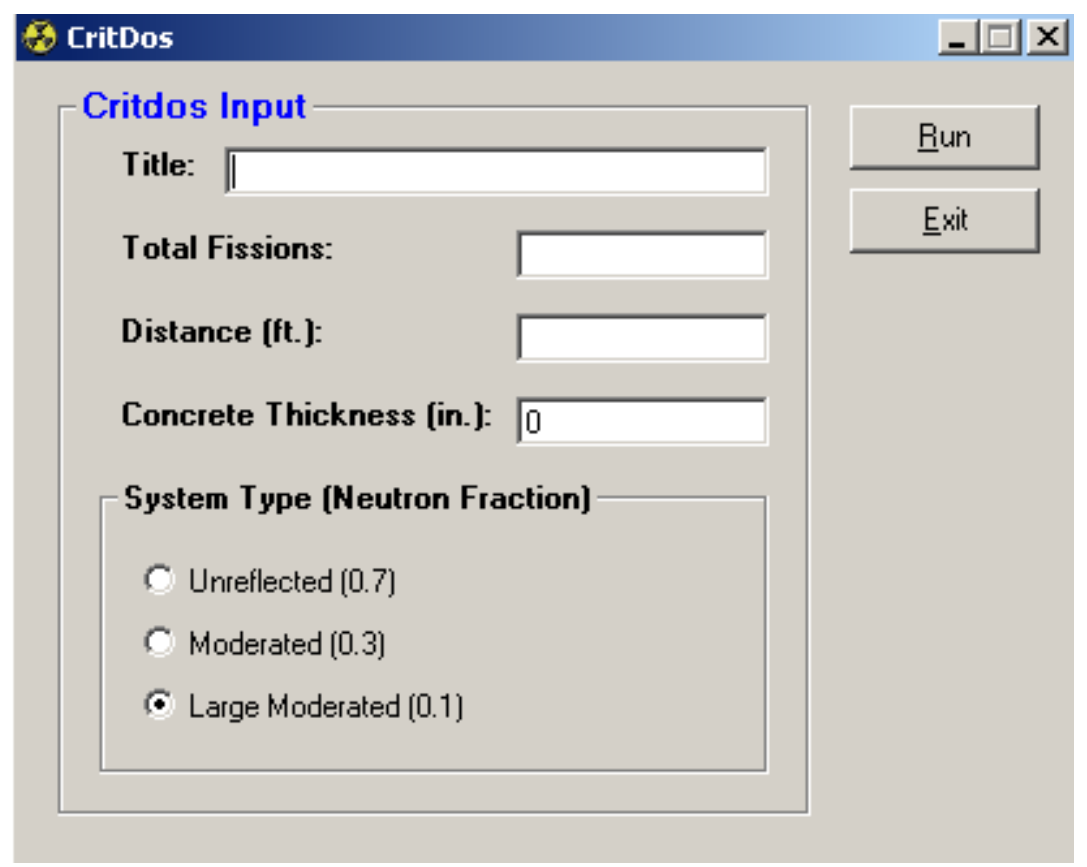

Figure 3-73. Screen 1, Data Input. 
Screen 2 - Program Output: Displays the output results from Critdos (Figure 3-74).

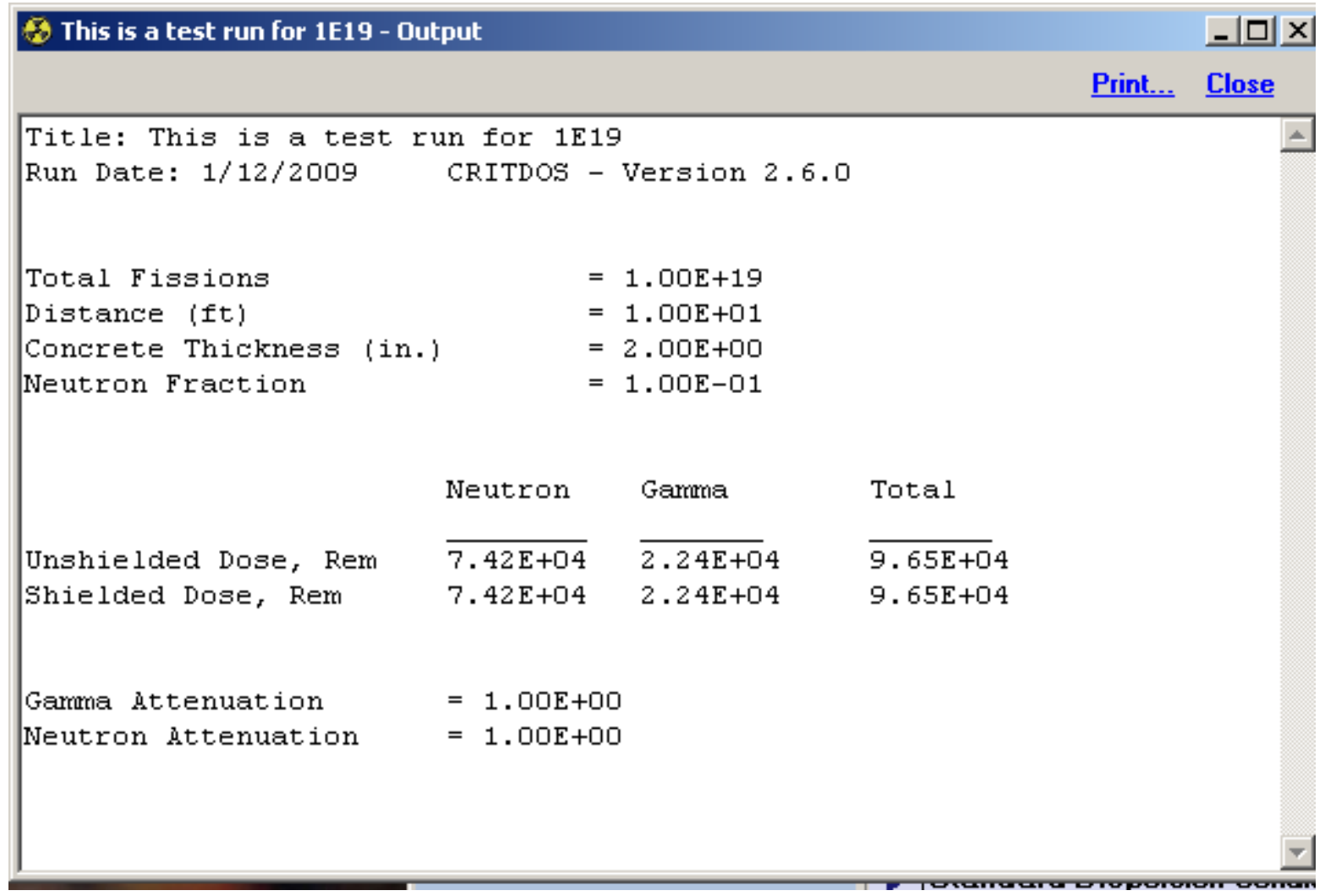

Figure 3-74. Screen 2, Program Output.

\subsection{MetCond Subroutine}

The metcond subroutine uses a joint frequency distribution to define the meteorlogical conditions where normalized concentrations (X/Q) are exceeded no more than 5\% and 50\% of the time. The metcond subroutine defines this condition on data as summarized by the National Weather Service (NWS) meteorological data, CD-144 format. The input is a joint frequency distribution of 6 windspeeds, 16 wind directions and 6 stability categories (Pasquill - Gifford: A through F) for the station and time period desired. The computational program is written in FORTRAN, and the user interface is written in VisualBasic for DOS.

The joint frequency data for a significant number of locations has been provided integral to the software. If your specific location is not available the data is available from the NWS and can be directly added to the library. 


\section{Joint Frequency Meteorological Conditions}

A description of the facility and its reason for selection is placed in the top frame. This program reads standard STAR data obtainable from most airports and consists of a reduction of hourly readings to a form that can be evaluated in a joint frequency model. The output is a metorlogical stability class and wind speed that represents the conditions where $95 \%$ of the time will result in lower dose to a receptor.

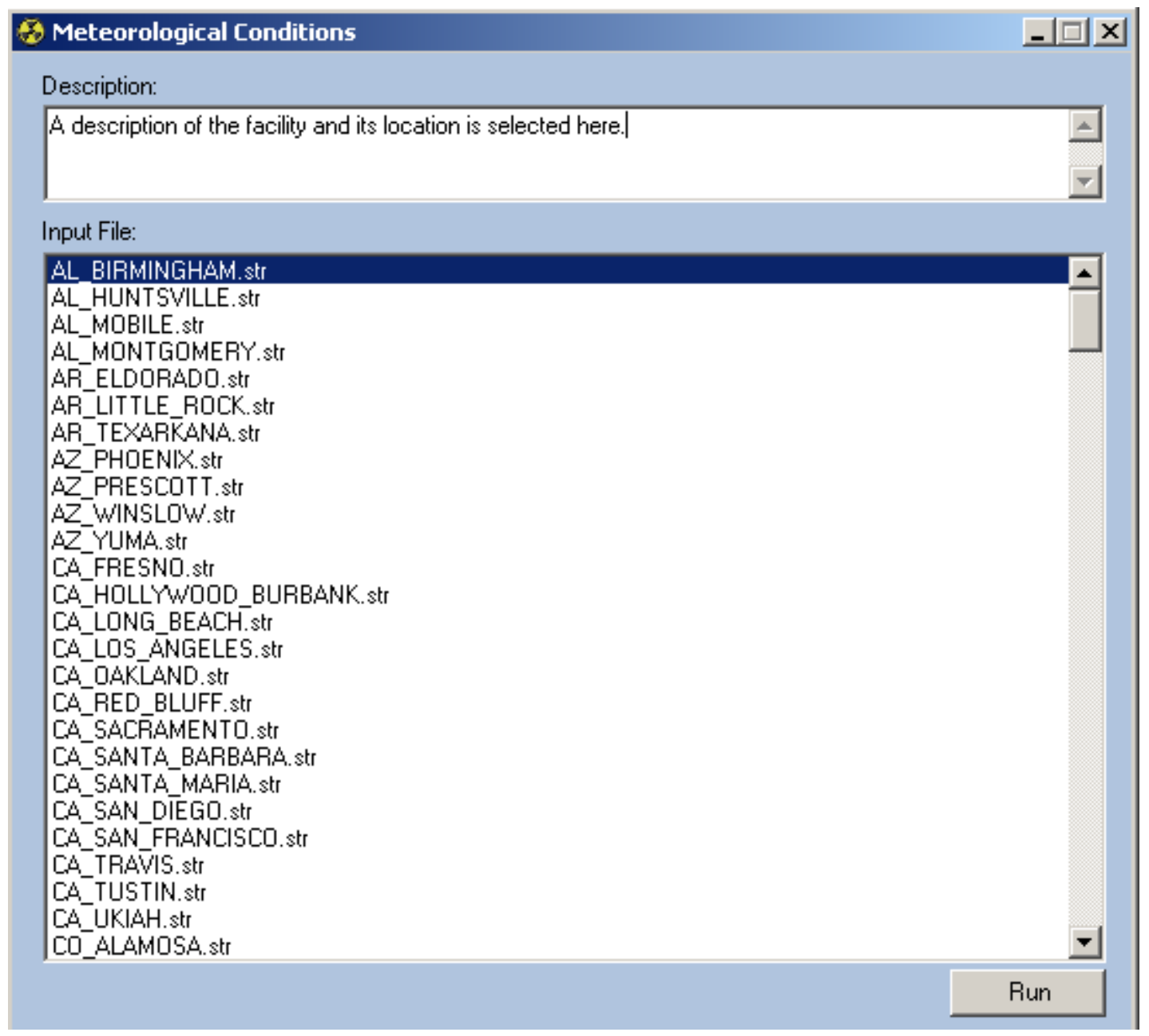

A joint frequency table is generated as shown below 


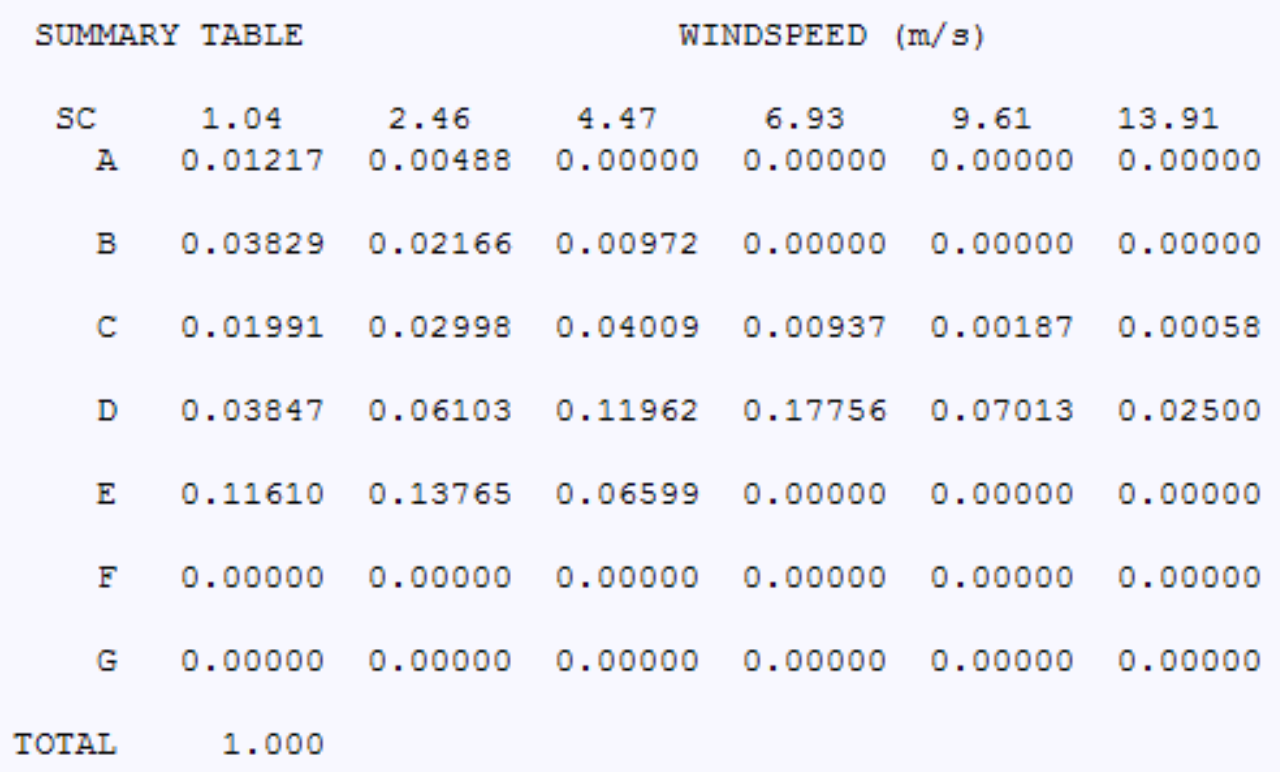

From that data two points of interest are reported 
5OTH PERCENTILE OCCURS IN STABLILTY CLASS C, $2.46 \mathrm{~m} / \mathrm{s}$ WINDSPEED

\begin{tabular}{cccccccc}
95 TH PERCENTILE & TABLE & \multicolumn{5}{c}{ WINDSPEED } & $(\mathrm{m} / \mathrm{s})$ \\
SC & 1.04 & 2.46 & 4.47 & 6.93 & 9.61 & 13.91 \\
A & 0.01217 & 0.00488 & 0.00000 & 0.00000 & 0.00000 & 0.00000 \\
B & 0.03829 & 0.02166 & 0.00972 & 0.00000 & 0.00000 & 0.00000 \\
C & 0.01991 & 0.02998 & 0.04009 & 0.00937 & 0.00187 & 0.00058 \\
D & 0.03847 & 0.06103 & 0.11962 & 0.17756 & 0.07013 & 0.02500 \\
E & 0.06603 & 0.13765 & 0.06599 & 0.00000 & 0.00000 & 0.00000 \\
F & 0.00000 & 0.00000 & 0.00000 & 0.00000 & 0.00000 & 0.00000 \\
G & 0.00000 & 0.00000 & 0.00000 & 0.00000 & 0.00000 & 0.00000
\end{tabular}

95TH PERCENTILE OCCURS IN STABLILTY CLASS E, $1.04 \mathrm{~m} / \mathrm{s}$ WINDSPEED

THE TABLE CAN BE USED TWO WAYS.

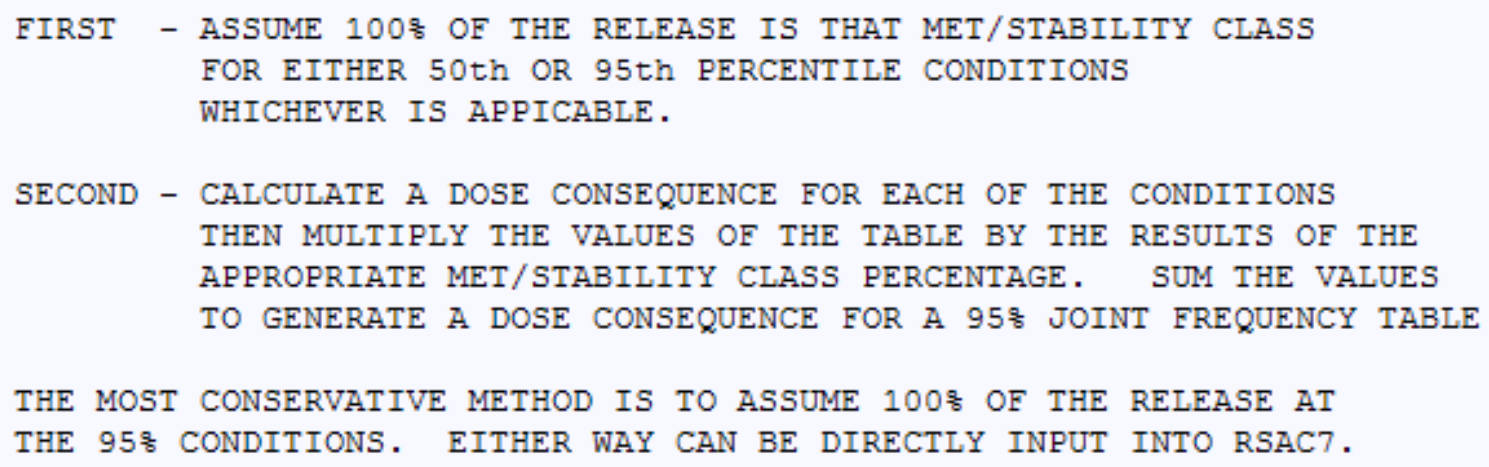




\section{Reading the RSAC-7 INPUT File}

\subsection{RSAC-7 Input}

A typical RSAC-7 input line includes

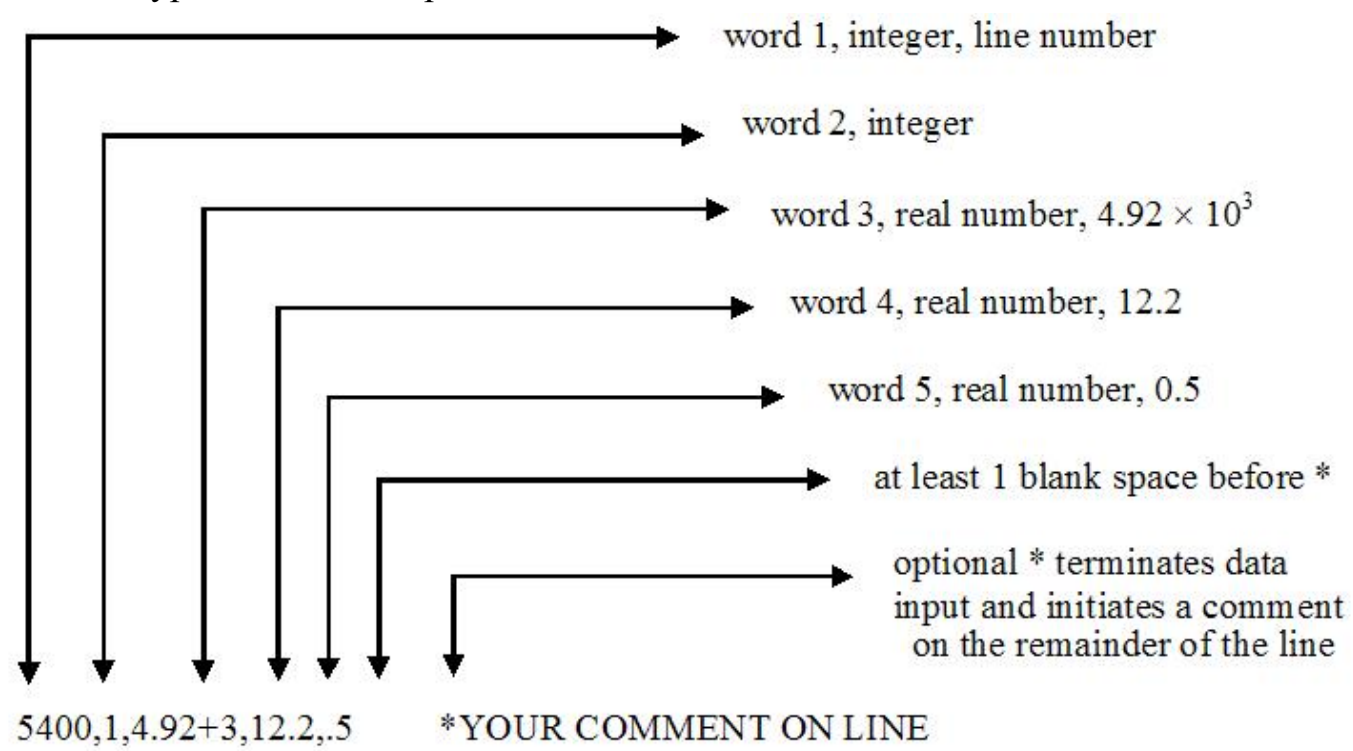

Other variations of this same line include

5400, 1, 4.92E3, 12.2, 5.E-1 *YOUR COMMENT ON LINE

\section{$54001492+4$ 1.22E+1 5.-1 *YOUR COMMENT ON LINE}

You can use a comma or a blank space as delimiters between entries. Each integer or real number entry is referred to as a "word." The first word of every line is referred to as the "line number," which is used to check input sequences.

As shown in the third word of the last variation above $(492+4)$, when a real number does not contain a decimal point, the decimal point is assumed to appear before the first digit. However, you are encouraged to place a decimal point in real numbers. The following RSAC-7 input descriptions assume that all words are real numbers unless otherwise noted. Changes from RSAC-6 to RSAC-7 are noted in red.

The input descriptions in this section include word, program name, entry, and description information. The word column presents the location of the entry. The program name column identifies the name given to the variable in the source program and is not input on a line. The entry and description columns provide the entry numbers or type of entry and their corresponding descriptions.

To insert a comment line, type a \# sign in the first column. There is no limit to the number of comment lines you can insert. Comment lines are printed in the RSAC-7 ASCII input file and appear in the list of input printed at the beginning of each output file.

The example runs in Section 5 will help you learn how to prepare ASCII input for the RSAC-7 program. 


\subsection{Calculation Title Line \\ Column Entry \\ 1 \\ $*$ \\ $2-72$ \\ Page heading (alphanumeric)}

RSAC-7 ignores all lines of input until it reads a line that contains an asterisk in column 1. This allows the program to start the next problem if an error is found in the input. If output is not received from an RSAC-7 run, check to see if a line contains an asterisk in column 1. 


\subsubsection{Series - Fission Product Inventory Calculation and Inventory Decay}

Use a Fission Product Calculation and Inventory Decay Control Line (1000) to initiate fission product inventory calculations or inventory decay calculations of a directly input radionuclide inventory. Input the following lines to describe the reactor operating history and the fractionation of the fission product inventory. This calculation generates a fission product inventory only. It does not calculate the actinides available for release. These should be directly input using a 2000 series and may be added to the calculated fission product inventory. If subsequent decay is required, an additional 1000 series should be used to calculate the decay of inventory. The 6000 series does not calculate a decayed inventory for subsequent release. It will only decay the inventory for printout purposes.

\subsubsection{Fission Product Inventory Calculation and Inventory Decay Control Line (1000)}

\begin{tabular}{|c|c|c|c|}
\hline Word & Variable & Entry & Docorintio \\
\hline & Name & & \\
\hline
\end{tabular}

\subsubsection{Inventory Control/Initial Reactor Data Line (1001)}

The required Inventory Control/Initial Reactor Data Line (1001) must immediately follow the Fission Product Inventory Calculation and Inventory Decay Control Line (1000). Use the control word on this line to indicate whether you are

a) calculating a new fission product inventory (actinides are not calculated) or

b) modifying a previously calculated radionuclide inventory.

If you want to calculate a new fission product inventory, enter the reactor power, and operating time on this line. The next line may be a Refueling Line (1002), Decay/Cycle Line (1003), or Fractionation Line (1004) to modify the release calculation.

If you are modifying a directly input radionuclide inventory, the remaining words on this line are ignored (but must be present) and the next line must be a Refueling Line (1002), Decay/Cycle Line (1003), or Fractionation Line (1004).

\begin{tabular}{|c|c|c|c|}
\hline Word & $\begin{array}{c}\text { Variable } \\
\text { Name }\end{array}$ & Entry & Description \\
\hline 1 & & 1001 & \\
\hline 2 & & Integer & Control word: \\
\hline
\end{tabular}

$0 \quad$ Calculations start with no previous radionuclide inventory.

1 Previous radionuclide inventory is retained and the next line must be a Refueling Line (1002), Decay/Cycle Line (1003), or Fractionation Line (1004). The values for the remaining words on this line are ignored; however, values for each of the following words must be present. 


Word $\begin{gathered}\text { Variable } \\ \text { Name }\end{gathered}$ POWER $\quad \begin{aligned} & \text { Description } \\ & \text { Reactor power (W) or } 0.0 \text { if word } 2=1\end{aligned}$
If megawatt days (MWd) of an operating cycle are known use
the following conversion to generate the inputs for words 3 and
4.
If operating power and MWd are known:
8.64 E10 W-s/MWd, then divide through by the average power
(W) for the cycle, and the resultant will give the reactor
operating time in seconds.
If operating time and MWd are known:
8.64 E10 W-s/MWd, then divide through by the operating time
(seconds) for the cycle, and the resultant will give an average
reactor power in watts.
Reactor operating time at the above power (s) or 0.0 if word 2
= 1.

\subsubsection{Refueling Line (1002)}

\begin{tabular}{|c|c|c|c|}
\hline Word & $\begin{array}{l}\text { Variable } \\
\text { Name } \\
\end{array}$ & Entry & $\underline{\text { Description }}$ \\
\hline 1 & & 1002 & \\
\hline 2 & & & $\begin{array}{l}\text { The fraction of radionuclide inventory remaining after } \\
\text { refueling. This is the same total inventory fractionation as } \\
\text { performed when word } 2 \text { of Fractionation Control Line (1004) } \\
\text { is equal to } 2 \text {. }\end{array}$ \\
\hline
\end{tabular}

The Decay/Cycle Line (1003) is used to calculate the inventory decay as generated with an Inventory Control/Initial Reactor Data Line (1001) or a 2000 series directly input radionuclide inventory. This is the only location in the program where the radionuclide inventory decay can be calculated. A 6000 series decay does not calculate an inventory decay for subsequent release. If a subsequent reactor cycle is required then words 3 and 4 can be used to cycle the reactor. 


\subsubsection{Decay/Cycle Line (1003)}

\begin{tabular}{|c|c|c|c|}
\hline$\underline{\text { Word }}$ & $\begin{array}{l}\text { Variable } \\
\text { Name } \\
\end{array}$ & Entry & $\underline{\text { Description }}$ \\
\hline 1 & & 1003 & \\
\hline 2 & TTROP & & Decay time or reactor shutdown time before this cycle (s). \\
\hline 3 & POWER & & $\begin{array}{l}\text { Reactor power for cycle (W). If zero, TROP below is set to } \\
\text { zero, and the next entry is ignored. }\end{array}$ \\
\hline$\underline{\text { Word }}$ & $\begin{array}{l}\text { Variable } \\
\text { Name }\end{array}$ & Entry & Description \\
\hline 4 & TROP & & $\begin{array}{l}\text { Reactor operating time at above reactor power for this } \\
\text { cycle (s). This quantity is set to zero if reactor power above is } \\
\text { zero. }\end{array}$ \\
\hline
\end{tabular}




\subsubsection{Fractionation Control Line (1004)}

Use this line to release a fraction of the radionuclide inventory and simulate removal of activity by cleanup systems such as HEPA filters. Use the control word on this line to determine whether the type of fractionation is by group, by a constant value, or by element. Specify fractionation by the following groups: solids, halogens, noble gases, cesium, and ruthenium. Enter the fractionation value for each group on this line. If the constant fractionation option is used, the entire radionuclide inventory is fractionated by the next value entered on this line. If fractionation by element is chosen, enter a fractionation value for those elements not described by an Element Fractionation Lines $(1101+)$ on this line. Enter the Element Fractionation Lines $(1101+)$, describing the fractionation of each desired element.

\begin{tabular}{|c|c|c|}
\hline$\underline{\text { Word }}$ & Entry & $\underline{\text { Description }}$ \\
\hline 1 & 1004 & \\
\hline 2 & -1 & $\begin{array}{l}\text { Fractionation by group as specified by the next } \\
\text { five words. }\end{array}$ \\
\hline 3 & & Fractionation for solids. \\
\hline 4 & & Fractionation for halogens. \\
\hline 5 & & Fractionation for noble gases. \\
\hline 6 & & Fractionation for cesium. \\
\hline 7 & & Fractionation for ruthenium. \\
\hline 2 & 0 & $\begin{array}{l}\text { Fractionation is by a constant specified } \\
\text { by the next word. }\end{array}$ \\
\hline 3 & FRAC & Fractionation for entire radionuclide inventory. \\
\hline 2 & 1 & $\begin{array}{l}\text { Fractionation by element. Following lines will } \\
\text { be Element Fractionation Lines }(1101+) \text {. }\end{array}$ \\
\hline 3 & FRAC & $\begin{array}{l}\text { Fractionation for elements not described by Element } \\
\text { Fractionation Lines }(1101+) \text {. }\end{array}$ \\
\hline
\end{tabular}




\subsubsection{Element Fractionation Lines (1101+)}

Use these lines only if you want fractionation by element.

$\begin{array}{lll}\text { Word } & \text { Entry } & \text { Description } \\ 1 & \text { Integer } & 11 \mathrm{XX}(\mathrm{XX}=01,02, \ldots, \text { etc. }) \\ 2 & \text { Integer } & \text { Atomic number of element. } \\ 3 & & \text { Fractionation for above element. } \\ \cdot & & \cdot \\ \cdot & & \cdot \\ 2 \mathrm{~N} & \text { Integer } & \mathrm{N}^{\text {th }} \text { atomic number } \\ 2 \mathrm{~N}+1 & & \mathrm{~N}^{\text {th }} \text { fractionation }\end{array}$

Enter additional sets of two values on this and following lines until all desired elements have been described. The number of sets per line is optional.

\subsubsection{Release During Simulated Reactor Operations Line (1200)}

Use this optional control line to simulate radionuclide releases from a reactor while it is operating. Insert a Release During Fission Product Calculation Line (1200) immediately following either the Initial Reactor Data Line (1001) or the Cycle Line (1003) to modify the reactor operations requested by the (1001) or (1003) lines.

A Reactor Linear Leak Rates Line (1201) must immediately follow a (1200) line. Activity is removed from the reactor incrementally using the number of chosen steps (1 to 100) over the entire reactor operating cycle requested by a (1001) or (1003) line. The number of steps should reflect the need for resolution of the release. The more steps, the more exact the totals will be for the shorter lived radionuclides.

RSAC-7 has two memory buffers for storing radionuclide inventories: main and hold. The activity remaining in the reactor is stored in a main memory buffer, and the activity released from the reactor is stored in the hold memory buffer. You can choose whether the activity leaked from the reactor (hold buffer) or that remaining in the reactor following operations (main buffer) is used in further calculations. When you chose the option to retain the activity remaining in the reactor after encountering a (1999) line, the main memory buffer is retained for further calculations and the hold buffer is deleted. Normally the activity leaked from the reactor (hold buffer) is used for release calculations.

When you choose the option to retain the activities released from the reactor during each step increment are summed to give the total amount of each radionuclide released from the reactor during the total operating period. After activity is entered into the hold memory buffer, it cannot be decayed until after a Fission Product Calculation and Inventory Decay End Line (1999) is encountered When you chose the option to retain the activity released from the reactor, the hold memory buffer is copied to the main memory buffer for subsequent calculations, and the radionuclide inventory that was remaining in the reactor is deleted.

After a (1200) line is encountered, it remains in effect on all subsequent reactor cycle operations [Cycle Line (1003)] until either another (1200) line or a Fission Product Calculation and Inventory Decay End Line (1999) is encountered. 
When the (1200) line option is used, all subsequent fractionations of the radionuclide inventory using (1004) lines [until a (1999) line is encountered] are made on the inventory chosen to be retained for subsequent calculations. If desired you can make even further decay (and fractionation) by exiting the 1000 Series with a (1999) line and reentering the 1000 Series with another (1000) line.

$\begin{array}{llll}\underline{\text { Word }} & \begin{array}{l}\text { Variable } \\ \text { Name }\end{array} & \underline{\text { Entry }} & \underline{\text { Description }} \\ 1 & & 1200 & \\ 2 & \text { NCS } & \text { Integer } & \text { Number of reactor release steps }(\leq 100) \\ 3 & \text { KEEPFLAG } & \text { Integer } & \text { Inventory to be retained for subsequent calculations: } \\ & & 0 & \text { Retain activity remaining in reactor } \\ & & & \text { Retain activity leaked from reactor }\end{array}$

\subsubsection{Reactor Linear Leak Rates Line (1201)}

You must insert the Reactor Linear Leak Rates Lines (1201) immediately following a (1200) line to establish the leak rates for the different groups of fission products. Calculation of the Linear Leak Rate is performed by dividing the fraction of the group to be released from the reactor by the total reactor operating time of the cycle in seconds.

$\begin{array}{llll}\underline{\text { Word }} & \begin{array}{l}\text { Variable } \\ \text { Name }\end{array} & \underline{\text { Entry }} & \begin{array}{l}\text { Description } \\ 1\end{array} \\ 2 & \text { RR(1) } & & \text { Radionuclide leak rate from the operating reactor (fraction/s) } \\ 3 & \operatorname{RR}(2) & \text { Solids } \\ 4 & \operatorname{RR}(3) & \text { Halogens } \\ 5 & \operatorname{RR}(4) & \text { Noble gases } \\ 6 & \operatorname{RR}(5) & \text { Cesium }\end{array}$

\subsubsection{Fission Product Calculation and Inventory Decay End Line (1999)}

Use this line to end the fission product inventory calculation or inventory decay requested by the last Fission Product Calculation and Inventory Decay Line (1000).

$\underline{\text { Word }} \quad \underline{\text { Entry }}$

1999 


\subsubsection{Series - Direct Radionuclide Input}

Use the Radionuclide Direct Input Control Line (2000) to initiate directly entering the radionuclide inventory in curies instead of using a fission product inventory. All radionuclides are identified by the radionuclide identification number (NUCL) or by entering the element symbol followed by the atomic number.

\subsubsection{Radionuclide Direct Input Control Line (2000)}

This control line has one data word that identifies whether an existing radionuclide inventory should be deleted, changed, or appended. If the option to change or append the file is chosen, the previous radionuclide inventory can be from another directly calculated (1000 series), input or another external file. It is important to understand that if an inventory decay is required, it must be done in a 1000 series decay (1003) line. A 6000 series decay calculation is for display and print purposes only and will not calculate the active inventory decay.

\begin{tabular}{|c|c|c|}
\hline Word & Entry & Description \\
\hline 1 & 2000 & \\
\hline \multirow[t]{3}{*}{2} & 0 & $\begin{array}{l}\text { Radionuclide inventory input option is chosen. Any previous } \\
\text { radionuclide inventory is deleted. Radionuclide entry lines or } \\
\text { an external file (2002) may be identified. If direct input of } \\
\text { radionuclides and their respective activities is desired then the } \\
\text { requirements of Radionuclide Entry Lines must be followed. If } \\
\text { an external file is requested the requirements of line (2002) } \\
\text { must be followed. }\end{array}$ \\
\hline & 1 & $\begin{array}{l}\text { Same as for entry } 0 \text { except the previous radionuclide inventory } \\
\text { is retained and the activity of the chosen radionuclide is } \\
\text { changed to that indicated on either the Radionuclide Entry } \\
\text { Lines or an external file. }\end{array}$ \\
\hline & -1 & $\begin{array}{l}\text { Same as for entry } 0 \text { except the previous radionuclide inventory } \\
\text { is retained and the activity of the chosen radionuclide is added } \\
\text { to that indicated on either the Radionuclide Entry Lines or an } \\
\text { external file. }\end{array}$ \\
\hline \multirow[t]{3}{*}{3} & 0 & curie \\
\hline & 1 & gram \\
\hline & 2 & $\mathrm{~Bq}$ \\
\hline
\end{tabular}




\subsubsection{Radionuclide Entry Lines}

Radionuclide Entry Lines are present only when an external file (2002) line option is not selected. Following the last entry of an inventory for a radionuclide, you must enter an Input End Line (2999).

\begin{tabular}{|c|c|c|c|}
\hline Word & $\begin{array}{l}\text { Variable } \\
\text { Name } \\
\end{array}$ & $\underline{\text { Entry }}$ & $\underline{\text { Description }}$ \\
\hline \multirow[t]{5}{*}{1} & NUCL & Integer & $\begin{array}{l}\text { Radionuclide identification number (see } 4000 \text { Series, } \\
\text { Radionuclide Data Change Line). An alternate entry can be } \\
\text { made by replacing NUCL with the element symbol (in capital } \\
\text { letters) followed by the mass number and metastable state } \\
\text { indicator. Examples of allowable styles include }\end{array}$ \\
\hline & & & Cs137, Cs-137, Cs 137 \\
\hline & & & Ba $137 \mathrm{~m}, \mathrm{Ba}-137 \mathrm{~m}, \mathrm{Ba} 137 \mathrm{~m}$ \\
\hline & & & CS137, CS-137, CS 137 \\
\hline & & & BA137M, BA-137M, BA 137M \\
\hline 2 & & & The amount in curies of this radionuclide. \\
\hline
\end{tabular}

Make additional line entries until all desired radionuclides have been entered into the radionuclide inventory. Only one radionuclide and associated curies per line is allowed. Line numbers are not required.

\subsubsection{External Radionuclide File Control Line (2002)}

This optional line allows you to specify an external file for inputting radionuclide inventories. This line may follow Line (2000). Data in the external file have the same format as that on the Radionuclide Entry Lines with one exception. The first line in the external file is used to identify the data set and is printed on the RSAC-7 output file. The program stops reading radionuclide inventories from an external file when it encounters either a blank line or the end of the file. An Input End Line (2999) must immediately follow a (2002) line.

\begin{tabular}{|c|c|c|c|}
\hline Word & $\begin{array}{l}\text { Variable } \\
\text { Name } \\
\end{array}$ & $\underline{\text { Entry }}$ & Description \\
\hline 1 & & 2002 & \\
\hline 2 & EXTFILE & & $\begin{array}{l}\text { Enter the name of the external file containing the radionuclide } \\
\text { inventory input. The name entered must be a valid DOS } \\
\text { filename with no extensions. }\end{array}$ \\
\hline
\end{tabular}

\subsubsection{Radionuclide Direct Input End Line (2999)}

Use this line to end the direct input of radionuclide inventory input.

$\begin{array}{ll}\text { Word } & \text { Entry } \\ 1 & 2999\end{array}$




\subsubsection{Series - Dose Summary Option}

Use this option to summarize, add, and report in summary tables doses from different exposure pathways and multiple RSAC-7 calculations.

\subsubsection{Dose Summary Option Control Line (3000)}

RSAC-7 automatically initiates the dose summary. Following dose calculations for the pathways desired, enter additional (3000) lines to request dose summaries. Changes can be made in the 5000 Series (Dispersion Control Input) following initiation of the 3000 Series option; however, downwind distances cannot be changed.

\begin{tabular}{|c|c|c|c|c|}
\hline$\underline{\text { Word }}$ & Name & Entry & \multicolumn{2}{|l|}{ Description } \\
\hline 1 & & \multicolumn{3}{|l|}{3000} \\
\hline \multirow[t]{9}{*}{2} & ISUMTYPE & Integer & \multicolumn{2}{|c|}{ Type of calculation: } \\
\hline & & 1 & \multicolumn{2}{|c|}{$\begin{array}{l}\text { Re-initiate the dose/cancer risk summary option } \\
\text { (used only to zero dose history for stacked cases } \\
\text { in the same run). }\end{array}$} \\
\hline & & 2 & \multicolumn{2}{|c|}{ Summary of dose by pathway. } \\
\hline & & 3 & \multicolumn{2}{|c|}{ Summary of dose by pathway and radionuclide. } \\
\hline & & 4 & \multicolumn{2}{|c|}{$\begin{array}{l}\text { Summary of dose/cancer risk by organ/cancer [requires a } \\
\text { (3001) Line to follow]. }\end{array}$} \\
\hline & & 5 & \multicolumn{2}{|c|}{$\begin{array}{l}\text { Summary of dose/cancer risk by organ and radionuclide } \\
\text { [requires a (3001) line to follow]. }\end{array}$} \\
\hline & & 6 & \multicolumn{2}{|c|}{ Contribution to the effective dose. } \\
\hline & & 7 & \multicolumn{2}{|c|}{ Contribution to E-50/cancer risk by radionuclide. } \\
\hline & & 8 & \multicolumn{2}{|c|}{$\begin{array}{l}\text { Contribution to E-50/cancer risk by radionuclide sorted by } \\
\text { dose. }\end{array}$} \\
\hline \multirow[t]{11}{*}{3} & INAGE & $\begin{array}{l}\text { Inhalat } \\
\text { intake }\end{array}$ & $\begin{array}{l}\text { on/Ingestion } \\
\text { ge }\end{array}$ & $\begin{array}{l}\text { Mortality/Morbidity } \\
\text { age group }\end{array}$ \\
\hline & & \multicolumn{3}{|c|}{ ICRP-72 model } \\
\hline & & 1 & 3 months & $0-5$ years \\
\hline & & 2 & 1 year & $5-15$ years \\
\hline & & 3 & 5 years & $15-25$ years \\
\hline & & 4 & 10 years & $25-70$ years \\
\hline & & 5 & 15 years & $0-100$ years \\
\hline & & 6 & \multicolumn{2}{|l|}{ Adult } \\
\hline & & 7 & \multicolumn{2}{|c|}{ Adult Worker, ICRP-68 model } \\
\hline & & 8 & \multicolumn{2}{|c|}{ Acute inhalation dose } \\
\hline & & 9 & \multicolumn{2}{|c|}{ [CRP-30 model } \\
\hline
\end{tabular}




\subsubsection{Dose Summary Organ Selection (3001)}

This line is present only if word 2 on the (3000) line is 4 or 5 . Dose summaries for up to four organs can be entered. When additional dose summaries for organs are desired, add additional (3000) and (3001) lines.

Variable

Word Name Entry Description

1

3001

2 INORGAN(1) Integer Organ number

$4 \quad$ INORGAN(4)

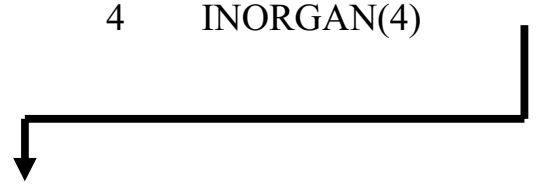

ICRP-72 Dose

Adrenals

ICRP-30 Dose

Bladder Wall

Bone Surface

Brain

Breast

Colon

Esophagus

ET Airways

Kidneys

Liver

LLI Wall

Lungs

Muscle

Ovaries

Pancreas

Red Marrow

SI Wall

Skin

Spleen

Stomach Wall

Testes

Thymus

Thyroid

ULI Wall

Uterus

26 Effective

Spleen

Muscle

Skin

Brain

Thymus

Bladder Wall

Adrenals

Esophagus

Ovaries

Uterus

\section{Mortality/}

Morbidity

Cancer Risk

Bladder

Bone

Breast

Colon

Esophagus

Kidney

Leukemia

Liver

Lung

Ovary

Residual

Skin

Stomach

Thyroid

Total

\section{Acute Dose}

Small Intestine

Bone Marrow

Lung

Alveolar Interstitial Region 


\subsubsection{Series - Dispersion Control Input}

The 5000 Series creates the conditions under which the release parameters will be evaluated.

\subsubsection{Dispersion Control Line (5000)}

Use a Dispersion Control Line (5000) to initiate input of meteorological or room release data.

$\begin{array}{lll}\text { Word Entry } & \text { Description } \\ 1 & 5000 & \\ 0 & \begin{array}{l}\text { Release will be modeled using meteorological dispersion data. } \\ \text { A } 5001 \text { line will immediately follow the } 5000 \text { line. }\end{array} \\ 1 & \begin{array}{l}\text { Release will be into a building/room. A } 5500 \text { line will } \\ \text { immediately follow the } 5000 \text { line. }\end{array}\end{array}$

\subsubsection{General Meteorological Information Line (5001)}

\begin{tabular}{|c|c|c|c|}
\hline Word & $\begin{array}{l}\text { Variable } \\
\text { Name }\end{array}$ & $\underline{\text { Entry }}$ & Description \\
\hline 1 & & 5001 & \\
\hline 2 & UBAR & & Average wind velocity $(\mathrm{m} / \mathrm{s})$ \\
\hline 3 & $\mathrm{SH}$ & & $\begin{array}{l}\text { Stack height }(\mathrm{m}) \text {. Typical stack heights are at least } \\
2.5 \text { times the building height. }\end{array}$ \\
\hline 4 & $\mathrm{H}$ & & Mixing layer depth (m). If zero, defaults to $400 \mathrm{~m}$. \\
\hline 5 & ADEN & & $\begin{array}{l}\text { Air density }\left(\mathrm{g} / \mathrm{m}^{3}\right) \text {. If zero, defaults to } 1.099 \mathrm{E}+3 \text { (average } \\
\text { density for } 5000 \mathrm{ft} \text {. altitude). }\end{array}$ \\
\hline 6 & AMBDA & & $\begin{array}{l}\text { Wet deposition scavenging coefficient }(1 / \mathrm{s}) \text {. Set equal to zero } \\
\text { when no plume depletion by wet deposition is desired. This } \\
\text { coefficient simulates rainout of the plume and will very quickly } \\
\text { deplete the release. Values for wet deposition scavenging } \\
\text { coefficient range from } 4.0 \text { E- } 6 \text { to } 3.0 \mathrm{E}-3 \mathrm{~s}^{-1} \text { with a median } \\
\text { value of } 1.5 \mathrm{E}-4 \text {. Avoid too large a value to prevent plume } \\
\text { overdepletion. }\end{array}$ \\
\hline 7 & SW1 & Integer & Plume depletion by dry deposition: \\
\hline & & 0 & No \\
\hline & & 1 & Yes \\
\hline
\end{tabular}




\subsubsection{Deposition Velocities Line (5002)}

Entering this line is optional. However, the line must be present if you are making ingestion or ground surface dose calculations.

$\begin{array}{llll}\underline{\text { Word }} & \begin{array}{l}\text { Variable } \\ \text { Name }\end{array} & \underline{\text { Entry }} & \underline{\text { Description }} \\ 1 & & 5002 & \text { Deposition velocity }(\mathrm{m} / \mathrm{s}) \text { for: } \\ 2 & \text { DV(1) } & \text { Solids } \\ 3 & \text { DV(2) } & \text { Halogens } \\ 4 & \text { DV(3) } & \text { Noble gases } \\ 5 & \text { DV(4) } & \text { Cesium } \\ 6 & \text { DV(5) } & \text { Ruthenium }\end{array}$

\subsubsection{Downwind Distance Lines (5101+)}

\begin{tabular}{lcll}
\multicolumn{1}{l}{ Word } & $\begin{array}{l}\text { Variable } \\
\text { Name }\end{array}$ & Entry & Description \\
1 & & Integer & $510 \mathrm{X}(\mathrm{X}=1,2, \ldots$, etc. $)$ \\
2 & DIE(1) & & \\
$\cdot$ & $\cdot$ & & \\
$\cdot$ & $\cdot$ & & \\
$\cdot$ & $\cdot$ & & \\
$\mathrm{N}$ & $\mathrm{DIE}(\mathrm{N})$ &
\end{tabular}

Enter a maximum of eight downwind distances. The valid range of downwind distances is 10 to 1.E+5 $\mathrm{m}$. Diffusion for distances less than $1 . \mathrm{E}+2 \mathrm{~m}$ is extrapolated. 


\subsubsection{Leakage Decay Constants Lines (5201+)}

Use leakage decay constants to calculate the radionuclide inventory decay before release to the environment. When the radionuclide inventory decay has already been corrected to the actual amount to be released, treat the release as an instantaneous release as described below to avoid double decay.
Variable
$\underline{\text { Word Name }}$ Entry Description
1
Integer $52 \mathrm{XX}(\mathrm{XX}=01,02, \ldots$, etc. $)$
$2 \quad \mathrm{~K} 1(1)$
Linear constant in the leakage rate function $\left(\mathrm{s}^{-1}\right)$
$3 \quad \mathrm{~K} 2(1)$
Exponential constant in leakage rate function $\left(\mathrm{s}^{-1}\right)$

Enter additional sets of two values on this and following lines up to a maximum of 10 sets.

Values of $\mathrm{K} 1$ and $\mathrm{K} 2$ can be either positive or negative. If a constant leakage is desired, set K2 = 0 and $\mathrm{K} 1=$ the reciprocal of the time that it takes for the activity to be released to the atmosphere. The use of one set of leakage constants is normally sufficient for most calculations.

When an instantaneous release is desired, enter only one set of leakage constants and set $\mathrm{K} 1=1$., $\mathrm{K} 2$ $=0$., and the exposure time to the plume to 1 second.

When decay correction is desired for a constant release, set $\mathrm{K} 1=$ the reciprocal of the release time (s), $\mathrm{K} 2=0$, and the decay time for the leakage rate function $=$ the time (s) over which the release occurs [see Appendix A, Equation (A-28)].

When an exponential release as a function of time is desired, set $\mathrm{K} 2=1 / \mathrm{T}_{\mathrm{h}}$, where $\mathrm{T}_{\mathrm{h}}$ is the release half-time (s) for the exponential decay function. K1 can be calculated using the following equation:

$$
\mathrm{K} 1=\frac{\mathrm{L}_{\mathrm{f}} \mathrm{K} 2}{1 .-\mathrm{e}^{-\mathrm{K} 2 \mathrm{~T}}}
$$

where $L_{f}$ is the fraction of the total source volume to be released over the time $T(s)$.

Decay times for the leakage rate function used with these constants are entered on lines (6001), (7001), (8020), and (9000) lines. An option is provided for the program to automatically calculate the necessary decay times to give a $100 \%$ release if only one set of constants is entered $(\mathrm{K} 1>0$ and $\mathrm{K} 1>$ $\mathrm{K} 2$ ). When these conditions are not met, you must directly enter the decay time for the leakage rate function. It is important not to decay the radionuclide inventory twice before its release to the atmosphere. This can inadvertently occur when the total activity of each radionuclide to be released to the atmosphere over an extended period of time is entered directly into RSAC-7 rather than using RSAC7 to calculate the radionuclide inventory. When this is the case, no additional decay of the activity before release is desired even though the total activity entered may represent a release over an extended period of time. 


\subsubsection{Crosswind Distance Lines (5301+)}

You can omit these lines if no crosswind calculations are desired.

$\begin{array}{llll}\underline{\text { Word }} & \begin{array}{l}\text { Variable } \\ \text { Name }\end{array} & \text { Entry } & \underline{\text { Description }} \\ 1 & & \text { Integer } & 53 \mathrm{XX}(\mathrm{XX}=01,02, \ldots, \text { etc. }) \\ 2 & \text { ELB(1) } & & \\ \cdot & & \text { Crosswind distance (m) } \\ \cdot & & \\ \text { N } & \text { ELB(N-1) }\end{array}$

Additional values on this and following lines are entered up to a maximum of 15 crosswind distances.

\subsubsection{Diffusion Control Line (5400)}

\begin{tabular}{|c|c|c|c|}
\hline Word & $\begin{array}{l}\text { Variable } \\
\text { Name }\end{array}$ & Entry & Description \\
\hline 1 & & 5400 & \\
\hline \multirow[t]{3}{*}{2} & NTRL & 1 & $\begin{array}{l}\text { A set of standard deviations of plume concentrations is entered } \\
\text { on the Standard Deviation Lines }(5401+) \text { for each downwind } \\
\text { distance. }\end{array}$ \\
\hline & & 2 & $\begin{array}{l}\text { Program-calculated standard deviations of plume } \\
\text { concentration. A (5410) line will immediately follow this line. }\end{array}$ \\
\hline & & 3 & $\begin{array}{l}\chi / \mathrm{Q} \text { values are input directly. The remainder of this line is } \\
\text { ignored, and } \chi / \mathrm{Q} \text { values are read from }(542 X) \text { lines. }\end{array}$ \\
\hline 3 & DUMMY & & Building width (m) (Smallest representative width). \\
\hline 4 & DUMMZ & & Building height $(\mathrm{m})$ (Smallest representative height). \\
\hline
\end{tabular}




\subsubsection{Standard Deviation Lines (5401+)}

Enter these lines only if word 2 on the Diffusion Control Line (5400) is equal to 1.

\begin{tabular}{|c|c|c|c|}
\hline Word & $\begin{array}{l}\text { Variable } \\
\text { Name }\end{array}$ & Entry & Description \\
\hline 1 & & Integer & $540 X(X=1,2, \ldots$, etc. $)$ \\
\hline 2 & $\operatorname{SIGY(1)}$ & & $\begin{array}{l}\text { The horizontal dispersion standard deviation for the first } \\
\text { downwind distance }(\mathrm{m}) \text {. }\end{array}$ \\
\hline 3 & SIGZ(1) & & $\begin{array}{l}\text { The vertical dispersion standard deviation for the first } \\
\text { downwind distance }(\mathrm{m}) \text {. }\end{array}$ \\
\hline
\end{tabular}

Enter additional sets of standard deviations on this and following lines for the additional downwind distance until values have been entered corresponding to each downwind position entered on the $(5100+)$ lines above. A set of standard deviations must be entered for each downwind distance. 


\subsubsection{Plume Standard Deviation Control Line (5410)}

Enter this line only if word 2 on the Diffusion Control Line (5400) is 2. See Appendix C for information on the different sets of $\sigma \mathrm{s}$ that are available. Hilsmeier-Gifford $\sigma \mathrm{s}$ (Clawson et al. 1989) should be used for desert terrains (such as the Idaho National Laboratory) for effluent releases from a few minutes to 15 minute in duration. Markee $\sigma s$ (Clawson et al. 1989) should be used for desert terrains for effluent releases from 15 to 60 minute in duration. Pasquill-Gifford $\sigma$ s were developed from the Prairie Grass experiments for effluent releases from 10 to 60 minutes in duration. The Pasquill-Gifford $\sigma$ s are presented in Regulatory Guide 1.145 (NRC 1982) and by Slade (1968). Carefully evaluate the appropriateness of using the program-generated $\sigma \mathrm{s}$ for effluent releases of different durations than noted above. When you consider the program-generated os inappropriate, word 2 on the Diffusion Control Line (5400) should be set to 1 , and os should be entered directly using the (540X) lines.

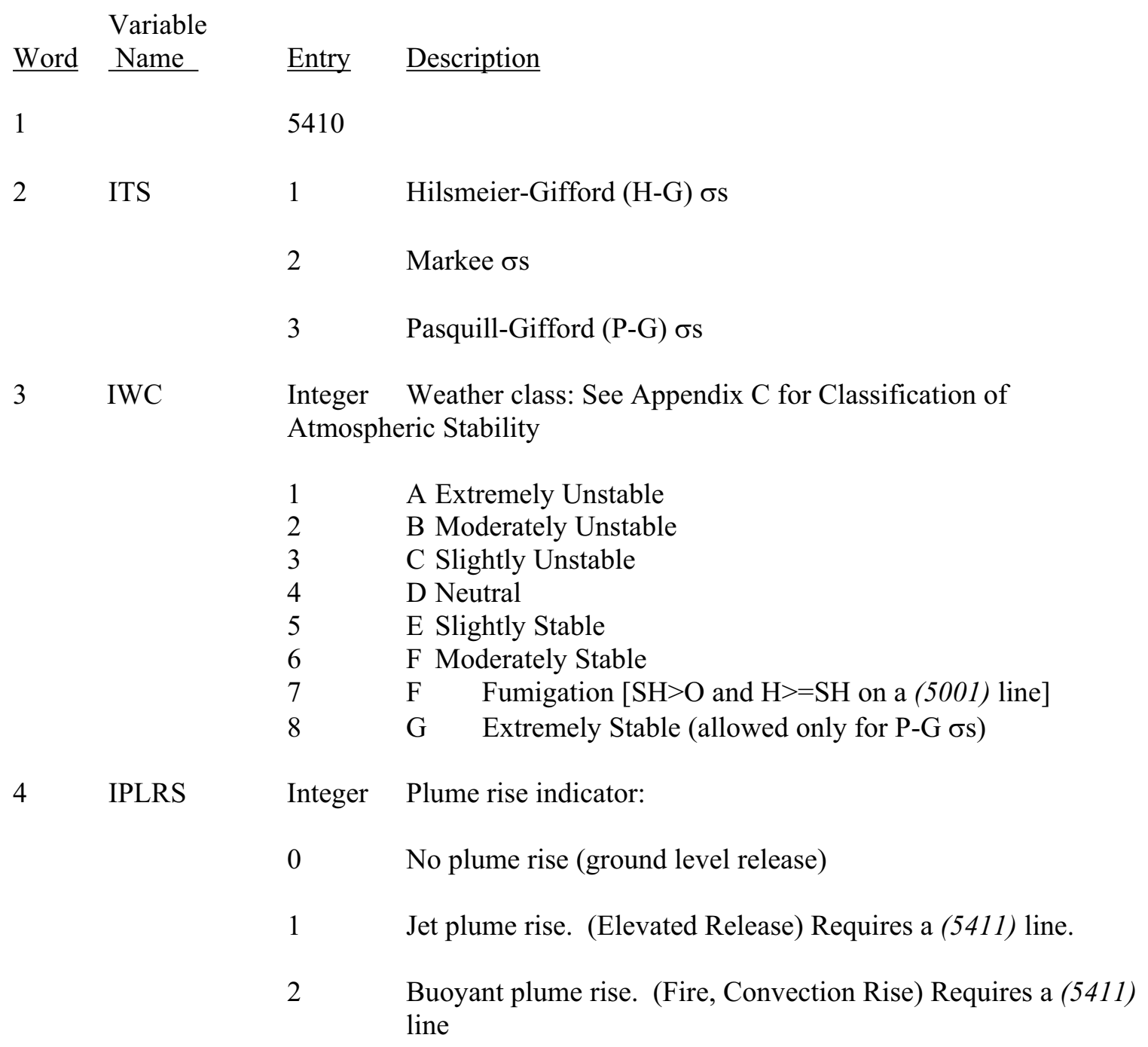

Add a 5th word to Line 5410

$\underline{\text { Word }} \quad \underline{\text { Description }}$

$5 \quad$ Plume meander. If 0 , defaults to 1. 


\subsubsection{Plume Rise Control Line (5411)}

The (5411) line is present only when word 4 on the (5410) line is not equal to 0.

Variable

$\underline{\text { Word Name }} \underline{\text { Entry }}$ Description

1

5411 Plume rise parameters:

$2 \quad$ SDIA

Internal stack diameter (m).

$3 \mathrm{RS}$

Restoring acceleration $\left(\mathrm{s}^{-2}\right)$. If zero, defaults to program calculated values of 8.7E-4 $\left(\mathrm{s}^{-2}\right)$ for a weak inversion and $1.75 \mathrm{E}-3\left(\mathrm{~s}^{-2}\right)$ for a strong inversion.

$4 \quad$ WO

Effluent velocity of gases from the stack $(\mathrm{m} / \mathrm{s})$.

$5 \quad \mathrm{QH}$

Stack gasses heat emission (cal/s) for buoyant plume rise. Enter zero for jet plume. 


\subsubsection{Direct $\chi / Q$ Input Lines (5421+)}

Enter these lines only if word 2 on the Diffusion Control Line (5400) is 3. Cloud gamma calculations using the finite plume model and plume depletion by ground deposition are not allowed when using this option.

\begin{tabular}{|c|c|c|c|}
\hline$\underline{\text { Word }}$ & $\begin{array}{l}\text { Variable } \\
\text { Name } \\
\end{array}$ & Entry & $\underline{\text { Description }}$ \\
\hline 1 & & Integer & $542 \mathrm{X}(\mathrm{X}=1,2, \ldots$, etc. $)$ \\
\hline 2 & & CQ & $\chi / \mathrm{Q}$ for the lst downwind distance \\
\hline$\cdot$ & & $\cdot$ & \\
\hline$\cdot$ & & · & \\
\hline$\cdot$ & & & \\
\hline $\mathrm{N}$ & & CQ & $\chi / \mathrm{Q}$ for the $\mathrm{N}^{\text {th }}$ downwind distance \\
\hline
\end{tabular}

Enter additional values on this and following line for each downwind distance entered on the (5101) line. A (5999) line must immediately follow the input of the (542X)lines.

\subsubsection{Dispersion to Building/Room Line (5500)}

Enter the volume in cubic meters of the building/room in which the release will occur. Input the exposure time for an individual in the room on a 7001 line.

$\begin{array}{llll}\underline{\text { Word }} & \begin{array}{l}\text { Variable } \\ \text { Name }\end{array} & \text { Entry } & \text { Description } \\ 1 & & 5500 & \\ 2 & \text { ROOMVOL } & & \text { Volume }\left(\mathrm{m}^{3)}\right.\end{array}$

\subsubsection{Meteorological Data End Line (5999)}

Use this line to end the meteorological data input and calculations as requested by the Meteorological Control Line (5000).

Word Entry

$1 \quad 5999$




\subsection{5 $\quad 6000$ Series - Radionuclide Inventory Decay for Printout}

This series is used only to calculate the radionuclide inventory decay for printout. Radionuclide decay for subsequent dose calculations must be calculated in the 1000 Series. Use the Decay Control Line (6000) to initiate radionuclide inventory decay calculations. Decay of either the entire radionuclide inventory or selected radionuclides can be calculated. Decay times can be entered directly with Decay Times Lines $(6101+)$ or they can be established from the 5000 Series meteorological downwind data lines. Individual radionuclides selected are printed. If desired, rather than printing the entire radionuclide inventory you can select other printout options.

\subsubsection{Decay Control Line (6000)}

\begin{tabular}{|c|c|c|c|}
\hline$\frac{\text { Word }}{1}$ & $\begin{array}{l}\text { Variable } \\
\text { Name } \\
\end{array}$ & $\frac{\text { Entry }}{6000}$ & Description \\
\hline \multirow[t]{3}{*}{2} & $\mathrm{NCH}$ & Integer & Printout control: \\
\hline & & 0 & $\begin{array}{l}\text { Decay of radionuclides in the RSAC-7 library will be } \\
\text { calculated. }\end{array}$ \\
\hline & & 1 & $\begin{array}{l}\text { Only radionuclides selected following a (6021) line will be } \\
\text { printed. }\end{array}$ \\
\hline \multirow[t]{5}{*}{3} & ISW2 & Integer & Printout options: \\
\hline & & 0 & No individual radionuclide inventories are printed. \\
\hline & & -1 & $\begin{array}{l}\text { Print all fission products and any activation products, actinides, } \\
\text { and daughters of actinides with positive values. }\end{array}$ \\
\hline & & 1 & $\begin{array}{l}\text { Same as }-1 \text { option except suppress short-lived fission products } \\
\text { that have no available dose conversion factors. }\end{array}$ \\
\hline & & 2 & $\begin{array}{l}\text { Print inventory of radionuclides that have positive values at or } \\
\text { following the first requested decay time. }\end{array}$ \\
\hline \multirow[t]{4}{*}{4} & ISW & Integer & Units control word: \\
\hline & & 0 & Curies \\
\hline & & 1 & $\mathrm{MeV} / \mathrm{s}$ (gamma only) \\
\hline & & 2 & Grams \\
\hline \multirow[t]{3}{*}{5} & LEAK & Integer & Exponential leakage option \\
\hline & & 0 & No exponential leakage corrections are included. \\
\hline & & 1 & $\begin{array}{l}\text { Correction for exponential leakage decay included. A ( } 6001) \\
\text { line must immediately follow this line. This option provides an } \\
\text { inventory of the radionuclides reaching a downwind location }\end{array}$ \\
\hline
\end{tabular}


following a release that varies exponentially as a function of time.

\subsubsection{Decay Time for Leakage Rate Function (6001)}

Use this line only when LEAK on the (6000) line is equal to 1

\begin{tabular}{|c|c|c|c|}
\hline$\underline{\text { Word }}$ & $\begin{array}{l}\text { Variable } \\
\text { Name } \\
\end{array}$ & Entry & Description \\
\hline 1 & & 6001 & \\
\hline 2 & $\mathrm{~T}$ & & $\begin{array}{l}\text { Decay time (s) for the exponential decay function. If zero, } \\
\text { defaults to the time necessary to give } 100 \% \text { release. }\end{array}$ \\
\hline
\end{tabular}

\subsubsection{Leakage Decay Constants (6002+)}

Use these lines only when the exponential leakage option is requested (i.e., LEAK $=1$ ). You can omit these lines if leak rate exponentials have been previously entered with $(5201+)$ lines.

$\begin{array}{llll}\underline{\text { Word }} & \begin{array}{l}\text { Variable } \\ \text { Name }\end{array} & \text { Entry } & \underline{\text { Description }} \\ 1 & & \text { Integer } & 60 \mathrm{XX}(\mathrm{XX}=02,03, \ldots, \text { etc. }) \\ 2 & \mathrm{~K} 1(1) & & \text { Linear constant in leak rate function }\left(\mathrm{s}^{-1}\right) \\ 3 & \mathrm{~K} 2(1) & & \text { Exponential constant in leak rate function }\left(\mathrm{s}^{-1}\right)\end{array}$

Enter additional sets of two values on this and following lines up to a maximum of 10 sets. 


\title{
4.2.5.4 Radionuclide Selection Option Line (6021)
}

This line is required only if $\mathrm{NCH}$ (word 2) entered on the Decay Control Line (6000) is equal to 1. This line is followed by additional lines described as following:

\author{
Variable \\ $\underline{\text { Word Name }}$ Entry Description \\ 1 NUCL Integer Radionuclide identification number (see Series 4000, \\ Radionuclide Data Change Line). An alternate entry can be \\ made by replacing NUCL with the element symbol followed by \\ the mass number and metastable state indicator. Examples of \\ allowable styles include: \\ Cs137, Cs-137, Cs 137 \\ Ba137m, Ba-137m, Ba 137m \\ CS137, CS-137, CS 137 \\ BA137M, BA-137M, BA 137M
}

Make additional line entries until all desired radionuclides have been entered into the radionuclide inventory. A (6101) or (6999) line must follow last radionuclide identification entered.

\subsubsection{Decay Times Lines (6101+)}

You can omit these lines if decay times have been established using the $(5001+)$ lines.

\begin{tabular}{|c|c|c|c|}
\hline$\underline{\text { Word }}$ & $\begin{array}{l}\text { Variable } \\
\text { Name } \\
\end{array}$ & $\underline{\text { Entry }}$ & $\underline{\text { Description }}$ \\
\hline 1 & & Integer & $61 \mathrm{XX}(\mathrm{XX}=01,02, \ldots$, etc. $)$ \\
\hline 2 & IUNIT & Integer & $\begin{array}{l}\text { Decay time unit: } \\
\begin{array}{l}1=\text { Second } \\
2=\text { Minute } \\
3=\text { Hour } \\
4=\text { Day } \\
5=\text { Year }\end{array}\end{array}$ \\
\hline 3 & $\operatorname{TIME}(2)$ & & Decay time \\
\hline . & . & & \\
\hline . & . & & \\
\hline $\mathrm{N}$ & TIME(N-1) & & \\
\hline
\end{tabular}

Enter additional values on this and following lines up to a maximum of eight values. When you want to see all of the output data on an unshifted screen or printed on a standard 80-column page, a maximum of three decay times should be entered on each 6000 Series input. 


\subsubsection{Summation Control Line (6200)}

This line is present only if the entire radionuclide inventory decay is calculated and it can be deleted if desired. A summation of the radionuclide inventory by group (solids, halogens, noble gases, cesium, and ruthenium) and/or by element can be printed. If summation by element is requested, enter the Element Summation Lines (6201+) next, selecting the elements to be summed.

\begin{tabular}{|c|c|c|}
\hline Word & Entry & Description \\
\hline 1 & 6200 & \\
\hline 2 & & Group summation control word: \\
\hline \multirow{5}{*}{3} & 0 & No summation or printout. \\
\hline & 1 & $\begin{array}{l}\text { The fission product inventory for each group (solids, halogens, } \\
\text { noble gases, cesium, and ruthenium) is summed and printed. }\end{array}$ \\
\hline & Integer & Element summation control word: \\
\hline & 0 & No summation or printout. \\
\hline & 1 & $\begin{array}{l}\text { The radionuclide inventory is summed for each element } \\
\text { selected by the Element Summation Lines }(6201+) \text { that follow. }\end{array}$ \\
\hline
\end{tabular}

\subsubsection{Element Summation Lines (6201+)}

These lines are required only if the entire radionuclide inventory decay is calculated and if the element summation option on the Summation Control Line (6200) is chosen. Enter any number of these lines.

$\begin{array}{lll}\text { Word } & \text { Entry } & \text { Description } \\ 1 & \text { Integer } & 62 \mathrm{XX}(\mathrm{XX}=01,02, \ldots, \text { etc. }) . \\ 2 & \text { Integer } & \text { Atomic number of element to be summed. }\end{array}$

Enter additional words on this and following lines until the desired elements have been selected for summation.

\subsubsection{Decay End Line (6999)}

Use this line to end the fission product inventory decay and printout as requested by the Decay Control Line (6000).

$\underline{\text { Word }} \quad \underline{\text { Entry }}$

$1 \quad 6999$




\subsubsection{Series - Internal/External Dose Calculation}

Use the initial line of this series to establish the type of dose calculation to be made and the amount of output data. Air-immersion doses are calculated using dose-rate conversion factors from Federal Guidance Report 12 (Eckerman 1993) developed for a semi-infinite plume. Use caution to ensure that the plume size is large compared to the mean free path of the gamma rays. If there is any doubt, make cloud gamma calculations (see 9000 Series in this section) using both the finite plume model and the semi-infinite plume model and ensure that the doses are converged.

\subsubsection{Dose Calculation Control Line 1 (7000)}

\begin{tabular}{|c|c|c|c|}
\hline Word & $\begin{array}{l}\text { Variable } \\
\text { Name } \\
\end{array}$ & $\underline{\text { Entry }}$ & Description \\
\hline 1 & & 7000 & \\
\hline \multirow[t]{10}{*}{2} & \multirow[t]{10}{*}{ IMOD } & Integer & Type of calculation: \\
\hline & & 1 & Inhalation, program default parameters. \\
\hline & & 2 & Inhalation, user-supplied parameters on the (7003) line. \\
\hline & & 3 & Ingestion, default to program calculated chronic parameters. \\
\hline & & 4 & Ingestion with user supplied parameters on the (7004) line. \\
\hline & & 5 & Ground surface. \\
\hline & & 6 & Air immersion (see caution above). \\
\hline & & \multicolumn{2}{|r|}{ Mortality risk, add 10 to the above values of IMOD. } \\
\hline & & \multicolumn{2}{|r|}{ Morbidity risk, add 20 to the above values of IMOD. } \\
\hline & & \multicolumn{2}{|r|}{ Resuspended Activity, enter IMOD as a negative value. } \\
\hline \multirow[t]{6}{*}{3} & \multirow[t]{6}{*}{ ISW } & Integer & Output control: \\
\hline & & -2 & Only dose summaries by organ. \\
\hline & & -1 & Only total organ doses. \\
\hline & & 0 & Above plus doses for each element. \\
\hline & & 1 & Above plus doses for each radionuclide. \\
\hline & & 2 & Above plus dose summary tables by organ. \\
\hline
\end{tabular}


IDU Integer Dose unit:

$1 \quad$ rem

$2 \mathrm{~Sv}$

$5 \quad \mathrm{NCH} \quad$ Integer Number of elements for which calculation is done:

$0 \quad$ All elements.

$1 \quad$ As indicated on Optional Element Selection Lines $(7081+)$.

6 IONC Integer Organ number choice:

1 Default to all organs.

2 As indicated on the Optional Selection of Organs Line (7002).

7 AGE Inhalation/Ingestion Mortality/Morbidity intake age age group

ICRP-72 model

$0 \quad$ All ages All age groups

13 months $\quad 0-5$ years

$2 \quad 1$ year $\quad 5-15$ years

35 years $\quad 15-25$ years

$4 \quad 10$ years $\quad 25-70$ years

$5 \quad 15$ years $\quad 0-110$ years

$6 \quad$ Adult

7 Adult Worker, ICRP-68 model (inhalation only)

$8 \quad$ Acute inhalation dose (inhalation only)

$9 \quad$ ICRP-30 model

If word two, IMOD, was entered as 'ground surface' or 'air immersion' calculation, then the final word in this line, 'age,' is not used in any calculations. However, this word must be present. It is suggested that you use ' 0 ' for this value, though integers 1-9 would have the same results.

A special test option has been added to print out the actual dose conversion factors used in RSAC-7. This is initiated by putting -201 in word 4 of Line 7001 for the variable TB. This should be very useful for performing V\&V. The place to look closely is for the elements with special chemical forms. 


\subsubsection{Dose Calculation Control Line 2 (7001)}

\begin{tabular}{|c|c|c|c|}
\hline$\underline{\text { Word }}$ & $\begin{array}{l}\text { Variable } \\
\text { Name } \\
\end{array}$ & Entry & Description \\
\hline 1 & & 7001 & \\
\hline 2 & BREATH & & $\begin{array}{l}\text { Breathing rate }\left(\mathrm{m}^{3} / \mathrm{s}\right) \text { for inhalation calculations. If zero, } \\
\text { defaults to } 3.33 \mathrm{E}-4 \text {. Use } 2.66 \mathrm{E}-4 \text { for } 24 \text {-h average breathing } \\
\text { rate. }\end{array}$ \\
\hline 3 & TINHA & & $\begin{array}{l}\text { Release to atmosphere: } \\
\text { Decay time (s) for the exponential decay function (see } \\
\text { Appendix A, "Leakage Rate Function"). If zero, defaults to } \\
\text { the time necessary to give } 100 \% \text { release. }\end{array}$ \\
\hline & & & $\begin{array}{l}\text { Release to building: } \\
\text { Time that receptor is exposed (s). If zero, defaults to } 60 \mathrm{~s} \text {. }\end{array}$ \\
\hline 4 & $\mathrm{~TB}$ & & $\begin{array}{l}\text { Values for the term "TB" depend the type of calculation } \\
\text { being made: }\end{array}$ \\
\hline & & & $\begin{array}{l}\text { For acute releases: TB is the number of years that crops are } \\
\text { grown on the contaminated soil. TB should be } 1 . \text { year for } \\
\text { dose during the year of intake. Values greater than } 1 . \text { year } \\
\text { give the dose from growing crops on the contaminated soil } \\
\text { for the specified number of years. If zero, defaults to } \\
15 \text { years. }\end{array}$ \\
\hline & & & $\begin{array}{l}\text { Ingestion from chronic release: For chronic releases, TB is } \\
\text { the years of long-term buildup of activity in the soil. TB } \\
\text { should be equal to the plant mid-point of operating life (y). If } \\
\text { zero, defaults to } 15 \text { years. }\end{array}$ \\
\hline & & & $\begin{array}{l}\text { Ground surface: TB is the time in years that the receptor is } \\
\text { exposed to the contaminated ground surface following } \\
\text { initiation of the release. If }>0 \text { and }<1 \text {, a warning will be given } \\
\text { that an exposure period of }<1 \text { year has been chosen. If zero, } \\
\text { defaults to } 1 \text { year. }\end{array}$ \\
\hline 5 & BS & & $\begin{array}{l}\text { Building shielding factor for ground surface dose calculations. } \\
\text { If zero, defaults to } 0.7 \text {. }\end{array}$ \\
\hline 6 & OCFACT & & $\begin{array}{l}\text { Occupancy factor for ground surface dose calculations } \\
\text { (entry of word is optional). If zero, defaults to } 1.0 \text {. }\end{array}$ \\
\hline
\end{tabular}




\subsubsection{Optional Selection of Organs Line (7002)}

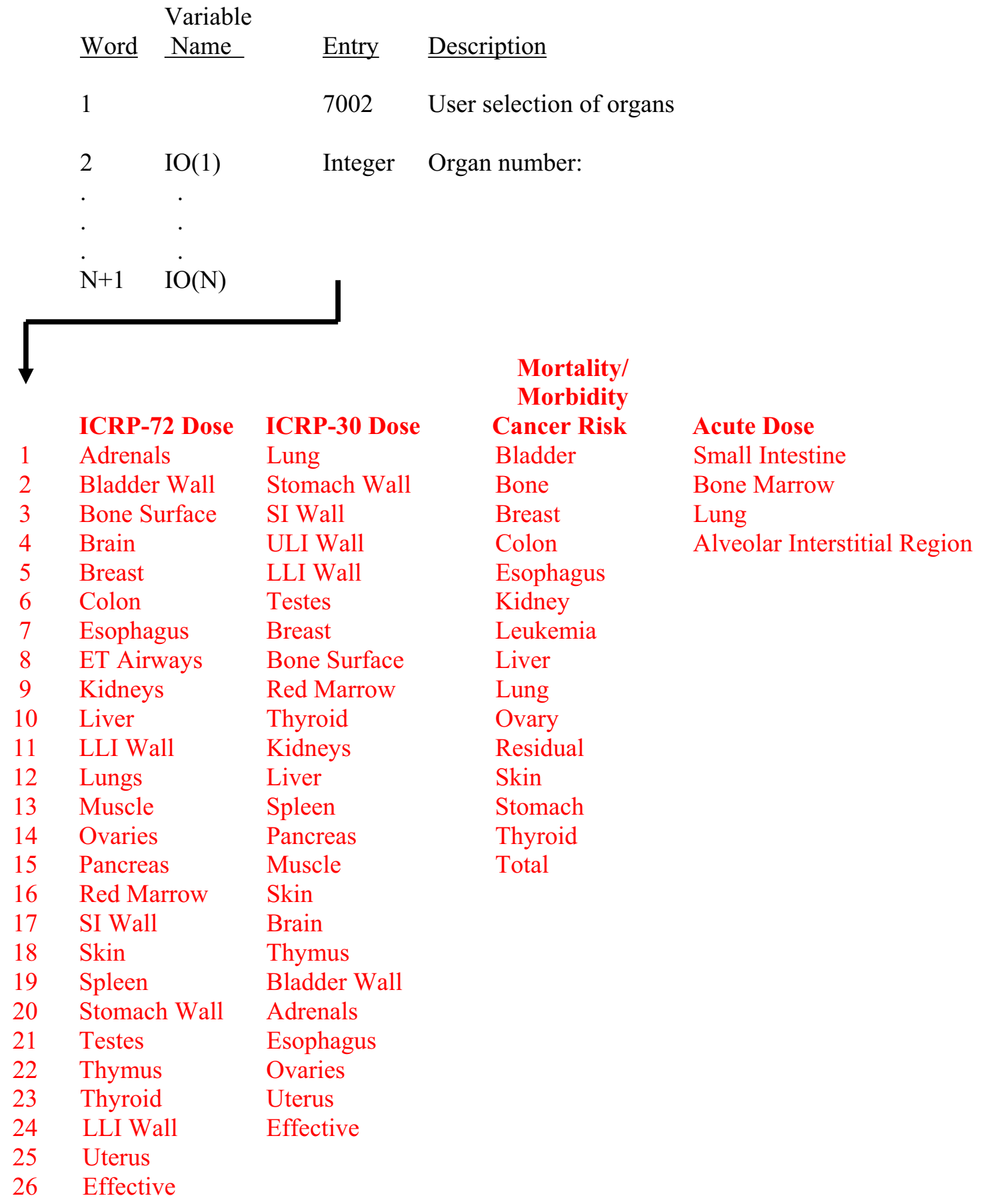

Line 7003

AMAD only is used with the ICRP-30 model. A value must be present, but it is ignored in other calculations. Default to 0 . 


\subsubsection{Optional Inhalation Dose Calculation Control Line (7003)}

This line is present only if IMOD (word 2) on the (7000) line is 1.

\begin{tabular}{|c|c|c|c|}
\hline Word & $\begin{array}{l}\text { Variable } \\
\text { Name }\end{array}$ & Entry & $\underline{\text { Description }}$ \\
\hline 1 & & 7003 & User-supplied inhalation parameters. \\
\hline 2 & AMAD & & $\begin{array}{l}\text { Activity median aerodynamic diameter }(\mu \mathrm{m}) \text {. If zero, defa } \\
\text { to } 1 \text {. AMAD must be } \geq 0.1 \mu \mathrm{m} \text {. }\end{array}$ \\
\hline \multirow[t]{5}{*}{3} & ICCI & & Clearance class indicator: \\
\hline & & 1 & $\begin{array}{l}\text { Default to program-generated classes for oxides and } \\
\text { hydroxides. }\end{array}$ \\
\hline & & 2 & $\begin{array}{l}\text { User input of classes on }(703 X) \text { lines. Unchanged classes } \\
\text { default to those for oxides and hydroxides. }\end{array}$ \\
\hline & & 3 & $\begin{array}{l}\text { Default to program-generated classes selected to give } \\
\text { maximum element dose. }\end{array}$ \\
\hline & & 4 & $\begin{array}{l}\text { User input of classes on }(703 X) \text { lines. Unchanged classes } \\
\text { default to those selected to give maximum element dose. }\end{array}$ \\
\hline
\end{tabular}

\subsubsection{Optional Ingestion Dose Calculation Control Line (7004)}

This line is present only if IMOD (word 2) on the (7000) line is 3.

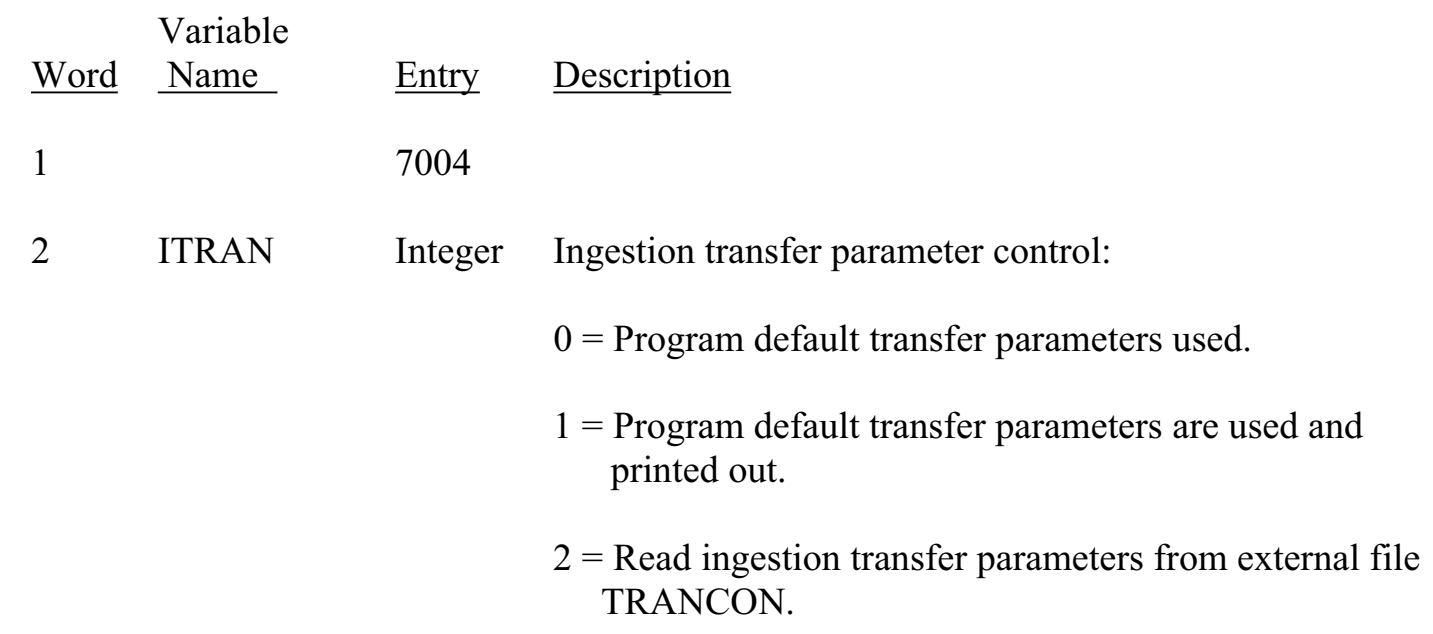


3

ITYPE Integer User control for ingestion calculations

$0=$ Chronic release with program default parameters

$1=$ Acute release with program default parameters.

$2=$ User-supplied ingestion parameters on (705X) lines.

4 ATIME

Time period (d) that crops are exposed to contamination during the growing season. A time period of $\geq 60$ days signifies a chronic release with vegetable and forage exposure times to the plume as indicated in Series 7000, Ingestion Constants Line 3 (7052). A time period of $<60$ days signifies an acute release.

ITYPE $=0$. Variable not used.

ITYPE $=1$. Time must be between 0.04167 day (1. hour) and $<60$. day.

ITYPE $=2$. If zero or $>60$., defaults to 60. days. Otherwise, must not be $<0.04167$.

$5 \quad$ THD

Harvest duration time period $(0 . \leq \mathrm{THD}<60$.) following an acute release (d). If zero, defaults to 7 days. When the sum of ATIME and THD exceeds ETV [see (7052) line], the program automatically decreases the value input for THD to give a sum of ETV days for produce calculations. The program also automatically calculates a value for THD for forage calculations so that the sum of ATIME and THD do not exceed the value of ETM [see (7052) line].

\subsubsection{Optional Clearance Class by Element Lines (7031+)}

These lines are present only if ICCI (word 3) on the (7003) line is equal to 2. Make entries in pairs of two: the element's atomic number followed by the clearance class code. Refer to Appendix D for valid clearance classes.

\begin{tabular}{|c|c|c|c|}
\hline Word & $\begin{array}{l}\text { Variable } \\
\text { Name }\end{array}$ & Entry & Description \\
\hline 1 & & Integer & $703 X(X=1,2, \ldots$, etc. $)$. \\
\hline 2 & $\mathrm{NN}$ & Integer & Atomic number for element. \\
\hline 3 & $\mathrm{ICI}(\mathrm{NN})$ & $\begin{array}{l}\text { Integer } \\
1 \\
2 \\
3\end{array}$ & $\begin{array}{ll}\text { ICRP-72 } & \text { ICRP-30 } \\
\text { Type F } & \text { Class D } \\
\text { Type M } & \text { Class W } \\
\text { Type S } & \text { Class Y }\end{array}$ \\
\hline
\end{tabular}

Enter as many pairs of entries on this or following lines as desired. 


\subsubsection{Optional Ingestion Dose Constants Lines (7051+)}

These lines are present only if ITYPE (word 3) on the (7004) line is equal to 2.

Ingestion Constants Line 1 (7051)

\begin{tabular}{|c|c|c|c|c|}
\hline Word & $\begin{array}{l}\text { Variable } \\
\text { Name } \\
\end{array}$ & $\underline{\text { Description }}$ & $\begin{array}{l}\text { Default } \\
\text { Value } \\
\end{array}$ & $\begin{array}{c}\text { Variable } \\
\text { Name } \\
\end{array}$ \\
\hline 1 & & 7051 & & \\
\hline 2 & UFSV & $\begin{array}{l}\text { Stored vegetable } \\
\text { usage factor } \\
\text { (kg/yr wet weight) }\end{array}$ & 520. & $\mathrm{U}^{\mathrm{v}}$ \\
\hline 3 & UFFV & $\begin{array}{l}\text { Fresh vegetable } \\
\text { usage factor } \\
\text { (kg/yr wet weight) }\end{array}$ & 64. & $\mathrm{U}^{\mathrm{L}}$ \\
\hline 4 & UFMP & $\begin{array}{l}\text { Meat usage factor } \\
\text { (kg/yr wet weight) }\end{array}$ & 110. & $\mathrm{U}^{\mathrm{F}}$ \\
\hline 5 & UFM & $\begin{array}{l}\text { Milk usage factor } \\
\text { (L/yr) }\end{array}$ & 310. & $\mathrm{U}^{\mathrm{m}}$ \\
\hline 6 & FG & $\begin{array}{l}\text { Fraction of stored } \\
\text { vegetables from } \\
\text { garden }\end{array}$ & 0.76 & $f_{g}$ \\
\hline 7 & FY & $\begin{array}{l}\text { Fraction of fresh } \\
\text { vegetables from } \\
\text { garden }\end{array}$ & 1.0 & $f_{1}$ \\
\hline
\end{tabular}

Ingestion Constants Line 2 (7052)

$\begin{array}{lllll}\text { Word } & \begin{array}{l}\text { Variable } \\ \text { Name }\end{array} & \text { Description } & \begin{array}{l}\text { Default } \\ \text { Value }\end{array} & \begin{array}{l}\text { Variable } \\ \text { Name }\end{array} \\ 1 & \text { RF1 } & \begin{array}{l}7052 \\ \text { Retention factor } \\ \text { for activity on } \\ \text { forage }\end{array} & 0.57 & \mathrm{r} \\ 3 & \text { RF2 } & \begin{array}{l}\text { Retention factor } \\ \text { for activity on } \\ \text { vegetables }\end{array} & 0.2 & \mathrm{r} \\ & & & \end{array}$




\begin{tabular}{|c|c|c|c|}
\hline 4 & RFI & $\begin{array}{l}\text { Retention factor } \\
\text { for iodines on } \\
\text { forage }\end{array}$ & 1.0 \\
\hline 5 & $\mathrm{RRC}$ & $\begin{array}{l}\text { Removal rate } \\
\text { constant for crops } \\
(1 / \mathrm{h})\end{array}$ & 0.0021 \\
\hline 6 & ETV & $\begin{array}{l}\text { Vegetable exposure } \\
\text { time to plume for } \\
\text { chronic release (d) }\end{array}$ & 60. \\
\hline 7 & ETM & $\begin{array}{l}\text { Forage exposure time } \\
\text { to plume for chronic } \\
\text { release }(d)\end{array}$ & 30. \\
\hline 8 & HRHT & $\begin{array}{l}\text { HTO removal half } \\
\text { time (d) }\end{array}$ & 1. \\
\hline
\end{tabular}

Ingestion Constants Line 3 (7053)

\begin{tabular}{|c|c|c|c|c|}
\hline Word & $\begin{array}{l}\text { Variable } \\
\text { Name } \\
\end{array}$ & $\underline{\text { Description }}$ & $\begin{array}{l}\text { Default } \\
\text { Value } \\
\end{array}$ & $\begin{array}{c}\text { Variable } \\
\text { Name } \\
\end{array}$ \\
\hline 1 & & 7053 & & \\
\hline 2 & SD & $\begin{array}{l}\text { Effective surface } \\
\text { density for soil } \\
\left(\mathrm{kg} / \mathrm{m}^{2}\right)\end{array}$ & 225. & $\mathrm{P}$ \\
\hline 3 & THS & $\begin{array}{l}\text { Stored vegetable } \\
\text { holdup time after } \\
\text { harvest }(\mathrm{d})\end{array}$ & 60. & $t_{h}$ \\
\hline 4 & THF & $\begin{array}{l}\text { Fresh vegetable } \\
\text { holdup time after } \\
\text { harvest }(\mathrm{d})\end{array}$ & 1. & $t_{h}$ \\
\hline 5 & QF & $\begin{array}{l}\text { Animals daily forage } \\
\text { feed }(\mathrm{kg} / \text { day dry } \\
\text { weight })\end{array}$ & 16. & $\mathrm{Q}_{\mathrm{F}}$ \\
\hline 6 & TRAN & $\begin{array}{l}\text { Feed-milk receptor } \\
\text { transfer time }(\mathrm{d})\end{array}$ & 2. & $t_{f}$ \\
\hline 7 & TSLA & $\begin{array}{l}\text { Slaughter to } \\
\text { consumption time (d) }\end{array}$ & 20. & $t_{c}$ \\
\hline
\end{tabular}


Ingestion Constants Line 4 (7054)

\begin{tabular}{|c|c|c|c|c|}
\hline Word & $\begin{array}{l}\text { Variable } \\
\text { Name }\end{array}$ & Description & $\begin{array}{l}\text { Default } \\
\text { Value }\end{array}$ & $\begin{array}{l}\text { Variable } \\
\text { Name }\end{array}$ \\
\hline 1 & & 7054 & & \\
\hline 2 & FPAST & $\begin{array}{l}\text { Fraction of year } \\
\text { that animals graze }\end{array}$ & 0.4 & $\mathrm{f}_{\mathrm{p}}$ \\
\hline 3 & FS & $\begin{array}{l}\text { Fraction of feed that } \\
\text { is pasture when animal } \\
\text { grazes on pasture }\end{array}$ & .43 & $\mathrm{f}_{\mathrm{s}}$ \\
\hline 4 & THSF & $\begin{array}{l}\text { Stored feed holdup } \\
\text { time (d) }\end{array}$ & 90. & $t_{h}$ \\
\hline 5 & VYV & $\begin{array}{l}\text { Vegetable vegetation } \\
\text { yield }\left(\mathrm{kg} / \mathrm{m}^{2} \text { wet }\right. \\
\text { weight })\end{array}$ & 2. & $\mathrm{Y}_{\mathrm{v}}$ \\
\hline 6 & VYM & $\begin{array}{l}\text { Forage vegetation } \\
\text { yield }\left(\mathrm{kg} / \mathrm{m}^{2} \text { dry }\right. \\
\text { weight })\end{array}$ & 0.28 & $\mathrm{Y}_{\mathrm{v}}$ \\
\hline 7 & HUM & $\begin{array}{l}\text { Absolute humidity } \\
\left(\mathrm{g} / \mathrm{m}^{3}\right)\end{array}$ & 4.9 & $\mathrm{H}$ \\
\hline
\end{tabular}

\subsubsection{Optional Acute Ingestion Constants Line 4 (7055)}

You can omit this line; however, when it is not entered, all acute ingestion constants are set equal to 1.

\begin{tabular}{|c|c|c|c|c|}
\hline Word & $\begin{array}{l}\text { Variable } \\
\text { Name } \\
\end{array}$ & Description & $\begin{array}{c}\text { Default } \\
\text { Value } \\
\end{array}$ & $\begin{array}{c}\text { Variable } \\
\text { Name }\end{array}$ \\
\hline 1 & & 7055 & & \\
\hline 2 & $\mathrm{AFG}$ & $\begin{array}{l}\text { Fraction of annual } \\
\text { stored vegetables } \\
\text { that are contaminated } \\
\text { by acute release }\end{array}$ & $\begin{array}{l}0.5^{\mathrm{a}} \\
1.0^{\mathrm{b}}\end{array}$ & $\mathrm{F}_{\mathrm{a}}$ \\
\hline 3 & $\mathrm{AFY}$ & $\begin{array}{l}\text { Fraction of annual } \\
\text { fresh vegetables } \\
\text { that are contaminated } \\
\text { by acute release }\end{array}$ & $\begin{array}{l}0.33^{\mathrm{a}} \\
0.67^{\mathrm{b}}\end{array}$ & $\mathrm{F}_{\mathrm{a}}$ \\
\hline
\end{tabular}


4

AFFS

5

AFFF
Fraction of annual

stored forage that

is contaminated by

acute release

Fraction of annual

fresh forage that is

contaminated by acute

release $0.5^{\mathrm{a}} \quad \mathrm{F}_{\mathrm{a}}$

$1.0^{\mathrm{b}}$

$0.33^{\mathrm{a}}$

$0.67^{\mathrm{b}}$

$\mathrm{F}_{\mathrm{a}}$

a. $\quad$ Crops exposed to contamination between 1 hour and $<30$ days.

b. Crops exposed to contamination between 30 days and $<60$ days.

\subsubsection{Optional Element Selection Lines (7081+)}

These lines are present only if word $5(\mathrm{NCH})$ on the (7000) line is greater than zero.

\begin{tabular}{|c|c|c|c|}
\hline$\underline{\text { Word }}$ & $\begin{array}{l}\text { Variable } \\
\text { Name }\end{array}$ & Entry & $\underline{\text { Description }}$ \\
\hline 1 & & Integer & $708 X(X=1,2, \ldots$, etc. $)$. \\
\hline 2 & NUMBER(1) & Integer & Atomic number of element \\
\hline$\cdot$ & . & & \\
\hline$\dot{\mathrm{N}}$ & NUMBER(N) & & \\
\hline
\end{tabular}

Enter additional values on this and following lines until the number of elements indicated on the (7000) line have been entered.

\subsubsection{Resuspension Control Line (7090)}

Enter the parameters for evaluating inhalation dose from resuspended activity. Ingestion and External dose from resuspension of activity is not calculated due to its negligible contribution to CEDE.

$\begin{array}{llll}\text { Word } & \begin{array}{l}\text { Variable } \\ \text { Name }\end{array} & \text { Entry } & \text { Description } \\ 1 & & 7090 & \\ 2 & \text { TSD } & & \text { Time since deposition (days). } \\ 3 & \text { RET } & & \text { Exposure time to resuspended activity. }\end{array}$


4 ARL

Linear constant in the resuspension rate function $\left(\mathrm{d}^{-1}\right)$. Defaults to $4.9 \mathrm{E}-8\left(\mathrm{~d}^{-1}\right)$.

$5 \quad$ BRE

Exponential constant in the resuspension rate function $\left(\mathrm{d}^{-1}\right)$. Defaults to $4.1 \mathrm{E}-3\left(\mathrm{~d}^{-1}\right)$.

\subsubsection{Dose Calculation End Line (7999)}

Use this line to end the input for the calculations requested by a Dose Calculation Control Line 1 (7001).

$\begin{array}{ll}\text { Word } & \text { Entry } \\ 1 & 7999\end{array}$




\subsubsection{Series - Cloud Gamma Dose Calculation}

Use a (9000) control line to initiate a cloud gamma dose calculation.

$\begin{array}{llll}\text { Word } & \begin{array}{l}\text { Variable } \\ \text { Name }\end{array} & \text { Entry } & \text { Description } \\ 1 & 9000 & & \\ 2 & \text { IT } & 0 & \text { All calculations are made using the finite plume model } \\ 3 & \mathrm{~T} & & \begin{array}{l}\text { All calculations are made using the semi-infinite model } \\ \text { Decay time for the leakage rate function }(\mathrm{s}) \text {. If zero defaults to }\end{array}\end{array}$

\section{EXAMPLE RSAC-7 RUNS}

RSAC-7 is provided with 20 examples that are useful in helping you learn how to run RSAC-7. The examples have been added solely to demonstrate the capabilities of RSAC-7. 


\section{REFERENCES}

American National Standards Institute, Inc./American Nuclear Society (ANSI/ANS), 1987, American National Standard Guidelines for the Verification and Validation of Scientific and Engineering Computer Programs for the Nuclear Industry, ANSI/ANS-10.4.

American Society of Mechanical Engineers (ASME), 1989, Quality Assurance Program Requirements for Nuclear Facilities, ASME-NQA-1.

Abramowitz, M and I. A. Stegum (eds.), 1964: Handbook of Mathematical Functions with Formulas, Graphs, and Mathematical Tables, AMS 55, pp. 887-890.

Baes, C. F. III, R. D. Sharp, A. L. Sjoreen, R. W. Shor, 1984, A Review and Analysis of Parameters for Assessing Transport of Environmentally Released Radionuclides through Agriculture, ORNL5786, Oak Ridge National Laboratory, Oak Ridge Tennessee.

Berger, M. J. and R. G. Jaeger, 1968, Engineering Compendium on Radiation Shielding, Vol. I, New York: Springer-Verlag Inc., p. 218.

Boone, F. W., Y. C. Ng, J. M. Palms, 1981, "Terrestrial Pathways of Radionuclide Particulates," Health Physics, 41, pp. 735-747.

Briggs, G. A., 1969, Plume Rise, TID-25075, U.S. Atomic Energy Commission, Oak Ridge, Tennessee.

Chamberlain, A. C., 1953, Aspects of Travel and Deposition of Aerosol and Vapour Clouds, AERE-HP/R-1261, Harwell, Great Britian.

Chu, S. Y. F., L. P. Ekstrom and R. B. Firestone, The Lund/LBNL Nuclear Data Search, Version 2.0, Ernst O. Lawrence Berkeley National Laboratory, Berkely, California, and LUND University, Sweden, February 1999.

Clawson, K. L., G. E. Start, N. R. Ricks, 1989, Climatography of the Idaho National Engineering Laboratory, 2nd Edition, DOE/ID-12118, U.S. Department of Commerce, National Oceanic and Atmospheric Administration, Environmental Research Laboratories, Air Resource Laboratory, Field Research Division, Idaho Falls, Idaho, December.

Coates, R. L. and N. R. Horton, 1966, RSAC-A Radiological Safety Analysis Computer Program, IDO-17151, Idaho National Engineering Laboratory, Idaho Falls, Idaho.

Croff, A. G., R. L. Haese, N. B. Gove, 1979, Updated Decay and Photon Libraries for the Origen Code, ORNL/TM-6055, Oak Ridge National Laboratory, Oak Ridge Tennessee. 
Croff, A. G., 1980, ORIGEN2-A Revised and Updated Version of the Oak Ridge Isotope Generation and Depletion Code, ORNL-5621, Oak Ridge National Laboratory, Oak Ridge, Tennessee.

DOE, 1994, Airborne Release Fractions/Rates and Respirable Fractions for NonReactor Nuclear Facilities,DOE-HDBK-3010-94, U.S. Department of Energy, Washington, D.C.

Eckerman, K.F., and Ryman, J.C. 1993, External Exposures to Radionuclides in Air; Water; and Soil, Federal Guidance Report No. 12, EPA-402/R-93-081U.S. Environmental Protection Agency Washington, D.C.

Eckerman, K.F., Wolbarst, A.B., and Richardson, A.C.B., 1988, Limiting Values of Radionuclide Intake and Air Concentration and Dose Conversion Factors for Inhalation, Submersion, and Ingestion. Federal Guidance Report No. 11, EPA-5201/1-88-020, U.S. Environmental Protection Agency, Washington, D.C.

Hanna, S. R., G. A. Briggs, R. P. Hosker Jr., 1982, Handbook on Atmospheric Diffusion, DOE/TIC-11223, U.S. Department of Energy, Oak Ridge, Tennessee.

ICRP (International Commission on Radiological Protection), 1977, Report of the Task Group on Reference Man, ICRP Publication 23, Pergamon Press, Oxford, Great Britain.

ICRP, 1979, Limits for Intakes of Radionuclides by Workers, Part 1, ICRP Publication 30, Pergamon Press, Oxford, Great Britain.

ICRP, 1983, Radionuclide Transformations, Energy and Intensity of Emissions, ICRP Publication 38, Pergamon Press, Oxford, Great Britain.

INEEL, 2001, Verification and Validation of RSAC-6.2, Idaho National Engineering and Environmental Laboratory, Idaho Falls, Idaho

Islitzer, N. F., 1965, Aerodynamic Effects of Large Reactor Complexes Upon Atmospheric Turbulence and Diffusion, IDO-12041, Idaho National Engineering Laboratory, Idaho Falls, Idaho.

Markee, E. H. Jr., 1967, "A Parametric Study of Gaseous Plume Depletion by Ground Surface Adsorption," in Proceeding of USAEC Meteorological Information Meeting, C. A. Mawson, Editor, AECL-2787, pp. 602-613.

NRC (U.S. Nuclear Regulatory Commission), 1977a, Calculation of Annual Doses to Man from Routine Releases of Reactor Effluents for the Purpose of Evaluating Compliance with 10 CFR Part 50, Appendix I, Regulatory Guide 1.109 Revision 1, Washington, D.C.

NRC, 1977b, Methods for Estimating Atmospheric Transport and Dispersion of Gaseous Effluents in Routine Releases from Light-Water-Cooled Reactors, Regulatory Guide 1.111 Revision 1, Washington, D.C. 
NRC, 1982, Atmospheric Dispersion Models for Potential Accident Consequence Assessments at Nuclear Power Plants, Regulatory Guide 1.145, Revision 1, Washington, D.C.

Ramsdell, J.V., Jr., Simonen, C.A., 1997, Atmospheric Relative Concentrations in Building Wakes, Report NUREG/CR-6331. U.S. Nuclear Regulatory Commission, Washington, D.C.

Richardson, L. C., 1968, User's Manual for the FORTRAN Version of RSAC, IDO-17261, Idaho National Engineering Laboratory, Idaho Falls, Idaho.

RSIC (Radiation Shielding Information Center), 1981, RSIC Data Library Collection, "DRALIST, Radioactive Decay Data for Application to Radiation Dosimetry and Radiological Assessments", DLC-80, Oak Ridge, Tennessee.

RSIC, 1991, RSIC Computer Code Collection, "ORIGEN 2.1, Isotope Generation and Depletion Code Matrix Exponential Method", CCC-371, Oak Ridge, Tennessee.

Rubinson, W., 1949, "The Equations of Radioactive Transformation in a Neutron Flux," Journal Chemical Phys, 17, pp. 542-547.

Sehmel, G. A., 1980: "Particle and Gas Dry Deposition: A Review," Atmospheric Environment, 14, pp. 983-1011.

Slade, D. H. (ed), 1968: Meteorology and Atomic Energy, AEC/TID-24190, U.S. Atomic Energy Commission, Silver Spring, Maryland.

SRA (Shonka Research Associates, Inc.), 1993, Software Verification and Validation Report for the WINCO RSAC-5 Code, Marietta, Georgia.

Till, J.E., and Meyer, H.R., eds., 1983, Radiological Assessment: A textbook on Environmental Dose Analysis, Report NUREG/CR-3332. U.S. Nuclear Regulatory Commission, Washington, D.C.

Turner, D. B., 1970, Workbook of Atmospheric Dispersion Estimates, Revised, U.S. Environmental Protection Agency, Research Triangle Park, North Carolina.

Wenzel, D. R., 1973, Preliminary User's Manual for the Revised Radiological Safety Analysis Computer Program-RSAC-2, ACI-139, Allied Chemical Corporation, Idaho National Engineering Laboratory, Idaho Falls, Idaho.

Wenzel, D. R., 1982, RSAC-3, Radiological Safety Analysis Computer Program, ENICO-1002, Idaho National Engineering Laboratory, Idaho Falls, Idaho. 
Wenzel, D. R., 1990, Interim Users Manual for RSAC-4, Radiological Safety Analysis Computer Program, Version 4.03, Westinghouse Idaho Nuclear Company, Inc., Idaho National Engineering Laboratory, Idaho Falls, Idaho.

Wenzel, D. R. 1994, The Radiological Safety Analysis Computer Program (RSAC-5) User's Manual, WINCO-1123, Revision 1, Idaho national Engineering and Environmental Laboratory, Idaho Falls, Idaho.

Yanskey, G. R., E. H. Markee Jr., A. P. Richter, 1966, Climatography of the National Reactor Testing Station, IDO-12045, Idaho National Engineering Laboratory, Idaho Falls, Idaho. 